Papers and Proceedings of the Royal Society of Tasmania, Volume 110, 1976

(ms. received 5.1.1975)

\title{
OBSERVATIONS ON SOME TASMANIAN FISHES : PART XXII
}

by E.O.G. Scott, Launceston

(with seven tables and one plate)

\section{ABSTRACT}

Three species, Raja dentata Klunzinger, 1872 (Rajidae), AZabes parvulus McCulloch, $1909^{\text {l }}$ (Alabetidae), Acanthistius serratus (Cuvier, 1828) (Epinephelidae) are added to the local list; some observations are made on the material on which the two latter records are based. It is pointed out that while Somiosus antarcticus whitley, 1939 (Somniosidae) does not appear in Australian, but is sometimes included in New Zealand, catalogues, the type locality, Macquarie Island, is formally part of a Tasmanian municipality.

A first record in Tasmanian waters of Halsydms maximus (Gunner, 1765) (Halsydridae) in 1936 is supplemented by two records in January and March 1974; one specimen is figured.

General observations are made as follows. Echelidae, morphometric data, coloration in 20 specimens of Murcenichthys ogizbyi Fowler, 1908: Scorpidae, relative growth, development of color pattern in Atypichthys strigatus (Günther, 1860): Trichiuridae, Tasmanian material of Lepidopus caudatas (Euphrasen, 1788), status of L. Zex Phil1ipps 1932, discounted: Soleidae, new locality record for Zebrias fasciatus (Macleay, 1882): Gobiescocidae,general review of the three Tasmanian species, Creocele cardinalis (Ramsay, 1882), Aspasmogaster tasmaniensis (Günther 1861), Cochzeoceps spatula (Günther, 1861): Gobiidae, morphometric and other data on long series of Arenigobius bifrenatus (Kner, 1865) and A. tamarensis (Johnston, 1883): Scorpaenidae, juveniles, growth curve of Gymapistes mamoratus (Cuvier, 1829): Aploactidae, Aploactisoma mizesii (Richardson, 1850), general description, length-position relationships of spines and rays, subspecific status.

Keys are provided to Tasmanian representatives of the families Alabetidae, Epinephelidae.

\section{INTRODUCTION}

This paper follows the general plan of others in the series. Linear measurements are given, unless otherwise snecified, in millimetres, the name of the unit common $1 y$ being omitted. The symbols Ls Lt, TLs, TLt denote standard length, total length, thousandths of standard length, thousandths of total length, respectively. Sample standard deviation is calculated with $n$ degrees of freedom; derived statistics being computed from the value thus obtained. Registration numbers are those of the Queen Victoria Museum, Launceston. Certain other conventions are noted in earlier contributions.

1 For earlier published record see NOTE, ADDED IN PRESS on p. 217. 
Fami1y HALSYDRIDAE (olim CETORHINIDAE)

\author{
Genus HALSYDRUS F1eming, 1809
}

Halsydrus Fleming, 1809, Scots Mag., p. 17. Haplotype, H. pontoppidiani Fleming Squalus maximus Gunner.

Halsydrus maximus (Gunner, 1765)

(P1ate 1)

Squalus maximus Gunner, 1765, K. Norske Vidensk Selsk. Trondh, p. 17. Type locality: Trondhjem, Norway.

Synonymy

The basking shark appears in the general literature under upwards of a score of scientific names (Whitley 1939, p.241). Up to the early 1930's it was referred to by most Australasian authorities either as Selache maxima (genus Selache Cuvier, 1816), or (in 1ater texts with increasing frequency) as Cetorhinus maximus (genus Cetorhinus Blainville, 1816): the latter name has continued in current use among a few local writers, and remains the preferred form of most overseas workers. Since, on the one hand, the proposed recognition by Barrett (1933) of a separate Australian species, Tetroras maccoyi (genus Tetroras Rafinesque, 1810), and, on the other hand, the statement by Whitley (1934) that the 'Sea Serpent' of Stronsay, Orkney Is 1ands, on which Fleming's genus Hatsydrus was based (remains in the Royal College of Surgeons' Museum, London) was later identified as a basking shark, the shark has appeared in most Australasian and a few extralimital sources under Barrett's name, or as Halsydrus maceoyi, or as Halsydrus maximus. Specimens from Australia have been treated by some ichthyologists as a separate subspecies (third trinomen maccoyi): other trinomial names have been suggested for examples from other areas. An extensive bibliography of the basking shark extending from the earliest times to about 1940 has been given by Bigelow \& Schroeder (1948): this is supplemented by a list by Whit1ey (1967) of upwards of a hundred and fifty references, of which about a quarter are Australasian.

\title{
Australasian records
}

A series of Australasian records of the basking shark between 1883 and 1956 has been compiled by Whitley (1967, table 2): it comprises 3 reports from New South Wales, 5 from Victoria, 5 from South Australia, 1 from the Great Australian Bight, 1 from Tasmania, 12 from New Zealand. The greatest length recorded is 34 feet 3 inches $(10.4 \mathrm{~m})$, the least 8 feet $(2.4 \mathrm{~m})$. For the 17 examples for which the datum is available the length distribution, in feet, is:10 feet or 1ess 4; $11-156$; 16-20 2; $21-252 ; 26-301 ; 31-351 ; 36-401$.

\section{First Tasmanian record}

In the latest (fifth) published catalogue of Tasmanian fishes (Lord 1927) an unnumbered entry, interpolated between items 19 and 20 reads: 'Cetorhinus maximus Basking Shark. One record, Banis Bay, 1926. No account of this specimen was published in the Papers and Proceedings of the Royal Society of Tasmania, to which Lord had earlier contributed notices of additions to the local faunal list, and no additional information about it has been found. In response to an inquiry to the Tasmanian Museum Hobart, Mr A.P. Andrews, Curator of Vertebrates, who kindly made a search of the institution's records, has reported they include no reference to this shark.

The locality 'Banis Bay' cited in Lord's paper (and regularly repeated in derivative literature) is unknown to the writer, and the suggestion is advanced that it could quite probably represent a misprint for Barnes Bay, the name of a large well-known bay on the west coast of the northern half of Bruny Island, southern Tasmania (misprints in the paper are numerous). Mr E.W. Clennet, Secretary, the Nomenclature Board of Tasmania, informs me the Board has no record of the name Banis Bay, and expresses the opinion the entry indeed seems likely to be an error for Barnes Bay. 
Second Tasmanian record

On 16 January 1974 , through the good offices of Mr A.J. Harrison, Secretary, Fisheries Division Agricultura1 Department, the writer learnt that the caudal fin of a large shark was on display on the deck of a Japanese fishing vessel moored at a Hobart wharf. The next day a photograph of the fin, with a member of the ship's crew standing beside it, appeared in the Hobart Mercury, the caption noting the ship was the Fukuichi Maru No. 31, and the shark, said to have measured 'about 15 metres', was caught on 4 January in Japanese fishing grounds off Tasmania.

Later, at the writer's request, Mr A.K. Way, Southern Regional Inspector of Fisheries, was good enough to take and make available for examination two colour photographs of the fin: these showed no spots (such as might be expected in a $f$ in of the other very large species, the Whale Shark - in any case, a highly unlikely visitor to our waters). (The Whale Shark has conventionally been known hitherto as Rhincodon typicus Smith, 1829. In a recent paper (Penrith 1972) evidence has been adduced to show it should probably be called Rhiniodon typus Smith, 1828).

Mr Way provided a sketch, with measurements, of the (somewhat mutilated) caudal fin, showing the length of the superior lobe $(1.04 \mathrm{~m})$, the length of the inferior lobe $(0.93 \mathrm{~m})$, the direct distance from the line, close to the level of the origin of the inferior lobe, along which the fin had been severed from the body to the angle of the junction of the lobes $(0.70 \mathrm{~m})$, and the direct distance between the tips of the lobes $(0.16 \mathrm{~m})$. Included among the measurements given by $\mathrm{M}^{\prime}$ Coy (1885) of his specimen (the first formally recorded in Australia, type specimen of Tetroras maccoyi Barrett, 1933, ex Whitley \& Phillipps MS) are: length of upper caudal lobe to pit at base $5 \mathrm{ft} 7 \mathrm{in}$., length of lower caudal lobe to pit at base $4 \mathrm{ft} 0$ in., length from tip to tip of caudal fin $7 \mathrm{ft} 0 \mathrm{in}$. These three dimensions exhibit tolerably constant ratios (1.21, 1.31, 1.33, respective1y) to the corresponding dimensions recorded by Mr Way for the Tasmanian shark. As percentages of total length, $\mathrm{M}^{\prime}$ Coy's values are $18 \%, 11 \%, 23 \%$. With an assumed total length of $15 \mathrm{~m}$ ( $49 \mathrm{feet}$ ), the corresponding percentages for the Fukuichi Maru specimen are 9, 6, 11: however, the loosely stated 'about 15 metres' would clearly seem excessive, 36 feet being given by a number of writers as a probable maximum length, though estimates of 40-45 feet have been suggested. With an assumed length of $7.5 \mathrm{~m}$ (25 feet), the percentages would become 19, 12, 21, comparable with M'Coy's values. In the West Coast example noted below the distance between the tips of the lobes of the caudal (the on $1 y$ item available) was, on the measurements given, $20 \%$ of the length of the shark.

\section{Third Tasmanian record}

In their issues of Thursday 7 March the Burnie Advocate and the Hobart Mercury carried reports of a basking shark netted in Macquarie Harbour by Mr R.A. Larsson, Strahan. Mr Larsson has been good enough to fill in a questionnaire submitted to him: from the information supplied the following points may be noted here. The shark was found entangled in a net left overnight, during a change-over of nets, on Tuesday 5 March, on the off chance of catching school fish, about 4 miles $(6-7 \mathrm{~km})$ south of Sapphire Point in Macquarie Harbour. Its length (direct, not following curves) was 25 feet $(7.6 \mathrm{~m})$, and the distance between the tips of the caudal lobes was 5 feet $(1.5 \mathrm{~m})$. In reply to a question about colour, Mr Larsson noted it lacked spots or lines, and it was overall very dark, almost black, after having remained for some hours in the ore-contaminated water of the Harbour. It was a male. Other information supplied by Mr Larsson in answer to inquiries regarding features likely to be of value in identifying the specimen (including shape of head, size of gill slits, nature of teeth, presence of short keel on caudal peduncle) were fully consonant with its determination as a basking shark. Subsequent examination of three photographs (two here reproduced, pl.1, figs a, b) leaves no doubt about the species.

The taking in Tasmanian waters, after a lapse of almost half a century, of two examples of Halsydrus maximus within the space of a few months has appeared to be worthy of record. 


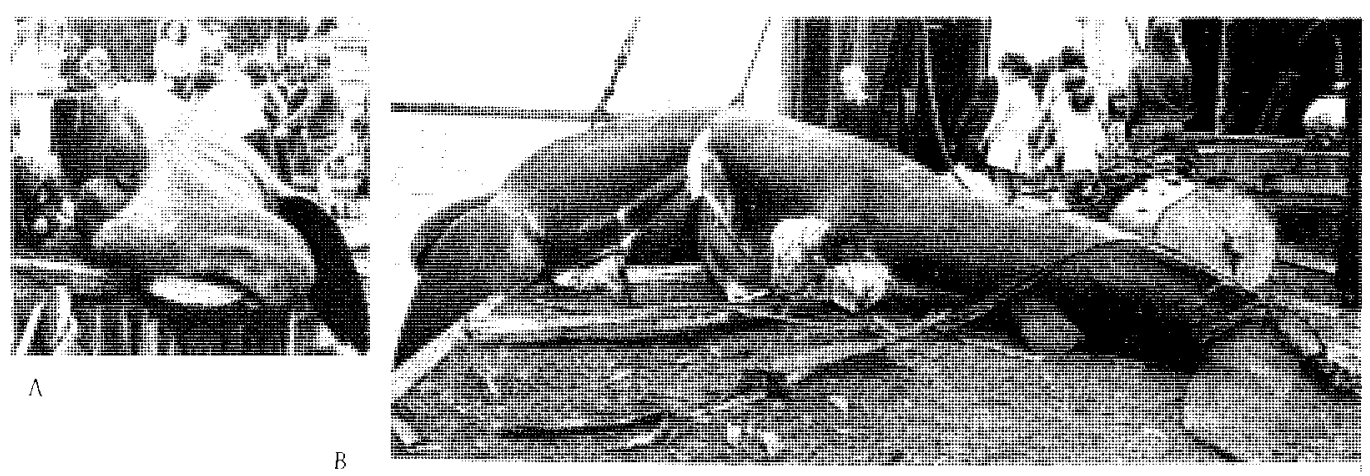

PLATE 1. Halsydrus martme (Gunner, 1765); Strahan, March 1974; (a) anterior view, (b) postero-lateral view. Photographs by courtesy of the Advocate.

Family SOMNIOSIDAE

Genus SOMNIOSUS Le Sueur, 1818

Somiosus Le Sueur, 1818, J. Acad. Nat. Sei. Phizad., 1 (9), p.222. Haplotype, G. brevipinimis le Sueur.

\section{Somiosus antareticus whitley, 1939}

Somiosus sp. Waite, 1916, Australas. Antaret. Exped., 1911-1914, Sci. Rep. (C) 3 (1) 1, p.51, fig. 10 .

Somiosus antareticus Whitley, 1939, Aust. Zool., 9 (3), p.242. Type locality: Remarks Macquarie Island.

A sketch by a Mr Hamilton of a curious shark, 8 feet 2 inches $(4.5 \mathrm{~m})$ long found cast up on a beach on Macquarie Island in 1912 was published by Waite (1916), who referred it to Somiosus, otherwise represented only by three northern hemisphere species : parts of the animal were preserved and later whitley (1939) provided a specific name.

An account of Somniosus antaretions is included by Whitley in his general work on Australian fishes (1940, p.152, fig. 170), but in the bcheme of classification of the fishes and fish-like animals of Australia'therein the entry Family Somiosjdac is followed immediately by the notation '(Sleepers - not Australian)'; the specics occurs in Whitley's check-1ist for the New zealand region (1968, p.11), but not in his name-1ist of fishes recorded from Australia (1964); not noted in Munro's Australian handbook (1956); included by Garrjck $(1960$, p.595) in a kcy to the New Zcaland Squaloidea; noted by Garrick \& Schultz (1963, p.59) as being found at Macquaric Island 'south of Australia.'

Macquarie Island, about 31 by $2 \mathrm{~km}$, is situated in the South Pacific in 1 at. 54.295. long. 158.58E. The climate, flora and fauna are typically subantarctic (Anst. Whal., no date, 5, p.453). Politically, it is part of Tasmania, being included in Esperance, the southernmost municipality of the main island.

It would thus appear that if Sminose matroetime is to be included in the faunal list of any Australasian state or country, it should be Tasmania, not Now Zcaland. 


\section{E.O.G. Scott}

Family RAJIDAE

Genus RAJA Linné, 1758

Raja Linné, 1758, Syst. Nat., ed, 10, p.231. Logotype, Raja batis linné.

\section{Raja dentata K1unzinger, 1872}

Faja dentata klunzinger, 1872, Arch. Naturges., 38, p.46. Type locality: Port Phillip, Victoria.

Raja (Dentiraga) dentata. Whitley, 1940, THF FishES OF AUST., Part 1, p.164, figs $31,214$.

History of species

In terms of primary references the history of Raja dentata, the thira rajid described with an Australasian type locality, is brief. The species, our least known ray, was based on two females from Victoria by klunzinger more than a century ago; seven years later (1879) he reported the male, noting differcnces in dentition and in some of the spines. The types, preserved in the württembergische Naturaliensammlung, Stuttgart, were examined there by the late Gilbert Percy Whitley, whose recent death has deprived ichthyology of one of its most outstanding Australian workers, and the present writer of an ever-helpful colleague and valued friend. He recorded (1939) that they were labelled'Port Phillip, Australien, V. Muller, 1869-1871, selected the larger individual as lectotype, gave a brief general description of the specimens and provided the first figure of the species (outline dorsal aspect, outline anterior portion of ventral surface, teeth, velum maxillare, buccal processes); noting in the same paper the existence in the Australian Muscum of one other Melbourne specimen (Regd No. I.12050). Later, in his general survey of Australian and New Zealand elasmobranchs (1940), he proposed for $R$. dentata the subgenus Dentiraja. Six types of rajid egg cases - of which only one is definitely associated with its species - are shown (fig. 31) in that work; a black egg case, about $4.4 \mathrm{~cm}$ by $3.2 \mathrm{~cm}$, with long horns and with woolly sides being labelled 'Raja dentata?' All other notices of the species are derivative.

Raja dentata escaped notice in the first comprehensive synopsis of Australian fishes, Macleay's descriptive catalogue $(1881,1882)$, but an account in translation was included in the supplement $(1884, \mathrm{p} .63)$. It appears in the systematic Victorian census of Lucas ( $1890, p .45$ ), where, however, the entry is placed in parentheses, the author's convention for records based on a single specimen and for species of whose occurrence in Victorian waters there is some doubt; in his introduction Lucas suggests there is a probability some confusion may have occurred in regard to Klunzinger's material, some specimens described as coming from Hobson's Bay and Port Phillip perhaps being South Australian fish. The species was not noticed by Stead (1963) in his general work on Australian sharks and rays. A conventional entry appears in the Australian Check-list (McCulloch 1929), and a brief diagnosis, on the pattern of those for related species, was given in the Handbook (Munro 1956): the Handbook's fig. 110 is the outline sketch of the dorsal aspect by Whitley (1939, fig. 16), which here (as in whitley 1940 , fig. 214) has been blocked in with monochrome grey.

Tasmanian record

Raja dentata is here reported from Tasmania. Three females, (b) total length 320, disc width 230 , (c) 335,237 , (d) 436,304 were taken, in the course of an Apex Fishing Competition, in the estuary of the Tamar, northern Tasmania, on 16 February 1975 (Q.V.M. Reg. No. 1975/5/23). It was later found the collections of the Queen Victoria Museum alrcady contained a smaller female, (a) 229, 160, caught in 1942 off the pier at Gravelly Beach, Tamar river (approximately $33 \mathrm{~km}$ from the sea), in 30-40 feet (9-12 m) of water (Miss Audrey Lee; Reg. No. 1942.27): the specjmen was labelled Raja tasmaniensis. 
Description, ${ }^{1}$ morphometric data A detailed description of this little known ray, based on the Tasianian material, accompanied by morphometric data and including a comparative study of disc form will, it is hoped, be presented in the next contribution in this series.

\section{Family ALABETIDAE}

The Check-list (McCulloch 1929) recognizes four species of Alabetidae [rendered Alabidae by, among others, Jordan (1923), Munro (1957), Scott (1962)], all referred to Alabes Cloquet, 1816, namely (a) Cheizobranchus dorsalis Richardson, 1895, (b) Chizobranchus mifus Macleay, 1881 (Chizobranchus Günther, 1870, emendation for Cheizobrachus Richardson, 1845), (c) CheiZobranchus paruzus McCulloch, 1909; (d) Alabes cuvieri Vaillant, 1905 ex Kaup MS, based on the type specimens in the British Museum upon which Alabes was formed; 1ocality given as India and New Holland. The Handbook (Munro 1957) accepts only $(a),(b)$ and $(c)$, but $(d)$ is retained in the name-list of Whitley (1964).

A. rufus, found in New South Wales, Victoria and South Australia, is abundant in this State (which is the type locality along with Port Jackson). A. dorsalis, reported in the Check-list as occurring in north-western Austra1ia (type locality), Tasmania, South Australia (the last named locality queried in the Handbook; this species is not included by Scott (1962) in his catalogue for that State or by Scott et al. in a later version), appears in a1l published local Iists - Johnston (1883, 1891), Lord (1923, 1927), Lord \& Scott (1924) - but appears to be rare here: the first two examples seen by the writer were the subject of some observations in Part XX (1973b). A. parvulus, hitherto known only from New South Wales, is here reported from northern Tasmania - one more instance of a species being recorded from these two state only.

The subjoined key will serve to separate the three Tasmanian species; it supersedes an earlier key $(1974 b, p .175)$ to the two species then on our list.

\section{KEY TO ALABETIDAE RECORDED FROM TASMANIA}

1. Dorsal originating shortly behind head, nearer to snout tip than to vent. Anal originating shortly behind vent, by $<0.5$ (about 0.05 ) head length. Colour pattern, if present, a median dorsal stripe; no transverse or vertical bars, no spots, no vertebral stripe. ......................... dorsalis

Dorsal originating well behind head, nearer to vent than to snout tip. Anal originating well behind vent, by $>0.5$ (about 0.9-2.7) head length. Colour pattem, if present, including some or all of these, transverse or vertical bars, spots, vertebral stripe; no median dorsal stripe. .. 2

2. Gill opening with on either side an ovoid lobe, its length one-third, or more, width of opening. Anal originating behind vent $<2$

(about 0.9-1.3) head length. Colour pattern, if present, 1-9 large spots on either side; no other markings. Size greater, total

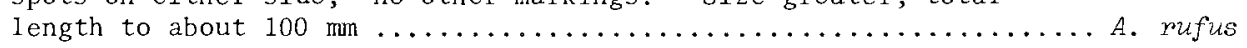

Gill opening without lateral lobes. Anal originating behind vent by $>2$ (about 2.5-2.7) head length. Colour pattern, if present, some or all of these bars and/or spots on back, on sides and ventral surface of head and trunk, vertebral stripe. Size less, total length to about

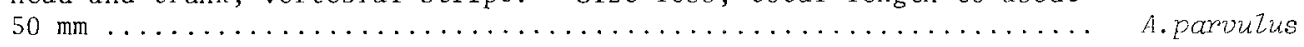

Approximate ranges given in parenthesis in the key are based on data for specimens noted in Part XX (A. dorsalis 2 individuals, A. rufus 5) and on examples here discussed (A. parvulus 2).

1 For earlier published record see NOTE ADDED IN PRESS on p. 217. 
Genus ALABES Cloquet, 1816

AZbes Cloquet, 1816, Diet. Sci. Nat., 1, suppl., 1816, p.99.

Ex Cuvier MS. Logotype, A. cuviem Vaillant.

\section{Alabes parvulus (McCulloch, 1909)}

Cheilobranchus parmulus McCulloch, 1909, Rec. Aust. Mus., 7 (4), p.316, fig. 18 (outline sketch). Type locality: rock pools near sydney.

AZabes parvulus McCulloch, 1929, Aust. Mus. Mem., $\frac{5}{7}$ (1), p.62. Id. Whitley, 1929, Rec. Aust. Mus., $17 \mathrm{n}(3), \mathrm{p} .108, \mathrm{p} 1.31$, fig $\overline{7}$ (colour figure by McCul1och). Id. Munro, 1957, Handok Aust. Fish., 10, p.44, fig 311.

Tasmanian record

Mr R.H. Green, Curator of Zoology, Queen Victoria Museum, has drawn the writer's attention to a $15 \mathrm{~mm}$ colour transparency taken by him of an Alabes collected at Greens Beach, northern Tasmania, on 14 November 1966. This fish and another taken on the same occasion prove to be the first examples of $A$. parvulus recorded from this State (Q.V.M. Reg. No. 1972/5/402.).1

Dimensions

Total length $37.5,45.3$. Other dimensions as millesimals of total length follow (absolute dimensions, mm, in parentheses). Length to dorsa1 origin 333,307 $(12.5,13.9)$, to anal origin $653,618(24.5,28.0)$, to vent (middle) 347,325 (13.0, 14.7). Head $125,110(4.5,5.0)$, snout $293,221(1.1,1.0)$, eye $267,199(1.0,0.9)$, interorbital $133,135(0.5,0.7)$. Depth at vent $104,66(3.9,3.0)$, immediately behind vent $80,64(3.0,2.9)$; greatest depth of head $77,42(2.9,2.2)$; maximum depth $112,77(4.2,3.5)$; corresponding measurements of width $53,33(2.0 ; 1.5), 51,29$ $(1.9,1.3), 56,42(2.1,1.9), 75,62(2.8,2.8)$.

Comparison of body ratios

A comparative schedule of some relevant body ratios as found in $A$. parvulus, A. dorsalis, $A$. mufus as represented by our material is set out in table 1 . Though the samples are small and obviously cannot be expected to provide critical differentiae in cases where values are not markedly different, some trenchant distinctions are provided by several ratios. Head in length to dorsal origin and head in dorsa 1 origin -vent interval conveniently distinguish $A$. dorsalis from the other species, while head, or trunk, in anal origin-vent interval sorts out all three species.

Attention may be drawn to the value (3) of the ratio head in trunk in $A$. mufus as given in the Handbook (Munro 1957, p.44), and as found in our material $(2.0-2.6, \bar{x} 2.31 \pm$ $0.074)$ : Waite (1906, p.195) recorded 2.3, and approximately the same value is derivable from his illustration ( 1.36 , fig. 1), a drawing by McCulloch.

Good agreement obtains between McCulloch's values for the metrical items noted in the original description of $A$. parvuzus and ours. Head nearly one-ninth of total length (our specimens $0.12,0.11$ ), head in distance between gi11 opening and vent 1.8 $(2.0,1.8)$, head equal to $(1.1,1.4)$ height of body, length to vent in rest of length $1.7-2(1.9,2.1)$, eye one-fourth $(0.22,0.18)$ head, snout longer than $(1.1,1.1)$ eye.

\section{Other features}

Jaws equal anteriorly in smaller individual, upper projecting somewhat in $1 \mathrm{arg}$ er; maxillary to just short of eye; snout spatulate, tip rounded, moderately acute (1ess obtuse than in $A$. rufus); interorbital 0.5, 0.7 eye; anterior nostril tubular, in advance of eye by about half an eye diameter, at about ten o'clock (1eft side viewed); posterior nostril closer to orbit at about nine o'clock; gill opening smal simple crescentic aperture, without lateral lobes.

\footnotetext{
1 For earlier published record see NOTE ADDED IN PRESS on p. 217.
} 
Coloration

As seen in Mr Green's colour transparency the fish is tolerably similar in overal1 colour and in colour pattern to the living specimen from Coogee Baths, near Sydney, as represented in Mcculloch's painting made available by Whit ley (1929b), p. 21, fig. 4). However, after preservation most of the original colours have disappeared.

Larger specimen with trunk and tail mostly pale yellowish brown becoming somewhat amber and/or golden posteriorly. Except for hinder part of operculum, which is almost concolorous with trunk, head more yellowish, particularly lips, chin, ventral surface of branchial basket; optic lobes and diencephalon, visible through skull wall, deep creani faint remains of upwards of a dozen well-rounded spots on either side of branchial basket; some variations in tone along middorsal line, apparently representing remnants of a colour pattern. Fins pale yellowish; no markings retained. Smaller specimen much 1ike larger; dorsum of head darker, more brownish; optic lobes and diencephalon not visible, but front part of medulla oblongata apparent, somewhat 1 ighter than adjacent region; two elliptical straw-coloured areas colfactory lobes visible through skul1?) on dorsum immediately in front of eyes.

\section{TABLE 1}

Alabes parwulus (McCulloch, 1909), A. dorsalis (Richardson, 1845), 1. yufus (Macleay, 1881). Some body ratios of $2,2,5$ individuals: mean values, with individual valucs in pirenthesis.

A. parvulus

$\begin{array}{lllll}1 . & 8.7 & (8.3,9.1) & 8.5 & (8.8,8.3) \\ \text { 2. } & 1.9 & (1.9,1.9) & 2.3 & (2.4,2.2) \\ 3 . & 2.8 & (2.8,2.8) & 1.2 & (1.2,1.2) \\ \text { 4. } & 0.14 & (0.11,0.16) & 2.1 & (2.2,2.0) \\ \text { 5. } & 2.6 & (2.6,2.7) & 0.034 & (0.035,0.033) \\ 6 . & 0.32 & (0.33,0.31) & 0.14 & (0.14,0.14) \\ 7 . & 3.0 & (2.9,3.1) & 2.6 & (2.6,2.6) \\ 8 . & 0.64(0.65,0.62) & 0.26 & (0.26,0.26) \\ 9 . & 0.71(0.59,0.82) & 0.93 & (0.92,0.93) \\ 10 . & 1.4 & (1.4,1.4) & 0.015 & (0.015,0.015) \\ 11 . & 10.7 & (8.5,12.9) & 8.9 & (9.2,8.7)\end{array}$

$8.8(8.6,9.3,8.4,8.9,8.9)$

$2.3(2.3,2.3,2.3,2.0,2.6)$

$2.9(2.9,3.0,3.1,2.7,3.3)$

$0.31(0.43,0.30,0.27,0.34,0.22)$

$1.1(1.29), 1.21,0.93,1.24,0.89)$

$0.35(0.33,0.33,0.37,0.33,0.38)$

$2.6(2.6,2.8,2.5,2.7,2.5)$

$0.51(0.53,0.49,0.51,0.53,0.50)$

$0.14(0.19,0.13,0.11,0.17,0.09)$

$0.49(0.56,0.52,0.40,0.61,0.35)$

$9.3(10.0,9.1,8.4,9.0,9.9)$

\section{RATIO}

1. Head in total length

2. Head in trunk

3. Head in length to dorsal origin

4. Head in dorsal origin-vent interval

5. Head in anal origin-vent interval

6. Length to dorsal origin in total length

7. Length to vent in total length

8. Length to anal origin in total length

9. Trunk in dorsal origin-vent interval

10. Trunk in anal origin-vent interval

11. Maximum depth in total length 
Family ECHELIDAE

Genus MURAENTCHTHYS Bleeker, 1853

Mrraenichthys Bleeker, 1853, Natuurk Tijaschr. Ned.-Ind., 4, p.505. Orthotype, Muraenichthys symopterus Bleeker (designated 1864).

Mraenichthys ogilbyi Fowler, 1908

Muraenichthys ogizbyt Fowler, 1908, Proc. Acad. Sci. Philad., 59, 3 (1907), p.423, fig. 3. Typo locality: Victoria.

Date of genus

The genus Muraenichthys is commonly attributed in Australian and New Zealand texts - including the present studies $(1953,1961,1963,1965,1974 a)$ - to Bleeker, 1864 , Nat. Tijaschr. lierk., 11, p.117. The reference given above, adopted by, c.g., Schultz (1953), is that listed in Neave (1940).

History of species

Fowler's species was based on one specimen included in a small collection of fishes from victoria. A Tasmanian example, length without caudal fin 238 , collected at Green's Beach, northern Tasmania in January 1969, providing probably the first nonderivative notice of the species since the description of the holotypc, was made the subject of fairly detailed observations in Part XIX (1974 a). A fine series of 20 specimens, netted by Mr R.H. Green, Queen Victoria Museum, at the same locality on 19 and 26 January 1975 (Q.V.M. Reg. No. 1975/5/213) provides valuable morphometric data over an $1, t$ range of $254.0-489.1$.

Dimonsions

Range, arithmetic mean, standard deviation and coefficient of variation, together with number of individuals lying within $\bar{x}$ and $s$ (normal curve, 14) for $L t$ $(\mathrm{mm})$ and for a number of dimensions expressed as thousandths of Lt ( $T$ t t) are set out in table 2 .

\section{Proportions}

Table 3 presents a similar set of statistics for a series of body ratios, including, for purpose of comparison, those recorded (table 1) in Part XXI (1975) for the holotype and the first (1969) Tasmanian example of the present species, a series of 8 Tasmanian examples of $M$. breviceps Günther, 1876, and the holotype of M. Zingowenah Scott, 1975. It includes also the Schmidt index, $s\left(s=\frac{a-d}{d} \times 100\right)$, where $a=1$ ength to vent, $d=$ length to dorsal origin, $t=$ total length) : this criterion was introduced by E.J. Schmidt in his worldwide investigations on the Anguillidae (e.g.,1928); it was given its nominal designation in his honor in Part VI (1953, p.142) of the present series. Comparison of the two tables shows: for all listed proportions, values of the two earlicr specimens of $M$. ogizbyi fall within the range of those of the present material, with the sole exception of 6 . for the 1969 individual $(18.7, c f .18 .9-22.6)$, this transgression beyond the present lower extreme being, however, in accord with probable prediction, in view of the smaller size of that individual and the posjtive correlation of $S$ with $L t$; all values for $M$. Zingowench continue to lie outside those for $M$. ogilbyi; overlaps between joint values for the two examples of $M$. ogi $2 b y i$ and the range of the eight examples of $M$. breviceps found in the earlier table are confirmed, the range of common magnitude naturally being in some instances increased with the inclusion of the data for the larger sample of the present species.

\section{Relative growth}

Significant positive correlation of body element as a permillage of total length with total length occurs in the following cases: depth at vent, $r=+0.453(z=0.500)$, $t=2.155^{*} ;$ depth at middle of tail, $p=+0.707(z=0.882), t=4.247^{* *}$. 
Significant negative correlation obtains in maximum depth of body, $r=-0.452$ $(z=0.487), t=2.150^{*}$; maximum depth of branchia1 basket, $r=-0.522(z=0.579)$, $t=2.597^{*} ;$ 1ength of maxilla, $r=-0.735(z=0.940), t=4.850^{* *}$.

For the full sample of 20 the correlation of Schmidt's index with Lt is $r=+0.337$ $(z=0.351), t=1.922$, with significance a little above $P 0.05$; one individual (the smallest, Lt 254.0), however, contributing $65 \%$ of the negative dXdY total. For the remaining 19 examples $r=+0.540(z=0.605), t=2.647^{\star}$, slightly better than $P 0.02$. A positive correlation of $S$ with $L t$ in $M$. breviceps has been reported in earlier contributions (see below).

\section{Comparison with $M$. Breviceps}

A detailed comparison in Part XIX (1974 a) of the holotype and the first recorded Tasmanian specimen of $M$. ggi $l b y i$ with six Tasmanian examples of $M$. breviceps has shown these two species are very closely similar in nearly all gross morphological features; perhaps the only clear and ready distinction between them being provided by the differences in dentition - a feature, however, to which Schultz (1953), with extensive acquaintance with the group, attaches prime importance. Two dimensions for which, in the above material, the TLt value of the Tasmanian example of $M$. ogi $2 b y i$ lies outside the range for $M$. breviceps are: length to dorsal origin, 178 ( $\mathrm{f}$. 161-169, $\bar{x} 166.1$ \pm 0.97 ); dorsal-anal interval, 190 ( $f f .203-225, \bar{x} 213.9 \pm 2.89$ ). At the time it was pointed out that, with such limited material, it was not clear how much importance was attachable to these differences. For the present $20 \mathrm{M}$. ogizbyi length to dorsal origin, as $T L t$, is $159-186, \bar{x} 175.8 \pm 2.15$. Thus for the first relative dimension the lower $M$. ogizbyi value falls (in one individual only) within the $M$. brevicepe range; however the difference of the means is a significant one $\left(t=3.566^{* *}\right)$; for the second relative dimension, though the mean for $M$. ogizbyi remains below that for $M$. breviceps, no fewer than 15 individuals fall within the $M$. breviceps range, the difference of the means being statistically non-significant at $t=0.775$.

In the original investigation in Part VIII (1957) of the sample of six $M$. breviceps (three localities) it was found Schmidt's index (range 19.14-21.92) exhibited significant linear regression on $L t$, the equation being $S=0.007424 \mathrm{Lt}+17.53$; $t=4.73^{* *}$; mean percentage error of predicted on observed values of $S=1.3$. For the present sample of $M$. ogizbyi (range 18.86-22.57) $S=0.01194 L t+15.97$; $t=3.980^{* \star *}$; percentage error of predicted on observed values $0.0-11.1$ (smallest individual), $\bar{x} 3.5 \pm 0.61$.

\section{Coloration}

As preserved, all specimens exhibit the same general pattern of coloration. Dorsal surface somewhat brownish olivaceous; ventral surface varying from pale to fairly deep yellowish, uniform, immaculate about to level of vent, behind which it is subject to backwardly increasing invasion of brownish from the sides, the light colour being almost or wholly obliterated in the last one-fifth to one-fourth of the tail. On the trunk, and in some individuals in the anterior portion of the tail, the dark upper colour uniform, quite sharply demarcated from the yellowish; in others the dark region on much of the tail may be continued downward in alternating obscure streaks of contrasting intensity, the line of demarcation between upper and lower colours then becoming less definite. On trunk, and on a greater or less part of anterior portion of tail, yellow of ventral surface extending upwards on to flank, to an increasing extent cephalad; continuing on to head to include whole of lower jaw, upper jaw behind orbit; also at times presenting a sirip or patch on jaw between anterior and posterior nostrils, flap of latter usually remaining dark. Almost always a small more or less rounded lighter area at tip of upper jaw, commonly extending briefly on to dorsum here.

Dorsal mostly white, whitish, or pale yellow, anal mostly pale or medium yellow, both fins becoming somewhat dusky towards their termination. 
Muraenichthys ogizbyi Fowler, 1908. Dimensions of 20 examples from Greens Beach, northern Tasmania. First line, total length, absolute dimensions, mm: other lines relative dimensions, permillages of total length.

Feature

Range
Entries within

Total length

Length to dorsal origin

Length to vent

Length to anal origin

Length to front of gill opening

Length to back of gill opening (head)

(head)

Snout

Eye

Interorbital

Length to maxilla

Length of upper jaw to rictal membrane membrane

Length of lower jaw to rictal membrane membrane

Maximum depth of branchial basket

Maximum width of branchial basket

Maximum depth of body

Maximum width of body

Depth at dorsal origin

Depth at vent

Depth midway between vent and tail tip

$$
\bar{x} \pm s
$$

$\begin{array}{rrrrrrrr}24.7 & -30.7 & 27.9 & \pm & 0.0370 & 1.66 & \pm 0.262 & 5.9 \pm 0.9 \\ 21.4 & -27.9 & 24.8 & \pm & 0.414 & 1.85 & \pm 0.293 & 7.5 \pm 1.2 \\ 24.9 & -33.6 & 29.0 & \pm & 0.507 & 2.27 & \pm 0.359 & 7.8 \pm 1.2 \\ 23.5 & -36.5 & 28.7 & \pm & 0.732 & 3.27 & \pm 0.518 & 11.4 \pm 1.8 \\ 23.1 & -35.0 & 28.1 & \pm & 0.607 & 2.71 & \pm 0.429 & 9.7 \pm 1.5 \\ 21.7 & -29.0 & 25.1 & \pm & 0.469 & 2.10 & \pm 0.332 & 8.4 \pm 1.3 \\ 22.4 & -32.7 & 27.1 & \pm & 0.719 & 3.21 & \pm 0.508 & 11.9 \pm 1.9 \\ 22.6 & -27.4 & 24.9 & \pm 0.343 & 1.54 & \pm 0.243 & 6.2 \pm 1.0 \\ 20.0 & -25.1 & 22.7 & \pm 0.353 & 1.58 & \pm 0.250 & 6.9 \pm 1.1\end{array}$


Muraenichthys ogizbyi Fowler, 1908. Proportions of 20 examples, total length 254.0 - 489.1 mm, from Greens Beach, northern Tasmania.

Feature

Schmidt's index, $S$

Maximum depth in head

Maximum depth of body in total

$$
\text { length }
$$

Head in trumk

Head in total length

Head in dorsal-bearing trunk

Precaudal length in tail

Predorsal trunk in total trunk

Predorsal length in remainder

$$
\text { of length }
$$

Predorsa1 length in 1ength to vent

Eye in head

Eye in snout

Eye in interorbital
Range

$\bar{x}$

$18.9-22.6$

$20.56 \pm 0.246$

$1.18 \pm 0.187$

$2.68-3.84$

$3.25 \pm 0.0644$

$0.288 \pm 0.0455$

$7.0 \pm 1.1$

$9.6 \pm 1.5$

$28.5-43.3 \quad 35.9 \pm 0.773 \quad 3.46 \pm 0.546$

$2.91-3.70 \quad 3.20 \pm 0.0416 \quad 0.186 \pm 0.0294$

$\begin{array}{lllll}10.2-12.6 & 11.0 & \pm 0.125 & 0.559 & \pm 0.0884\end{array}$

$2.08-2.42 \quad 2.26 \pm 0.02260 .101 \pm 0.0160$

$1.47-1.75 \quad 1.61 \pm 0.01170 .0522 \pm 0.00825$

$2.86-4.21 \quad 3.45 \pm 0.0743 \quad 0.332 \pm 0.0526$

$5.8 \pm 0.92$

$5.0 \pm 0.80$

$4.5 \pm 0.71$

$3.2 \pm 0.51$

$9.6 \pm 1.5$

$5.0 \pm 0.79$

$4.3 \pm 0.68$

$9.7 \pm 1.5$

$2.04-2.33 \quad 2.17 \pm 0.0209 \quad 0.0934 \pm 0.0148$

$7.6-12.3$

$10.5 \pm 0.227$

$1.02 \pm 0.161$

$1.50-2.70$

$2.13 \pm 0.0417$

$0.187 \pm 0.0295$

$1.07-1.56$

$1.32 \pm 0.0295$

0.132

$\pm 0.0209$

$8.7 \pm 1.4$

$10.0 \pm 1.6$
Entries within

$$
\bar{x} \pm s
$$

14

14

13

11

14

13

12
13

16

13

15

16 


\section{Fami ly EPHINEPHELIDAE}

In recent overseas texts - probably influenced directly or indirectly by Berg (1940) - a number of familjes formerly recognized, among them the Ephinephelidae Greenwood et al (1966) list 18 others - are subsumed in Serranidae. However, in most Australian publications - including such basic references at the Check-1ist (McCulloch 1929), the Handbook (Munro 1961) and the various works of Whitley - Ephinephelidae accorded familial status. The latter usage is accordingly conveniently followed here - indeed, in any case, as one of the largest known families, with round about 600 species, the Serranidae constitutes an unwieldy assemblage, and there would seem to be tenable grounds for some subdivision of it.

This family, with upwards of fifty Australian members, occurring mainly in the northern States, has hitherto been represented in the Tasmanian list by a single species, Polyprionum oxygeneios (Bloch \& Schneider, 1801) [in Check-1ist (McCulloch 1929), in Handbook (Munro 1961) and widely in Australian 1iterature referred to Polyprion Schinz, 1882: it would appear (Whitley 1968) Polypmionum Bosc, 1818 has priority], which has a wide extralimital range, extending to New Zealand (type locality) and South Africa. A second species, Aconthistius serratus (Cuvier, 1828) with Check-1ist distribution Western Australia (type locality), Queensland, New South Wales, the Handbook adding Victoria, is here reported from a northern Tasmanian locality.

\section{KEY TO EPHINEPHELIDAE RECORDED FROM TASMANIA}

A. Dorsal spines XI-XII, rays 12-13. Lateral 1ine 85-90; scales in longitudinal series 140-180. Anal spine III longest. Operculum with horizontal ridge; with one spine. Teeth in jaws villiform, no enlarged teeth, tongue with

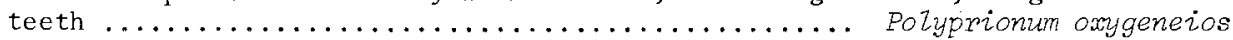

AA. Dorsal spines XIII, rays 16, Lateral line 60-67; scales in longitudinal series 90 - 110. Ana1 spine II longest. Operculum without horizontal ridge; with three spines. Teeth in $j$ aws villiform or cardiform with some enlarged outer teeth; tongue edentulous ................ Acanthistius serratus

The present fish, while apparently referable to Acanthistius serratus, differs in several points, notably in the nature of the scales, from available descriptions of that species: in the circumstances it has been deemed expedient to provide a tolerably full account of the specimen.

\section{Genus ACANTHISTIUS Gil1, 1863}

Acanthistius Gi11, 1863,Proc. Acad. Nat. Sci. Philad. (1862), p.235, footnote. Hap1otype, ELectropoma serratum Cuvier, 1828.

\section{Acanthistius serratus (Cuvier, 1828)}

Plectropoma serratum Cuvier, 1828, Hist. Nat. Poiss., 2, p.399. Type locality: King George's Sound (Quoy \& Gaimard.)

Acanthistius serratus McCulloch, 1929, Aust. Mus. 5, (1), p.442, (synonymy).

Material A specimen, Ls 129, L, 160 , collected at Tam O'Shanter Bay, northern Tasmania, on 20 January 1974; Q.V.M. Reg. No. 1974/5/31 (donor Mr J. Room).

Meristic characters

D.XIII,16. A.111,9. P.18/18. V.I.5. C.14+(4+4). L. late $59+8$ on cauda1. L.tr. 26/67. Sc.95. Gil1 rakers on lower $1 \mathrm{imb}$ of anterior arch 7 (1eft), 8 (right) +6 low, mounded (on each side). 
Chief dimensions

Values as TLS are followed in parentheses by measurements, $\mathrm{mm}$. Length to origin, termination (spine bases) of first dorsal 384 (49.5), 725 (9.3.5); of second dorsal (ray bases) 740 (95.5), 899 (116); of anal 721 (93.0), 876 (113). Length to pectoral origin 380 (49); length of fin from most advanced point on base 267 (34.5), from level of insertion of most advanced ray 244 (31.5); oblique extent of base 87 (11.2). Length to ventral origin 411 (53); length of fin 205 (26.5). Length to vent (middle) $647(83.5)$. Head 430 (55.5). Snout, full 115 (14.9), from tip of upper jaw $110(14.3)$. Eye 77 (9.9). Interorbital 42 (5.4). Internarial (posterior nostrils) 24 (4.4). Length of maxilla 182 (23.5), greatest width (6.3), shortest distance from eye $39(5.0)$. Depth at front of eyes 194 (25), at back of eyes 267 (34.5), at first dorsal origin 372 (48), at opercular border 380 (49). at vent 333 (43); maximum depth 388 (50); depth of caudal peduncle, minimum 124 (16), at second dorsal termination 141 (18.3). Widths at same five points $112(14.5), 140$ (18), 155 (20), 163 (21), 101 (13); maximum width 163 (21); widths of caudal peduncle $16(2.0)$, $39(5.0)$.

\section{General description}

Body form in terms of the specifications of Gregory (1928): hypsisomatic, gasterion postapical, apex anterior, gasterion posterior, mesonotic, bathygastric, nomopygidial, opisthion preuranic.

Elongate ovate, compressed, greatest width 2.4 in greatest depth; 1atter $2.58 \mathrm{~m}$ Ls, 0.90 head. Caudal peduncle stout, its least depth 1.3 its length, 3.5 in head. Head large, 2.32 in Ls, 1.50 in length to vent. Eye 5.6 in head, 1.5 in snout, 1.8 interorbital; almost cutting dorsal profile; shortest distance from maxilla subequal to width of maxilla at nearest point. Interorbital slightly concave between well developed ridges. Lower jaw projecting a little beyond upper. Mouth cleft strongly oblique. Least oblique width of preorbital half eye, greatest anteroposterior extension equal to eye. Maxilla with supplemental bone, extending to 0.7 eye, its greatest width subequal to direct distance of its posterosuperior angle from orbit. Operculum with three strong spines; middle longest, about half eye, tip just overlapping subtriangular membranous lobe; uppermost about on horizontal level of anterior nostril; lowest smallest, as far as uppermost from middle, divided at tip. Hind segment of preopercular border with 8-9 spines, subequally spaced, in general increasing in size downward; at angle 2 double spines; on inferior border 2 spines, hinder larger, double. Suboperculum, interoperculum entire.

Gill rakers on lower limb of anterior arch 7-8, elongate, subtriangular, minutely spinulose, on left side increasing in length to 5 th, which is two-thirds longest gill filament, on right side none longer than 1 st (uppermost) and 2 nd; below these 6 subcontinuous minutely spinose elevations.

Teeth in upper jaw comprising (a) on each side a dentigerous strip extending back for nine-tenths of jaw, its anterior one-fourth widening to form a patch of enlarged subconical recurved teeth, the remainder closely set with small teeth, those in anterior half cardiform, the rest (except for 3 larger, but still small, teeth near rictus on left side) villiform; $(B)$ on left side a short anterior outer row of 3 large teeth and 1 moderate tooth; no corresponding teeth on right. In hind half of lower $j$ aw a strip, less than half width of strip in upper jaw, of villiform teeth; in advance of this strip somewhat wider, broadening near symphysis to a patch of cardiform teeth of variable length : an imperfect outer row of larger teeth, comprising on left 3 large, followed after a diastema by 1 moderate, 2 large, 3 moderate, on right 1 large followed after a diastema twice that on left by 3 moderate, 2 large 1 moderate. Vomerine teeth cardiform, in a small lunule. Palatine teeth small, well separated posteriorly, where they are biserial or uniserial; more closely set, in scveral rows, anteriorly.

Trunk and tail with small scales, largest near middle of side, decreasing towards 
profiles and on pectoral base. Scales on head extend forward on dorsum to level of posterior nostrils; cover whole operculum; occur on lateral surface forward to a line from near middle of anterior border of orbit to upper lip (thus including most of preorbita1, though deeply embedded, obscure here). On head scales cycloid; on trunk and tail some, especially the smaller ones, cycloid, the majority ctenoid, the spinules 6-12, modally 9-10, largest and strongest in hinder half of fish. Most scales with fine but distinct longitudinal ridges, characteristically forming two series each of 5-9, modally 7-8, curved so as partly to follow scale border, the two innermost ridges continuous with one another in the distal one-fourth, or less, of the scale, but diverging somewhat as they run forward, leaving anarrow lanceolate space between them.

Dorsal originating above about middle of operculum; 13 spines, increasing in length to fourth, which is 3.3 in head, 2.3 first spine, 1.7 last; length to fin 2.61 in $L s$; spinous base 1.26 in $L s, 2.16$ soft base; 16 rays, first, last, longest (eighthninth) $3.3,6.9,3.0$ in head. Anal originating below first dorsal ray; 3 spines, first imperfect, second equal to full snout, 1.5 third; 9 rays, first, last, longest (fifth) $3.1,4.8,2.4$ in head. Pectoral rather large; total length 1.61 in head; distal half approximating a semi-ellipse; extending to middle of vent; 18 rays, first, last, longest (eighth) 3.0, 4.4, 1.8 in head. Ventrals set close together, originating just behind level of lower (more caudad) end of pectoral base; extending barely to front of vent; first (innermost), last, longest (fifth) ray, spine 3.2, 2.3, 2.2, 4.2 in head. Caudal rounded truncate; 14 branched rays, flanked above and below by 4 unbranched; length, from hypural, 1.8 in head.

Coloration

Sides medium brownish, somewhat darker above, noticeably lighter below a line from pectoral base to vent. Trunk and tail marked with some four score dark brown or blackish spots, showing some tendency to form half a dozen longitudinal series; spots involving 3-12, modally 6-8, scales; extending on to hinder part of head. Spinous dorsal dark olivaceous. Soft dorsal successively deep brown, greenish yellow, brownish. Anal mainly dark brownish, lighter proximally, approaching black distally. Pectoral successively yellowish brown, dark brown, yellowish (well developed arc), dusky. Ventral mainly dark brown, Iighter proximally, blackish distally.

\section{Specification of length of dorsal spines}

An introduction to these length-number relationships of fin spines and fin rays is to be found in Part XIX of these observations (1974 a, p.248): see also Part XX (1974 b).

The length, $L$, in ascending set (i.e., those increasing in length caudad) of dorsal spines $\{I-I V\}$ is given by the relation $L=b N$, where $N$ is serial number of spine, in the relevant set, counting, caudad; that of the descending set $\{$ V-XIII, omitting $I X$, imperfect\} by $L=b N 1\} k$, where $N^{1}$ is serial number of spine, in the relevant set, counting cephalad. These relations are conveniently plotted as linear graphs with equations $\log L=k \log N+\log b, \log L=k \log N^{1}+\log b$.

With measurements in $\mathrm{mm}, k$ for the ascending series is 0.6133 , for the descending series $0.2232, \log b$ being $0.8574,0.9930$. Significance of the regressions is high; $t=141.708^{* *}, 34.079^{* * *}$. Predicted lengths, $\widetilde{I}$, with measured length, $L$, in parentheses: $7.2(7.2), 11.0(11.0), 14.1(14.2), 16.9(16.8)$ and $16.1(16.0), 15.7(15.5), 15.2$ $(15.0), 14.7(14.8),-(-), 13.4(13.6), 12.6(12.8), 11.5(11.5), 9.8(9.7)$.

Specification of length of four ventral rays

$$
\text { For } N=\{1-4\}, L=b N^{k} \text {, with } k=0.2784, \log b=1.2418 ; \quad t=9.966^{*} ; \widetilde{L} \quad \text { (L) }
$$
$=25.7(25.1, .7(24.5), 21.2(21.0), 17.5(17.4)$. The formulation tor the two-member set of ray $5(23.8 \mathrm{~mm})$ and spine $(13.1 \mathrm{~mm})$ is in itself trivial; and no articulation of it with the set $\{1-4\}$ has been found. 
Specification of length of pectoral rays

Calculations are for right fin. An equation of the form $L=b N k$ is applicable to the formally earlier (upper) rays in two sets, $\{1-3\},\{4-8\}$, and an equation of the form $L=b N 1(k)$ to the remaining rays in three sets, $\{9-11\},\{12-15\},\{16-18\}$. values of $k$, in sequence from $\{1-3\}$, are $0.3202,0.04331,0.02803,0.0917,0.3000$; of $\log b 1.2672,1.4467,1.4546,1.2868,1.0962 ; t=86.242 * *, 3.599 *, 19.156 *$, $48.380^{\star \star \star}, 43.196^{*}$. From the severa1 equations, $\widetilde{L}(L)=18.5(18.5), 23.1(23.1), 26.3$ $(26.3), 28.0(28.0), 28.8(28.9), 29.3(29.4), 29.7(30.0), 30.0(30.2), 29.4(29.4), 29.0$ $(29.0), 28.5(28.5), 25.2(25.3), 23.9(23.9), 22.2(22.0), 19.4(19.4), 17.4(17.4), 15.4$ $(15.3), 12.5(12.5)$.

It will be seen the specification of the pectoral rays calls for the recognition of five sets - the existence of several sets has been found usual in other species examined, the curve of this fin being, at sight, more complex as a rule than that of the dorsal or the anal. As pointed out earlier (1974 a. p.250), the situation arising from the employment of a multiplicity of sets could, in the limit, resolve itself into a triviality, comparable to the formulation of the circumference of a circle by the specification of the perimeter of a polygon with a number of sides appropriate to the degree of precision deemed desirable. However, the actual plotting of the (logarithmic) length-number co-ordinates yields such clear visual evidence of linearity over successive small ranges associated with marked changes of gradient at points of inflection that it appears difficult not to attribute some validity to the overall pattern that thus presents itself. Possible indications of the status of the several graphs as indications of genuine morphological patterns are provided by the following relationships subsisting among them. The two sets of the ascending series are matched, in respect of mean $10 \mathrm{~g}$ length of ray, with the first two of the descending series, these lengths, in succession caudad, being $1.350,1.467,1.461,1.353$. When compared in respect of area below the graph, these two pairs again match, but with different partners, the areas in sequence as before being $0.641,1.02,0.645,1.01$. It would appear unlikely these cases of symmetry (the 1atter rendered more striking by the fact that the coupled sets differ in number of members) are purely coincidental. When the descending series of three sets is examined, it is found the plot of mean ray length (in sequence cephalad, as in the length-number equations for these sets) on logs of integral $1,2,3$, is linear with a fit better than $P 0.01\left(t=90.061^{* *}\right)$; the equation being $\log L / n=0.6022 \log N^{1}+1.1734$, with $\log L / n$, as measured, 1.1741 . $1.3529,1.4619$, as predicted, $1.734,1.3547,1.4608$.

Ana1 spines

of the ana1 spines only the second $(14.9 \mathrm{~mm})$ and the third (9.7) are intact.

\section{Discussion}

As noted above, the present specimen, while pretty clearly determinable as Acanthistius serratus, exhibits some differences from published accounts. A comparison with data at hand - the original account by Cuvier in Cuvier \& Valenciennes (for a photocopy of which I am indebted to Miss Joan Dixon, Curator of Vertebrates, National Museum of Victoria), of which rather less than half treats of externa1 features; the Handbook diagnosis (Munro 1961, p.161) and the tolerably detailed account by Günther (1859, p.161, pl. 12 cited, but apparently no plates bound) of his Plectropoma cyanostigma (name amended in addenda to $P$. ocellatum), this species generally being treated, as in the Check-1ist (McCulloch 1929a) as synonymic with A. serratus, together with the reproduction by McCulloch (1921, p.16, fig. 163a) of the figure by Quoy G Gaimard (1824, pl. 2,1) and the reproduction by whitley (1962, fig. on p.89) of a figure by Steindachner - yields the following results; minor variations being disregarded. In each case our datum is given first.

Dorsal rays 16 (G.15). Anal rays $9(G .8)$. P.18 (C.15; M.19-21). Scales in longitudinal series 95 (G.100, as 'lateral line'). L. lat. $59+8$ on caudal (M 60-67). Sc.tr. 26/67 (M 20-22/55-60). Gill rakers on lower limb of anterior arch 7-8 sabreshaped, followed by 6 low mounded (M.9-10; 'long' - low elevations on lower part 
of arch probably not counted); depth in total length 3.2 (G.4), eye in head 5.6 (G.6); maxilla to 0.7 eye (M.to or beyond hind edge of eye); lower jaw projecting slightly (C.'1es deux mâchoires sont d'égale longueur'); base of spinous dorsal 2.0 (G.11/2; C.'beaucoup plus longue') base of soft dorsal; twelfth dorsal spine 1.4 times (G. rather shorter than) second; first dorsal ray 1.5 times (G. one-third longer than) last spine; pectoral reaching to (Q. \& G.'s figure well short of) vent; preorbital obscurely squamous, scales deeply embedded (G., M. naked); upper and lower jaws naked (C. 'De petites écailles recouvrent la peau du maxillaire et de la mâchoire inférieure'); the teeth forming bands in the jaws, in parts villiform in parts cardiform (C.'en cardes .... assez fortes'; M.villiform); in upper jaw outer series of large teeth 4 only in front on right side, none on left (C."les dentes de la rangee externe sont fortes, courtes, coniques, un peu crochues et d'egale longueur; G.'a series of large teeth in each jaw in front and on the side'; M.'both jaws with ... an outer row of enlarged conical' teeth); opercular spines rather blunt (C.'très-acerées); cauda1 truncate (Q. \& G.'s figure emarginate) - however, it may be noted that in the closely allied Plectropoma macuzatum (Bloch, 1790) the caudal is stated to be truncate in the young fish, becoming emerginate with age; Quoy $\varepsilon$ Gaimard's figure shows soft dorsa1 and anal less rounded, pectoral more rounded than Steindachner's (latter agreeing better with our specimen); places ventral origin (incorrectly) in advance of pectoral origin. As preserved in alcohol, the specimen shows no sign of the dark bar noted by Cuvier as running from eye towards angle of preoperculum; on the contrary the greater part of the cheek is lighter in colour than rest of head. Nor is there any obvious indication of the bluish centre to the blackish spots reported by Günther - noticed also in a popular account by Whitley (1962, p.89), this author noting also "sometimes about 4 transverse dark and 1 ight bands', and remarking the blue spots may be few or absent.

The most striking feature of the Tasmanian fish is the presence of both cycloid and ctenoid scales (latter developed mainly in hinder part of body). Miss Joan Dixon, has been good enough to arrange for her assistant, Miss Linda Chegwidden, to examine the scales in a Victorian example of $A$. sermatus (Reg. No. Al6, Mallacoota, purchased 1933): in this fish also both types of scale occur. No reference to the nature of the scales appears either in Cuvier's description of $A$. serratus or in Günther's account of $P$. cyanostigma. However, Munro's diagnosis, under the former name, has 'Scales cycloid'. It should be remarked that the presence of both cycloid and ctenoid scales (the former usually confined to the head) is not uncommon in the allied Epinephalus Bloch, 1793, upwards of half a dozen Australian species of this genus being so characterized. A particularly interesting situation obtains in $E$. tawina (Forskal, 1775), in which the scales are ctenoid early but become cycloid with age. As the length of our specimen of $A$. serratus is only about one-third of the full size, it could be its possession of mixed scales is a subadult feature. On the other hand, in view of the fact that the type locality of Cuvier's species is King George's Sound, Western Australia, consideration deserves to be given to the possibility that differences from published accounts presented by our fish are indicative of the occurrence in our waters of an eastern subspecies - a matter towards the elucidation of which the above description may serve as a first step.

\section{Family SCORPIDAE}

Genus ATYPICHTHYS Günther, 1862

Atypichthys Gunther, 1862, Cat. Fish. Brit. Mus., 4, p.510. Nom. nov. pro Atypus, Günther, 1862 preocc. in Arachnida. Haplotype, Atypus strigatus Günther.

$$
\text { Atypichthys strigatus (Günther, 1860) }
$$

Atypus strigatus Günther, 1860, Cat. Fish. Brit. Mus., 2, pp.64 and 518. Type 1oca1ities: Swan River, W. Australia; Holdfast Bay, S. Australia; Raoul Is.; Erromanga, New Hebrides. 
Atypichthys mado Whitley, 1911, Aust. 20ol., 6 (4), p.319. Type locality: Man1y, New South Wales.

\section{Additional records}

The mado was first recorded from Tasmania in Part XX (1974 b) on the basis of three examples from George Bay, east coast, together with reports from scuba divers of its occurrence at Stony Head, north east coast, and Clarke Island, Furneaux Group, Bass Strait. Several examples from Boat Harbour, north west coast, collected by $\mathrm{Mr}$ H.J. Griffith have since been added to the Queen Victoria Museun's collections: among these are two juveniles, Ls 20.2, 21.9, Lt 23.9, 25.1, taken on 17 March 1974, (Q.V.M. Reg. No. 1974/5/122) that are here made the subject of some observations, chiefly on relative growth and development of colour pattern.

Relative growth

Comparisons of some dimensions expressed as permillages of standard length of the George Bay individuals (Ls 102.1, 104.5, 110.2) set out in Part XX with those of the present juveniles reveal regional variations of relative size with age. Consistently higher (though not necessarily statistically significantly greater) values of TLS are found in the younger fish for most dimensions involving anterior features: head 323,361 (cf. $293,278,272$ ), $t=2.987$, snout $94,82\left(67,67,64\right.$ ), $t=4.726^{*}$, eye $149,151(98,95,92), t=23.335^{* * *}$, length to (spinous) dorsal origin 386,393 $(326,331,335), t=14.293^{* * *}$; an exception being provided by the transverse measurement, interorbital width $74,89(101,99,95), t=2.057$.

On the other hand, the posterior dimensions length to (soft) dorsal termination $792,772(911,863,833), t=4.633^{*}$, 1ength to anal termination $812,813(917,883$, 871), $t=4.375^{*}$, are consistently less in juveniles. Lower TLS values, again with the young and old sets disjoint, obtain in the present material in respect of depth at opercular border $337,320(411,392,404), t=6.610^{* *}$, depth at spinous dorsal origin $347,338(470,440,454), t=22.285^{* * *}$, depth at vent 353,365, (470, $440,386), t=2.247$, maximum depth $396,384(495,459,481), t=6.200^{* *}$; the greatest proportional increase in relative depth occurring at the origin of the spinous dorsal, where the mean value of the older fish is one and one-third times that of the younger fish. Of the three small TLS magnitudes depth at front of eyes, depth at back of eyes and depth of caudal peduncle the first has the lower mean value among the juveniles (though the two sets intersect), the variates being 149, 155 (197, 163, 150), $t=0.988$; higher relative depths occurring in both the present specimens at back of eyes $302,297(289,292,288), t=4.574^{*}$ and at caudal peduncle (minimum) 119, 119 $(118,118,109), t=1.033$.

Development of colour pattern

In these juveniles the colour pattern - the full occurrence of which in the George Bay specimens is the subject of detailed description in Part XX (1974 b , p. 183) - is in a rather early stage of formulation, only the upper (in the adult, widest, most intense) stripes being developed. The general situation in the larger individual is as follows.

Uppermost black stripe at dorsal profile thin, extending to within 4-5 rays of end of dorsal: second beginning at profile about midway between eye and dorsal origin, continuing back, well developed, to superior profile of caudal peduncle just behind dorsal termination: third extending from near highest point on orbit to middle of caudal peduncle, ceasingas a continuous line an eye diameter in advance of hypural joint, represented thereafter only by a few dark specks: fourth effectively constituted as a stripe only from middle of orbit to about half an eye diameter beyond opercular border, continuing behind this, for a slightly greater distance, only in the form of dots (which, however, fairly clearly delimit its width), wholly ceasing, just above anal base, about one and one-third eye diameters short of hypural; no indications of other stripes (in adult usually three more); the abdominal viscera apparent as an off-white or pale yellowish ovoid, visually undifferentiated mass, about half as long 
again as deep; this region conspicuously patterned with 40-50 melanophores of varying size. many $0.1 \mathrm{~mm}$, or less, in diameter, several 3-4 times as 1arge; dotted area extending on to head, covering most of the cheek below fourth stripe forward nearly to level of front of eye, melanophores subequal; dorsum of head with forward continuation of second stripe, interstripe region without many chromatophores, but stripe liberally sprinkled with melanophores much larger and more intense than the microscopic ones marking its general course; median portion of upper border of upper lips slenderly margined with blackish; ventral surface mostly off-white, whiter on chin; immaculate save for a few dark splashes on throat; some dark 1 ines on spinous dorsal; soft dorsal, anal, pectoral quite colourless; ventral greenish with some dark spots; caudal with a vertical line of half a dozen spots across base.

The smaller specimen agrees broadly with the larger one. Chief differences: overall effect of second and third stripes a trifle lighter; portion of fourth stripe running back from mid-orbjt stopping at opercular border, with short hiatus (about half an eye diameter) between it and its extension on to trunk; dark line on upper lip not continuous; melanophores on cheek include several larger, less sharply delimited ones; marking on caudal base two obscure dark patches.

It thus appears that the sequence of development of the conspicuous longitudinal stripes so characteristic of the species is primarily from the dorsal profile ventrad, while within the stripe itself differentiation is initiated anteriorly and proceeds caudad.

\section{Life colours}

The specimens, examined while tolerably fresh, exhibited overall coloration probably not differing markedly from that in life - first dorsal pale greyish with large yellowish patches; dark brown marginal band; spines (strongly projecting) white; second dorsal pale yellowish, delicately tipped orange; anal from base successively whitish, briefly yellowish, darker and somewhat brownish, yellowish, some delicate orange tipping; pectoral yellowish or pale orange proximally, more or less colourless distally; ventral white, tipped greenish yellow; caudal proximally pale orange; indications of two dusky arcs near middle of length; beyond this yellowish, soon becoming lighter, distally approaching white.

Size, habits

Whitley (1962, p.158) observed, 'Rarely 10 in., usually much smaller.' When forwarding examples of a total length of round about $150 \mathrm{~mm}$, Mr Griffith noted that these were about as large as any he had met with. He added 'We [i.e., local scuba divers] have seen them on various occasions between Wynyard and Sisters Beach in groups of 3 or 4, and once in a school of about a dozen at Boat Harbour. They normally occur in depths around $40 \mathrm{ft}$ or so', [ca $12 \mathrm{~m}]$.

\section{Family TRICHIURIDAE}

While the Handbook (Munro 1958) recognized the Lepidopidae as a separate family represented in Australia by three genera, Lepidopus Gouan, 1770, Benthodesmus Goode $q$ Bean, 1882 [regarded by Whitley (1968, p.74) as a synonym of Scarcina Rafinesque, 1810], Assurger Whitley, 1933, each with a single species; only the first recorded from Tasmania - a procedure recently followed by Scott et al. (1974), Lepidopidae was subsumed by Greenwood et al.(1966) in their overall provisional Teleostean classification in Trichiuridae, thus reverting to the usage general among earlier authors - e.g., Günther (1881), Boulenger (1910), Jordan (1923), McCulloch (1929), Berg (1940) - and that adopted in the local lists of Johnston (1882), Lord $(1923,1927)$, Lord \& Scott (1924), and in the present Observations. 
Lepidopus Gouan, Hist. Pisc., pp.107 and 185. Haplotype, L. gouoni Gouan = Trichiurus caudatus Euphrasen.

\section{Lepidopus caudatus (Euphrasen, 1788)}

Trichiurus caudatus Euphrasen, 1788, K. Vet. Nya. Handl., 9, p.52.

Lepidopus caudatus McCulloch, 1929, Aust. Mus. Mem, 5 (2), p. 267 (synonymy).

Lepidopus Zex Phillipps, 1932, N. Z. J. Sei. Techn., 13 (4), p.232. Type 1ocality:

'all parts of New Zealand'.

Materia1

(a) An example, Ls 1302, Lt 1365, hooked at a depth of $150 \mathrm{fms}$ (274 m), east of Scamander, east coast, by Mr A.W. Yates (Q.V.M. Reg. No. 1975/5/140); (b) a specimen, Ls 1461, found by Mr E. Bennett in 1943 in shallow water at Little Devi1's E1bow, Tamar river, 40-45 km from river mouth (Q.V.M. Reg. No. 1943.78): the 1atter was the subject of some observations in Part IX of this series (1960, p.62).

Meristic characters

Data in parenthesis in this section relate to specimen (b).

D. $103(100)$. A. ca XXXII, embedded ('numerous'), 28 (25). P. 12 (12), lowermost, uppermost 2 unbranched ( 2 broad, undivided). C. $10+1+10(18-20$ principal rays). V. rudimentary, represented by 2 scales.

Dimensions and proportions

Where two values appear, the second relates to specimen (b). Lengths and '1ength to' measurements are made from tip of lower jaw, which projects beyond upper by 13 , $9 \mathrm{~mm}$.

Length to dorsal origin $(156,143 \mathrm{~mm}) 8.35,9.86$, to termination $(1273,1368)$, $1.02,1.03$; to ana1 origin (spine) (728) 1.79 or (ray) $(1208,1180), 1.80,1.21$, to termination $(1276,1373), 1.021 .04$ in $L s$. Length to vent (middle) (715, 723) 1.82, $1.95 \mathrm{in} \mathrm{Ls}$. Length to pectoral origin $(223,222) 5.84,6.35$ in $\mathrm{Ls}$, length of fin (107) 1.22 in $L s$, or 1.98 in head. Length to ventral origin $(271,277) 4.80,5.09$ : 1eft ventral scale, length (9), width (4); right, length (10.5), width (6). Depth at front of eyes (66) 19.7, at back of eyes (80) 16.3, at dorsal origin (90) 14.5, at opercular border (102) 12.8, at ventral origin (maximum depth) (105) 12.4, at vent (103) 12.6 in Ls. Depth of cauda1 peduncle $(7,7) 3.71,5.28$ in its length (26.37). Width at back of eyes $(41,43) 5.17,4.93$, at dorsal origin (43) 4.93, at opercular border $(38,42) 5.58,5.05$ in head.

Head $(212,212) 6.14,6.44$ in $L s$, or $6.44,6.88$ in $L t$. Eye $(35.5,39) 5.97$, 5.44; snout from tip of upper jaw $(7.9,8.6) 2.68,2.58$, from tip of lower jaw (92, 95) $2.30,2.23$; soft interorbital $(32.5,35) 6.52,6.06$ bony $(26.8,28) 7.91,7.57$ in head. Length of 8 th (first intact) dorsa1 ray (37.8) 5.61, 9th (36.3), 5.84, 13th (40.6) 5.22, ray at leve1 of vent (1ongest) (42.7) 4.96 , 1ast (17.3) 1.23 in head. Some dorsa1 ray lengths in specimen (b): longest, 1st (39) 5.44; shortest, 100th (19) 11.1 ; 11th, 21st, 31st . . 91st $(28,31,32,23,28,23,29,31) 7.57,6.84,6.61,9.92$, $7.57,9.22,7.31,6.84$ in head. Length of 1 st ana1 ray $(13.0,5) 16.3,42.4,1$ ast (15.4) 13.7 in head. Spread of caudal $(90,87) 2.36,2.44$ in head. First anal ray below 79 th, 77 th dorsal ray. Some ana1 ray lengths in (b): 11 th (18) 11.8; 21st (12) 17.7; 25 th (11) 19.3 in head.

General features

Dorsal begins behind eye by $0.9,0.6$ eye. Maxilla in $(a)$ failing to reach level of eye by 0.1 eye diameter, but gape extending to below 0.2 eye (in (b) maxilla (= gape?) recorded as to 0.2 eye]; its distance from eye subequal to its distal width. 


\section{E.O.G. Scott}

Ventral at, or slightly in advance of, level of middle of adpressed pectoral, behind border by $0.31,0.33$ length of head: this locates it relatively further forward than in the figure by Whitley (1962), where it is shown under about last one-fifth of pectoral, or behind operculum by about half head, but further back than in the figure by Günther (1880), in which it appears shortly behind dorsal base, or behind operculum by about one-fifth head.

The following observations relate to specimen $(a)$. Teeth in left upper jaw 28 , in right 25 , slender, somewhat compressed, acute, straight or very slightly curved forward, longest (about 0.1 eye) near middle of series; these teeth in 1 ower jaw much as in upper, but somewhat smaller, rather less closely set. One large fang at front on either side of upper jaw, inserted internal to series of smal1 teeth, 1eft 10.51 ong, right, situated a little further back, 8. Palatine teeth minute, $0.5 \mathrm{~mm}$ or 1 ess in a single series along each bone. The base of the caudal is largely occupied by a fleshy region, shaped roughly like the fin itself, its posterior width half width of fin at that level, its length, about half length of median rays; anteriorly it is constituted by a noticeable smooth subcircular pad (adipose?), its diameter approximately half total anteroposterior extension of whole feature: all the region is bluish black, the pigmentation heaviest on the pad.

\section{Dorsa1 marking}

Accounts agree in describing the frost-fish as being almost devoid of any distinctive colour patterning, the head and body being more or less uniformly silvery, the fins largely unmarked (outer margin of dorsal, or parts of it, may be very narrowly bordered with black or blackish, caudal may in part be dusky): however, a black or blackish blotch is characteristically found at, and extending for a short or moderate distance inwards from, the distal margin of the membrane between the first three dorsal rays (not shown in figure reproduced in McCulloch). It is of interest to note that while in the present specimen, in which remnants of the membrane associated with the anterior two or three of the first seven imperfect rays (represented only by a few millimetres of their bases) retain traces of apparently normal pigmentation, another well developed black blotch is present at the new effective beginning of the fin, occupying the outer one-third or more of the membrane between the 9 th and 11 th rays - suggesting perhaps that the loss of the original anterior rays has resulted from some injury, and that in their absence some stimulus has operated to bring it about that the region of these normally later rays, located above the pectoral instead of above the head, now effectively the anterior ones, are pigmented by virtue of their mere anteriority.

Status of the Australian Lepidopus

The table of species synonymy in the Australian Check-1ist (McCulloch 1929) comprises 10 entries, involving 8 second binomens : these references, however, are all extra-Australian and call for no comment here.

The history of the frost-fish in Australian and New Zealand literature divides into three epochs, the first prior to 1932, during which our fish was customarily identified as the Atlantic and Mediterranean species, L. caudatus, the second following the publication in that year of $L$. Zex that saw Phillipps' name applied to the Australasian fish, the third characterized by a recent recognition of the existence of a single species in both hemispheres. Thus, among local authors, Allport (1876, p.86), giving the first record for Tasmania, based on an example washed ashore at Battery Point, Hobart, Macleay (1881), Johnston (1883, 1891), Lord (1923, 1927), Lord \& Scott (1924), McCulloch $(1922,1929)$, all have the former name : Munro (1958), Scott (1960), Whitley $(1962,1964$; also in New Zealand Check-list 1968), Scott (1962), Scott et al. (1974) have the latter: however, Marsha11 (1964) accepts L. caudatus (in index candatus) as also do the New Zealand authors Heath \& Moreland (1973).

Phillipps' account is a somewhat sketchy one, unaccompanied by any dimensions 
other than length and weight, or by any actual fin counts. His comparison with the established species, based partly on a figure by Goode \& Bean, takes account of five main features - fewer dorsal rays, fewer anal rays, longer head, sixth dorsal ray 5 (cf. 8 or more) in head, no dorsal 'spines' [rays] exceeding eye diameter.

A point by point comparison (set out in full in the original draft of the present paper) of our material with available accounts and figures in Australian works, together with the description by Gunther $(1860, \mathrm{p} .345)$ resulted in the conclusion that it is not separable from $L$. caudatus. It now appears, however, that the invalidity of L. Zex has been satisfactorily established previously, and the writer is much indebted to Dr John Paxton, Curator of Fishes, Australian Museum, Sydney, for calling attention to the fact that Tucker (1956) has dealt with the synonymy of $L$. caudatus and after directly comparing specimens of the frost-fish from New Zealand and the North Atlantic placed $L$. Zex in the synonymy of Euphrasen's species. Tucker has been followed, Dr. Paxton adds, by Parin \& Becker (1972): as references cited above make clear, however, his conclusion has not hitherto been widely incorporated in local texts.

\section{Family SOLEIDAE}

Genus ZEBRIAS Jordan \& Snyder, 1890

Zebrias Jordan \& Snyder, 1890, Proc. U. S. Nat. Mus., 23, p.38. Orthotype, Solea zebrias Temminck \& Schlege1.

\section{Zebrias fasciata (Macleay, 1882)}

Synaptura fasciata Macleay, 1882. Proc. Linn. Soc. N.S.W., 7 (1), p.14. Type locality: Port Jackson.

Tasmanian records.

It was not until upwards of four-score years after the publication of the first Tasmanian catalogue (Johnston 1883) that this species appeared in the State list, one example, Ls 131, from between East Sandy Cape and Thirty Day Island. and a second, Ls 96, from off Prime Seal Island, Furneaux Group, being reported in Part XXI (1975). A third example, Ls 140, (Q.V.M. Reg. No. 1975/5/156) taken off St Helens, east coast, by the same collector, Mr P. Armstrong, provides a new locality. Two accompanying smaller soles, the larger 113 in standard length, both in a poor state of preservation, are probably referable to this species.

\section{Family GOBIESOCIDAE}

The clingfishes, characterized by the incorporation of the ventral fins into a distinctive adhesive apparatus, and constituting the Gobiesocidae, the sole family of the order Gobiesociformes (Xenopterygii), are to be met with, usually in shallow water, on most warm-temperate and some tropical coasts. "This order seems to be most closely related to the Haplodoci, but there is also some slight resemblance to the Callionymoidei. It may be considered a highly specialized divergence from a primitive percomorph stock' (Briggs 1962, p.444).

of just under a hundred species noticed by Briggs in his admirable monograph (1955), three are known to occur in Tasmania: Creocele cardinalis (Ramsay, 1882) (endemic), Aspasmogaster tasmaniensis (Gunther, 1862) (al1 states except Queensland), Cochleoceps spatula (Gunther, 1861) (Tasmania, Victoria, South Australia, Western Australia). Some notes on the history of the family in Australian literature to that time, with a key to the Australian species as then recognized, have been given in Part III of this series (1936), together with some observations on Aspasmogaster tasmaniertsis (with figure of a Tasmanian example) and on Creocele cardinalis. 
While the three Tasmanian Clingfish agree in having the adhesive apparatus constituted of an anterior lunule bearing the ventral rays and a posterior subcircle, each closely beset laterally with small flat dermal papillae but having a smooth central region, they differ trenchantly in detailed pattern. In Aspasmogaster tasmaniensis there is within the two bare areas only a single group of papillae, wholly confined to the posterior half of the apparatus. In the two other species the papillose island in the hind half presents a well developed forward extension reaching into the lunule: in Creocele cardinalis this extension is a four-pointed star, the hindmost arm the longest, overall longer than wide; in Cochleoceps spatula the extension is threesided, all borders convex caudad, the posterior border about twice as long as each of the anterior, overall wider than long. These disc patterns of papillae are generic, while the general nature of the whole apparatus as a double disc (as here) or a single disc is taxonomically significant at subfamily level.

Attachment or non-attachment by membrane of dorsal to caudal base - employed in keys by the writer (1936,p.120) and by (T.D.) Scott (1954, p.110) - is not a satisfactory differentia.

\section{Subfamily TRACHELOCHISMINAE}

Genus Creocele Briggs, 1955

Creocele Briggs, 1955, Stanf. Ichth. Buz2., 6, p.12, figs 15, 43, map 1. Orthotype, Gobiesox cardinalis Ramsay.

\section{Creocele cardinalis (Ramsay, 1882)}

Gobiesox cardinalis Ransay, 1882, Proc. Linn. Soc. N.S.W., 7 (2), p.148. Type 1ocality: George Town, Tasmania.

Diplocrepis cardinalis Waite, 1906, Rec. Aust. Mus., 6 (3), p.204, p1. 36, fig. 2

(text cites fig. 1, legend to plate gives fig. 4, notation on plate is 2).

Id. McCulloch, 1929. Mem. Aust. Mus., 5 (3), p. 360.

Volgiolus cardinalis Whitley, 1935, Aust. Mus. Mag., $\underline{5}$ (9), text fig. on p. 292.

Td. Scott, 1936, Pap. Proc. R. Soc. Tasm. (1935), p.123.

Creocele cardinalis Briggs, 1955, Stanf. Ichth. Bul2., 6, p.12, figs 15, 43, map 1.

Appearance in Tasmanian lists

Not included in main body of Johnston's first 1ist; appears, without 1ocality data, in Addenda (1883, p.143) as Diplocrepis cardinalis; 1isted under same name in Johnston's second 1ist (1891, p.33), Lord (1923, p.71), Lord \& Scott (1924, pp.14 and $89)$, Lord (1927, p.16).

Distinguishing features

In addition to the distinctive pattern of the disc, Creocele exhibits three features that mark it off sharply from the two other Tasmanian genera: gills three and a half (others three), vent much closer to disc than to anal fin (noticeably closer to anal), presence on lower pectoral base of a prominent fleshy pad with a free posterior margin, from which genus derives its name (kreas, flesh; kele, a swelling) (no such pad).

Creocele, which is monotypic, is regarded by Briggs as the most primitive known clingfish. It is characterized by the pectoral pad already mentioned, a strong, subopercular spine, a much larger disc and greater overall size than other members of the Trachelochisminae; further, it shares with the six other members of the subfamily a primitive dental arrangement in the form of patches of undifferentiated conical teeth.

Remarks

It is of interest to note that the most primitive genus of the Diplocrepinae, Diplocrepis Günther, 1861, a monotypic genus confined to New Zealand, resembles 
Creocete in possessing a well defined pectoral pad (represented in some other forms by a slight swelling, rarely developed into a true pad), and a particularly stout, rather simple pelvis, broadly subtriangular when viewed from below, not matched, as far as known, in any of the remaining thirty-odd genera. Pointing out that the complete absence of fossil material makes it necessary to depend on relict species for information on the distributional and evolutionary history of the family, Briggs (1955, p.150) observed 'The remarkable survival of Creocele ... in Tasmanian waters ... has been fortunate'; he comes to the conclusion that our shallow waters are evidently cold enough to prevent effective penetration and competition from the several more advanced species common elsewhere in Australia.

\section{Material.}

Ten specimens, lettered in sequence of ascending magnitude of $L s:$ ( $a$ ) Ls 25.0 , Lt 31.0, Falmouth, east coast, 31 October, 1970, E.0.G. Scott; (b), (c), (d), (e) Ls $33.0,34.0,35.4,37.4$, Lt 41.2, 41.5, 43.0, 46.0, Fisheries, Burnie, north west coast, 26 September, P. Sims, Q.V.M. Reg. No. 1953/5/6; $(f),(h),(i)$, Ls 39.5, 48.0, 49.0, Lt 48.4, 57.4, 59.0, locality unknown, probably northern Tasmania, Broadland House Schoo1; (g), Ls 40.7, Lt 48.9, Brown's Bay, Ulverstone, north west coast, 31 December 1939 , E.0.G. Scott, Q.V.M. Reg. No. 1975/5/215; (j), Ls 50.3, Ls 62.1, Low Head, north coast, R. Vogelpoel.

Meristic data.

Fin counts for the type specimen (Ramsay 1883, p.148) were D.8; A.6; V.4; P.22; C.18-20 [minor rays evidently included]. Briggs, wj.th 17 specimens at hand, reported D.9 (9-10); A.7 (6-7); P.25 (24-25); C.11 (10-12), the first figure being the arithmetic mean, the figures in parentheses the range. Our values (counting only clearly visible elements; in caudal, major rays only) are D.8 (6), 9 (4); A.5 (5), 6 (3), 7 (2); P. (left/right) $23 / 23$ (2), $23 / 24$ (2), $24 / 24$ (4), $25 / 24$ (2); C.11 (6), 12 (4), the figures in parentheses being the number of specimens. It will be seen that our D. and A. values are lower than those of Briggs: this is perhaps to be accounted for by our failure to include possible rays wholly embedded in the membrane and not externally visible. With six examples before him, Waite (1906, p.204) gave a single count for each fin, namely, D.10; A.7; P.22; C.11.

\section{Dimensions.}

Apart from several records of total length and standard length, no absolute measurements of this species have been published. Measurements, to the nearest tenth of a millimeter, have been made for some three dozen dimensions on each of our 10 specimens. For convenience of comparison, these have been converted to thousandths of standard length, and ranges and means are presented in this form in table 4 . For the TLS values in excess of 100 the entry provides three (for TLt four) significant figures - the last figure always makes possible the recovery of the absolute dimension; however, in general (excluding $T L t$ ) the values are usefully read to an integral percentage. In most cases they have been taken between parallels: however, the last six entries call for comment. These are made by the methods of Briggs; dorsal-caudal, postdorsalcaudal, length of caudal peduncle being the intervals, found by dividers, between, in each case, midcaudal base and first dorsal ray, last dorsal ray, last anal ray, respectively. Snout is measured from the median anterior edge of the upper lip to the anteriormost edge of the externally visible eye. Chin-disc and interorbital are both taken with dividers, the latter being, as in Briggs, the bony interval, the soft interval being recorded earlier in the table.

\section{Proportions.}

Values have been calculated for each of the nine proportions recorded in the species diagnosis in the monograph by Briggs. Each entry below gives arithmetic mean (with standard error), range, coefficient of variation (with standard error), followed, after a colon, by arithmetic mean, range in his material. 
Greatest depth in Ls $4.92 \pm 0.22,3.9-6.0,14.0 \pm 3.2: 5.4,4.9-6.0$. Depth of caudal peduncle in its (Briggsian) 1ength $0.98 \pm 0.34,0.74-1.07,11.0 \pm 2.5: 1.0$, 0.9-1.1. Length of head in Ls $2.49 \pm 0.43,2.3-2.7,5.5 \pm 1.2: 2.4,2.3-2.5$. Width of head in Ls $2.74 \pm 0.50,2.5-3.1,5.8 \pm 1.3: 2.6,2.5-2.8$. Snout (Briggsian) in head $2.94 \pm 0.10,2.5-3.7,10.8 \pm 2.4: 3.2,3.0-3.3$. Eye in bony (Briggsian) orbital $1.71 \pm 0.10,1.2-2.3,19.3 \pm 4.4: 1.3,1.1-1.6$. Eye in head $6.15 \pm 0.17$, 5.4-7.1, 8.8 $\pm 2.0: 5.5,4.7-6.0$. Postdorsal-caudal distance in dorsa 1 length 1.33 $\pm 0.042,1.1-1.6,10.6 \pm 2.4: 1.2,1.0-1.3$. Disc length in $L s 3.07 \pm 0.058,2.8-3.1$, $6.0 \pm 1.3: 2.9,2.8-3.0$.

As noted above, Briggs measures caudal peduncle length with dividers from base of anal ray to midcaudal base, and snout length from median anterior edge of upper to anteriormost edge of externally visible eye: these methods were observed in making the measurements above. With the more usual procedure of taking the measurements between parallels the results are as follows. Depth of caudal peduncle in its length, with length measured from level of last anal ray $0.73 \pm 0.48,0.57-1.0,20.6 \pm 4.8$, or, measured from level of point of attachment of ana1 membrane $0.42 \pm 0.067,0.12-0.77$, $51.0 \pm 14.1$ : it is evident that the extension of the membrane behind the ray exhibits such great variability $(V=51)$ that a caudal peduncle length measurement involving its point of attachment is of no taxonomic value. Snout in head 3.87 $\pm 0.16,3.3-5.2$, $13.0 \pm 3.0:$ the presence of the upper extreme value (5.24), provided by the smal1est individual, raises the coefficient to a magnitude that may be regarded as uncharacteristically high; the statistics with this fish omitted becoming $3.72 \pm 0.074,3.3-4.1$, $6.0 \pm 1.4$. Eye in soft interorbital $5.05 \pm 0.19,4.3-6.3,11.8 \pm 2.7$.

For the ratios considered the distribution in our material of the variates is satisfactorily symmetrical, the number of entries within one standard deviation on either side of the mean for block of nine ratios noted above being. $6,7,6,8,7,7$, $5,6,6$, respectively (in normal distribution, $N=\propto$, expected 7), and for the ratios of the last paragraph $7,6,8,6$ (expected value for third entry 6).

Comparison of proportions

Values of proportions noted above as being found in our material and in that of Briggs are in general in satisfactory agreement with those reported earlier by Waite (1906, p.204).

However, of the two statements on proportion contained in the original description (Ramsay 1883, p.148), one'the length of the head is $31 / 5$ in the total length, without caudal', presents difficulty, our range being 2.3-2.7, Briggs' range 2.3-2.5, and Waite's single value 2.7; while our range for head in $L t$ is $2.8-3.2$, mean $3.05 \pm 0.047$, and an approximate reading from Waite's figure is 3.2 . Formally, for our Lis values and Ramsay's $3.2 \mathrm{~d} / \sigma^{\prime}\left(\sigma^{\prime}\right.$, with $n-1$ degrees of freedom: e1sewhere in this paper, with $n$ degrees of freedom), is 4.87 , for our $L t$ values and 3.2 it is 0.96 . It thus seems highly probable that though in the original description length without caudal is expressly stated, the datum $31 / 5$ actually specifies head in total length, including caudal.

Relative growth

In a series as short as the present one, clear indications of possible systematic variation of body proportions with overall length are in general scarcely to be looked for. However, the ratio snout (Briggsian) in head exhibits significant correlation with Ls, with $x^{-0.677}(z-0.823), t 2.601^{*}$, a slightly better correlation being found when snout is measured between parallels, $r-0.748,(30.968), t=3.188^{*}$.

\section{Coloration}

The type (spirit specimen) was described as rich salmon red, reticulated on back and sides with lines of yellowish. Waite reported the colour of all his examples (preserved in formalin) as uniform yellow. The first account of the life colours was 
given in Part III of this series (1936, p.123); quoted by Briggs (1955, p.13).

Note on locality

Waite specified his material as 'Three specimens from near Launceston, Tasmania, and three from Ulverstone, Tasmania, forwarded by the Curator of the [Queen] Victoria Museum, Launceston, in 1903', and observed 'one of the former batch is very possibly the type of the species'. Launceston is 60-67 km from the sea; and, as far as is known, Creocele cardinalis is marine. The suggestion is here advanced that at that time Launceston might well present itself as a natural point of reference, and that 'from near Launceston' means from (or from near) George Town, situated near the mouth of the Tamar (habitat of type, 'near George Town, Tasmania').

\section{Brain}

In several specimens the dorsum of the brain is discernible through the skul roof. As far as can be determined by simple observation, without dissection, it exhibits the following features. The best-developed portion is the midbrain: the optic lobes, closely apposed throughout, are subelliptical, a little longer than wide. The cerebral hemispheres are ovoid, somewhat shorter, and distinctly narrower, than the optic lobes, their area 0.7-0.8 that of the latter. The cerebellum is ovoid, its area subequal to that of the two hemispheres, nearly twice as long as wide, its greatest width at its anterior one-third: it overlies the median four-fifths of the anterior width of the medulla oblongata, which is three times, or more, as long as wide, and which presents a median fissure in the middle half of its length. At the anterior border of the cerebral hemispheres there appear to be two small extensions that may represent olfactory lobes or enlarged bases of the auditory nerves: however, the presence here of a transverse skeletal element makes accurate observation impracticable.

The total width of the brain is equal to about half the shortest distance between the supraorbital ridges. A transverse bar (possibly marking the junction of nasals and frontals) crosses the hemispheres at the front, at the level of the hind one-third of the orbit; the level of the posterior orbital rim being at, or slightly behind, the middle of the optic lobes. Differences in these features in the brain of cochleaceps spatuza are noted in the account of that species below.

The general disposition of the parts is much as in the brain of the Pike, as figured by Huxley (1871) - minor differences of shape and proportion being the more rounded form of the cerebral hemispheres and of the optic lobes, the less linguiform outline of the cerebellum, and the relatively smaller size of the optic lobes in the present species.

In one individual the presence of some of the cranial nerves can be observed, the olfactory, the optic and the trigeminal being clearly traceable.

\section{Subfamily DIPLOCREPINAE}

Genus ASPASMOGASTER Waite, 1907

Crepidogaster Günther, 1861, Cat. Fish. Brit. Mus., 3, p.507. Logotype, Crepidogaster tasmaniensis Günther. Preocc. by Crepidogaster Boheman, 1848 (Coleoptera).

Aspasmogaster Waite, 1907, Rec. Aust. Mus., 6 (4), p.315. Nom. nov. pro Crepidojaster Günther. Virtual logotype, Crepidogaster tasmaniensis Günther.

Volgiolus Whitley, 1935, Aust. Mus. Mag., 5 (9), text fig. on p.292: advanced earlier, 1931, Alst. Zool. 6 (4), p.325, as subgenus of Diplocrepis Günther, 1861, with type species Dipiocrepis costatus ogilby, 1885 . Briggs (1955), in 1ist of literature cities for 1935 reference vol. 9, in error for vol. 5 . 


\section{E.O.G. Scott}

Aspasmogaster tasmaniensis (Günther, 1861)

Crepidogaster tasmaniensis Günther, 1861, Cat. Fish. Brit. Mus., 3, p.507. Type locality: Tasmanial.

Aspasmogaster tasmaniensis waite, 1921, Rec. S. Aust. Mus., 2, (1), p.179. Id. McCulloch, 1929, Mem. Aust. Mus., 5 (3), p.359. Id. Scott, 1936, Pap. Proc. R. Soc. Tasm. (1935), p.120, fig. 2 .

Diplocrepis costatus Ogilby, 1885, Abstr. Proc. Limn. Soc. N.S.W., p.iii (nom. nud.); 1885, Proe. Linn. Soc. N.S.W., 10 (2), p.270. Type locality: Shark Reef, Port Jackson. Tra. McCulloch, 1929, Mem. Aust. Mus, 5 (3), p.360 (part; New Caledonia record excluded).

Volgiolus costatus Whitley, 1935, Aust. Mus. Mag., 5 (9), fig on p.292. Id. Scott, 1936, Pap. Proe. R. Soc. Tasm. (1935), pp.119, 120.

Volgiolus interorbitalis Whitley, 1943, Proc. I,inn. Soe. N.S.W., 68, (4), p.141. Type locality: Albany, King George's Sound, Western Australia.

?Aspasmogaster patelza Scott, 1954, Rec. S. Aust, Mus., 11 (5), p.111. Type locality: Kingston Park, South Australia.

Appearance in Tasmanian lists

This species appears as Crepidogaster tasmaniensis in Johnston's first list (1883, p.123); omit.ted from his second list (1891); reappears in Lord (1923, p. 71), Lord \& Scott (1924, pp.14 and 89), Lord (1927, p.16) as Aspasmogaster tasmaniensis.

\section{Synonymy}

The action of Briggs in relegating to the synonymy of the present species Diplocrepis costatus Ogilby and Volgiolus interorbitalis, to type material of both of which he had access, is followed here; it should be noted, however, that in his Australian name-list, Whitley (1964, p.54) retained the latter species.

As regards $A$. patella, also treated by Briggs as a synonym, Scott himself apparently reached the same position, as later, in his South Australian catalogue (1962), he listed only $A$. tasmamiensis, illustrating his account with his original figure (1954, fig. 3) of A. patelza. However, there is a possibility, apparently not envisaged by Briggs, that Scott's material may be referable to A. Ziorhynchus Briggs, 1955 . of this species, first described in the monograph, it is stated, 'Although closely related to $A$. tasmaniensis, in other respects, it does not possess the characteristic fold of tissue across the tip of the snout'; the anus is located 'either half way between rear margin of djsc and origin of anal fin or else closer to the latter' (of. A. tasmaniensis closer to anal origin: in three Tasmanian examples described in Part III (1936, p.121) distance from disc is 1.3-1.6 distance from anal, in three examples noted below $1.92,1.80,1.49$; fewer pectoral rays, 21-23 (ef. 24-27); eye somewhat smaller, mean value 4.3 , of. 4.0 , in head. Scott's account of his $A$. patella does not mention, nor does his figure give any indication of, any accessory postlabial fold; vent is reported as midway between dise and anal; pectora1 18-19; eye 5.5 in head. A possible difference occurs also in the anterior dorsal profile, described by Scott as 'strongly convex from beginning [=end] of head to tip of snout', and so shown in his figure: in Tasmanian material of $A$. tasmaniensis the dorsal profile in advance of middle of eye is overall concave, much as depicted in a figure of a virtual topotype (Scott, 1936, fig. 2). Unfortunately no help is obtainable from colour pattern reported as including 21 cross bars in A. patella, instead of $14 \mathrm{in} \mathrm{A.} \mathrm{tasmoniensis,} \mathrm{but}$ not being recorded in $A$. Liorhynchus.

It may be observed in passing that the figure of Dipzocrepis costatus by waite (1904, pl. 24, fig. 4) - a species included by him in his South Australian catalogue (1921), but later dropped from that State's list by Scott (1962), also by scott et al. (1974) - shows the preorbital portion of the head with an evenly convex profile. 
Creocele cardinalis (Ramsay, 1882), 10 specimens, Cochleoceps spatula (Günther, 1861), 7 specimens, Aspasmogaster

tasmaniensis (Günther, 1861), 3 specimens. Dimensions : first line, standard length, in mm, other 1 ines as permillages tasmaniensis (Gunther, Mrs, 3 specimens. Dimensions : first line, standard length, in mm, other lines as permillages of standard length. Measurements made, in general, between parallels :
accordance with the procedures of Briggs (1955). Locality data in text.

creoce le

Standard length

Total length

Length to dorsal termination, ray

Length to dorsal termination, membran

Length to anal origin

Length to anal termination, ray

Length to anal termination, membrane

Length to pectoral origin

ength of pectoral

Length to ventral origin, ray

Length to front of disc

Length to junction of two element

$$
\text { of disc }
$$

Length to end of disc

Length to vent, middle

Head

Snout, between para1lels

Interorbital, soft

Depth at front of eyes

Depth at back of eyes

Depth at opercular border

Depth at vent

Depth of caudal peduncle

Maximum depth of head

Maximum depth of body

Width at front of eyes

Width at back of eyes

Width at opercular border

Width at vent

Width of posterior element of disc

Maximum width of head

Moximum width of

Dorsal-caudal

Postdorsa1-cauda1

Length of caudal peduncle

Chin-dis

nnout

Interorbital

$$
\text { cardinalis }
$$

Range

$\bar{x}$

$25.0-50.3$

$1188-1249$

$1188-1249$
$720-784$

Cochreoceps

spatula

Range

$\bar{x}$

$39.3 \pm 2.41 \quad 15.5-19.5$

$15.5-19.5$
$1160-1233$

$890-958$

$932-944$
$777-852$

$890-939$

917-987

$286-356$

$201-240$
$194-282$

173-234

$1220.8 \pm 6.53$

$917.1 \pm 5.51$

$961.0+5.88$

$818.4 \pm 6.21$

$922.2 \pm 4.15$

$952.5 \pm 5.84$

$313.2 \pm 6.61$

$214.8 \pm 10.6$

$205.9 \pm 5.28$

$377.9 \pm 3.10$

367-393

504.576

616-690

373-440

84-133

$59-76$

120-144

100-136

124-184

120-274

123-203

$76-110$

$76-110$
$140-228$

$167-254$
$197-253$

197-253

295-415

291-395

99-163

$237-306$

$325-404$

$246-304$

217-294

102-152

$79-116$

167-224

120-149

92-119
$533.0 \pm 5.46$

$650.2 \pm 5.59$

$420.6 \pm 7.01$

$106.8 \pm 3.85$

$65.8 \pm 1.82$
$130.8 \pm 2.36$

$118.6 \pm 3.00$

$155.6 \pm 5.88$

$196.9 \pm 12.3$

$102.2 \pm 2.96$

$207.2 \pm 8.71$

$327.2 \pm 10.1$

$320.5 \pm 9.80$

$142.6 \pm 8.16$

$261.8 \pm 7.86$

$357.6 \pm 4.44$

$273.3 \pm 6.65$

$120.5 \pm 4.91$

$99.2 \pm 3.44$

$197.4 \pm 5.46$

$135.9 \pm 2.63$

$105.9 \pm 2.62$
$810-851$

862-928

$17.3 \pm 0.542$ $1197.0 \pm 9.12$ $829.1 \pm 4.45$ $898.7 \pm 7.77$

815-856

$894-923$

260-317

173-212

250-306

216-2 72

323-367

$450-494$

$635-733$

$308-361$

$81-116$

56-91

67-90

83-105

$108-142$

$132-167$
$117-151$

$117-151$

$56-72$
$105-156$

$105-156$
$116-174$

$132-19$

$132-191$
$189-259$

$189-259$

(1)

$106-146$

$162-187$

$247-278$

$154-190$

$80-123$

65-110

206-269

106-126

$51-66$
$835.4 \pm 4.48$
$906.4 \pm 4.27$

$292.4 \div 7.20$

$188.1 \pm 4.24$

$273.1 \pm 6.82$

$241.0 \pm 7.31$

$349.3 \pm 4.95$

$474.7 \pm 5.66$

$667.9 \pm 10.9$

$332.9 \pm 5.78$

$750.0 \pm 4.97$
$75.1 \pm 4.22$

$80.1 \pm 3.38$

$93.4 \pm 2.57$

$118.7 \pm 4.58$

$155.1 \pm 4.73$

$133.1 \pm 4.90$

$63.1 \pm 2.24$

$126.3 \pm 6.11$

$142.7 \pm 8.04$

$162.1 \pm 7.52$

$21.1 \pm 9.81$

$256.0 \pm 3.06$

$175.0 \pm 3.74$

$260.6 \pm 3.74$

$265.3 \pm 4.04$

$175.3+4.02$

$102.6 \pm 5.69$

$95.6 \pm 5.82$

$237.1 \pm 7.91$

$113.0 \pm 2.92$
$58.4 \pm 2.16$
Aspasmogaster

tasmoniensis

Range

$\bar{x}$

$35.2-65.6 \quad 53.6 \pm 7.62$

$1152-1173 \quad 1164.0 \pm 5.12$

716-775 $\quad 747.7 \pm 14.0$

$935-943 \quad 939.7 \pm 1.94$

$988-997 \quad 992.3 \pm 2.16$

$739-764 \quad 754.3 \pm 6.33$

$957-986 \quad 973.7 \pm 7.06$

$322-366 \quad 340.3 \pm 10.8$

$180-217 \quad 200.7 \pm 8.90$

$281-307-200.7 \pm 8.90$

214-278 $244.7 \pm 12.9$

$342-391 \quad 360.0 \pm 7.10$

$511-540 \quad 525.7 \pm 6.84$

633-676 $\quad 659.7 \pm 11.0$

$381-406 \quad 392.0 \pm 9.54$

106-114 $\quad 109.7 \pm 1.91$

$75-85 \quad 81.3 \pm 2.69$

$53-114 \quad 102.0 \pm 5.10$

76-85 $\quad 82.0 \pm 2.45$

$117-120 \quad 118.7 \pm 0.723$

$139-159 \quad 149.3 \pm 4.74$

$\begin{array}{rr}149.0 \pm 0.745 \\ 92-96 & 94.0 \pm 0.943\end{array}$

$\begin{array}{rr}94.0 & \pm 0.943 \\ 131-165 & 148.7 \pm 8.03\end{array}$

$160-170-166.3+2.60$

$215.0+4.67$

$225.7 \pm 17.3$

$106-129-120.0 \pm 5.79$

$256.3 \pm 5.76$

$199-250-225.7 \pm 17.3$

$250-284-267.0 \pm 8.01$

$267.0 \pm 8.01$

$83-91 \quad 87.3 \pm 1.91$

205-277 $233.7 \pm 6.80$

$\begin{array}{rr}57-67 & 62.0 \pm 2.36\end{array}$ 
Materia1

Three examples: (a) Ls 35.2, Lt 41.3, (b) 59.9, 69.9, (c) 65.8, 75.8 al1 collected at Greens Beach, northern Tasmania, by Mr R.H. Green, Queen Victoria Museum; $(a) 11$ January 1962, Q.V.M. Reg.No.1962/5/3, (b), (c) 10 January 1964, Q.V.M. Reg. No.1972/5/190.

\section{Meristic data}

Entries in parentheses are ranges reported for the species. D.8,9,9, (8-10); A. 7, 8, 8, (7-9 Briggs; 6 Ramsay); P. (left/right) 25/25, 24/24, 25/25 (24-27 Briggs; 22 Ramsay; 18-19 Scott); V.4 (Scott i, 4); C.11,11,11 (11-12 Briggs; 13-14 Scott, possibly including some minor rays).

\section{Dimensions}

Table 4 sets out standard lengths and the same set of dimensions expressed as TLs for this species as are there recorded for Creocele cardinalis and Cochleoceps spatula.

\section{Proportions}

Values for our material for the nine standard ratios of specific diagnoses in Briggs' monograph, followed, after a colon, by that author's figures, arithmetic mean, range in parentheses for his 9 examples. Postdorsal-caudal distance in dorsal length 2.03, 2.02, 2.02: $1.7(1.5-1.8)$. Depth in Ls 5.86, 5.93, 6.27: 6.0 (5.7-6.5). Depth of caudal peduncle in its (Briggsian) length $0.85,0.96,1.13: 1.2(1.2-1.3)$; with length measured between parallels, from base of last ray $0.70,0.76,0.72$, from end of anal membrane $0.09,0.24,0.14$. Length of head in Ls $2.46,2.57,2.62 ; 2.7$ (2.6-2.8). Width of head in Ls 3.76,3.74, 4.11:3.9 (3.8-4.1). Snout (Briggsian) in head $3.11,3.28,3.18: 3.6(3.5-3.8)$; with length measured between parallels 3.58 , $3.58,3.60$. Eye in bony interorbital $0.67,0.80,0.84 ; 0.7(0.6-0.7)$; in soft interorbital 1.33, 1.18, 1.24. Eye in head 4.77,4.66,5.12: 4.0 (3.2-4.4). Length of disc in head $3.45,3.20,3.72: 3.5(3.4-3.7)$.

Some additional proportions of these three examples having diagnostic significance are here given, followed, where appropriate, by the range for the three 1936 Tasmanian specimens ( Ls 30.8,46,46): a single value or a range from a conflation of values from the date of Ogilby (Diplocrepis costatus), Whitley (Volgiolus interorbitalis), Scott (Volgiolus patelza) is added in parentheses where the information is available.

Head in $L t 2.89,3.00,3.02,2.9-3.1(2.9-3.6)$. Width of head in $L t 4.54,4.37$, $4.74,4.14(4.8)$. Depth of body in $L t 6.88,6.92,7.22,6.2-6.8(6.4)$. Depth at vent in $L t 7.64,7.77,7.73$ (8). Depth of caudal pedunc1e in head $4.33,4.24,3.98$ (3.82). Length to vent in $L t 1.75,1.72,1.74(1.82)$. Length of disc in $L t 4.49$, $3.74,4.23$ (5.0). Width of disc in $L t 6.88,5.78,5.38$ (5.8). Dorsal base in head, base without terminal membrane $2.04,2.33,2.09$, with membrane $1.44,1.71,1.56,(1.5-$ 1.6). Anal base in dorsal base, bases without membranes $1.04,0.97,1.09$, with membranes $1.32,1.04,1.06(1.2)$. Pectoral in head, whole fin 1.88, 2.16, 1.86, measured from base of median rays $3.04,2.91,2.82,(2.6-2.9)$. Caudal in Lt 6.77, 5.99, $6.58,5.9-7.6(c a 6-6.4)$.

Total and standard lengths

Reported lengths include: Ls, type of A. costatus 46.7 (20.5 1ines), types of A. interorbitalis 20,21 , six Tasmanian examples, 22.5, 30.8, 46, 46, 59.9, 65.8 (the last exceeding the maximum known size as recorded by Briggs, 62.0): Lt, A. patezza 56, 57, 64 (type), 72, six Tasmanian examples 25.7, 36, 53, 53, 69.9, 75.8 .

Coloration

Accounts of coloration show some variation. In life 'uniform pink, appearing almost transparent when removed from the water' (Ogilby); a similar description was given by Waite (1923, p.207). Part III (1936, p.121) recorded the collector's note 'Dark green with brown markings when found; but when placed in a white net turned 
light green', and added that, examined shortly after fixation in formalin, the two specimens each bore some fourteen dark bars. In alcohol, the colour of $A$. interombitalis was 'yellowish brown in the holotype, blotched with carmine in the paratype; sides with a few spaced minute brown speckles. Eyes blue'; while the holotype of A. patella was 'yellow ochre, with twenty-one reddish-brown bars completely encircling the body'. In a first record of Diplocropis costatus from New Caledonia Whitley (1927, p. 304) noted the colour in spirits as dull yellow, ' a dusky ill-defined cross bar across the nape, another over the pectoral, a third between the tips of the pectorals and the origin of the dorsal, and traces of another between dorsal and anal. Top of head dusky, interorbital lighter. Vertical fins with minute punctulatjons, with lighter spaces distally.'

The following notes were made on a small individual, Ls 22.5 , Lt 25.7 , shortly after its collection by Mr R.H. Green, Queen Victoria Museum, at Greens Beach, northern Tasmania, 16 April 1975 .

Dorsal surface uniform fairly deep green, vermiculated with (apparently not superficial) white; indications of red bars as follows, front of eye, back of eye, just before end of head, slightly in advance of disc, about at vent, across dorsal, and (faint, slender) at hypural; some obscure smaller red spots on dorsum of snout. Lateral surface concolorous with dorsal; the mesial two-thirds or so with a red flush extending from head about to below middle of dorsal, where it tends to develop some wavy lines that extend back on to peduncle; whitish vermiculations traceable only on head; a pale reddish patch on dorsal base; red markings on head comprising one subtriangular: area extending from lower two-thirds of orbit forward, somewhat downward, for half length of snout, its apex reaching ventral profile, and a similar-sized, but more intense, triang1e extending backward, somewhat downward, from orbit; below it three red dots, the upper two contiguous with it; running from eye almost to ventral profile three equally spaced markings, the front and back ones forwardly concave, the middle one straight, vertical, obscurely double. Ventral surface lighter green; on under surface of snout half a dozen reddish spots, followed on each side, at level of eyes, by three short, equally spaced forwardly concave arcs, those on right continuous lines, those on left series of dots, the two sets together occupying about two-thirds width of head here; posterior half of disc with two prominent dark green spots side by side near the middle, and with hind border darker than rest; one red spot just behind anal base and another midway between this and hypural.

Dorsal and anal virtually colourless, in parts slightly greenish basally. Pectoral colourless. Caudal in general green, about concolorous with peduncle; marked with three complete arcs of about 8 (basal), 6, 6 red spots, and one less perfect arc.

\section{Ridging}

Ogilby based his second binomen on the presence in his type of 'about 10 strongly marked vertical ridges on each side, caused by the contraction of the muscles after death, but not present in the living fish', noting that this peculiarity is shared by the New Zealand Diplocrepis puniceus (Richardson, 1846). These ridges (which presumably demarcate myomeres) are conspicuous features in the Greens Beach specimens, anteriorly, where best developed, taking the form of complete or nearly complete, about equally spaced parallel rings, their height in some instances almost equal to the space between their bases. Ogilby noted 'about 10': we find.10-11 between back of head and vent, 4 to dorsal origin, about 12 between this and hypural, much less evident in this last region, here appearing chiefly as short vertically running swellings closely spaced along the fin bases. 
Genus COCHLEOCEPS Whitley, 1934

Cochleoceps Whitley, 1943, Proe. Limn. Soc. N.S.W., 62 (4), p.141. Orthotype, Cochleoceps spatula (Günther, 1861)

\section{Cochleoceps spatula (Günther, 1861)}

Crepidogaster spatula Günther, 1862, Cat. Fish. Brit. Mus., 3, p.508. Type locality: Swan River, Western Australia.

Aspasmogaster spatula Waite, 1921, Rec.S. Aust. Mus., 2 (1), p.179, fig. 296.

Cochleoceps spatula. Whitley, 1943, Proe. Linn. Soc. N.S.W., 63 (4), p.141.

Tasmanian occurrence

Cochleoceps spatula is not included in any published Tasmanian list, and its occurrence in this state was not known to the writer when assembling some notes on the local species (1936). The first record for Tasmania, was provided by Whitley (1954, p.29), who noted one example from Wineglass Bay and one from Oyster Bay, both on the East Coast. Briggs' material included an Australian Museum specimen from wineglass Bay (his paper citing a registration number differing from that given by whitley).

The Queen Victoria Museum collection contains 9 examp1es, a11 sma1l, collected, on five occasions, at Greens Beach, northern Tasmania by Mr R.H. Green. The material, with samples listed chronologically, but with individuals lettered in sequence of increasing Ls, comprises: (d) Ls 16.0, Lt 19.5 (h) $18.9,22.9$, 11 November 1963, Q.V.M. Reg. No. $1972 / 5 / 195$; (b) $14.5,17.5,5$ Apri1 1965, Q.V.M. Reg. No. 1972/5/374; (a) $12.9,16.1,11$ September 1965, Reg. No. 1972/5/194; (c) $15.5,18.3$, (e) 16.2, 18.8, (f) $16.7,20.6$, (i) $19.5,22.9,19$ December 1965, Reg. No. $1972 / 5 / 422$; (g) $18.0,21.6$, 14 November 1966 , Reg. No. 1972/5/360.

Dimensions

Tab1e 4 sets out standard lengths and other dimensions.

\section{Proportions}

Values have been found for the same set of proportions as that recorded above for Creocele cardinalis and these are here presented in the same style. Greatest depth in $L s 7.16 \pm 0.40,5.8-8.6,14.7 \pm 4.0: 5.4,4.9-6.0$. Depth of caudal peduncle in $i t s$ (Briggsian) length $(1.58 \pm 0.10,1.1-2.0,17.4 \pm 4.8: 1.5,1.3-1.7$. Length of head in Ls $3.01 \pm 0.54,2.8-2.3,4.7 \pm 1.3: 2.4,2.3-2.6$. Width of head in $L s 3.90$ $\pm 0.038,3.7-4.1,2.6 \pm 0.7: 3.3,2.8-3.8$. Snout (Briggsian) in head 2.95 \pm 0.055 , $2.8-3.2,5.0 \pm 1.3: 3.1,2.9-3.9$. Eye in bony (Briggsian) interorbita1 $0.79 \pm 0.031$, $0.7-1.0,10.4 \pm 2.8: 1.0,0.7-1.2$. Eye in head $4.57 \pm 0.27,3.9-6.1,15.4 \pm 4.1: 4.4$, 3.8-5.0. Post-oral-caudal distance in dorsal 1ength $0.44 \pm 0.33,0.3-0.6,25.1 \pm 6.7$ : $0.6,0.6-0.7$. Disc length in Ls $4.23 \pm 0.98,3.6-4.5,6.1 \pm 1.6: 3.3,3.2-3.6$. Some of the difference between the two sets of results is perhaps attributable to probable difference of size of fish in the samples.

Two ratios with measurements between parallels are noted for comparison with comparab1e data from other sources. Depth of caudal pedunc1e in its length $1.51 \pm 0.11$, $1.19-1.9,19.2 \pm 5.1$; snout in head $3.35 \pm 0.13,3.0-4.1,10.5 \pm 2.8$. Eye in soft interorbital is $1.10 \pm 0.070,0.9-1.5,16.8 \pm 4.6$.

\section{Coloration}

The entry under this heading in Briggs' monograph reads: 'No coloration remained in the alcohol specimens available for examination'. Waite $(1923, p .206)$ reported the colour to be yellow with the upper half ornamented with crowded carmine spots.

The following account is based on two examples, Ls 18.2, 19.0, Lt 21.0, 23.6, collected by Mr R.H. Green, Queen Victoria Museum, at Greens Beach, northern Tasmania, 
16 April 1975.

Ground colour of whole of lateral and dorsal surfaces a1most uniform lettuce green (paler than in the two examples already noted, of Aspasmogaster tasmaniensis, taken at the same time). Virtually whole dorsum of head with very small rounded red spots (approaching carmine), abundantly and closely set everywhere, except on part of the posterolateral regions where they are noticeably fewer. Spots continued from back of head along mesial half, or a little more, of whole length of body: in one specimen distinct aggregations of some 6-12 spots (in anterior three sets larger than other spots), tending to form gross red areas as follows, a postorbital pair, distance between them subequal to their distance from eye; one, median, on occiput, behind eyes by length of snout; one, median, just in advance of level of hind border of disc, its distance behind last mentioned subequal to distance of latter behind eyes; two, median, about equally spaced, hinder about at level of vent; one, median, small, somewhat indistinct, on caudal peduncle: in other specimen postorbital marking single, not paired; other spot-groups somewhat less developed. Reddish brown streak running forward to tip of snout, back to end of head, continuing for distance about equal to length of snout on trunk: these lines on head just visible from above, outlining it in brown. Lateral surface of body unmarked save for anterior brown streak just mentioned, and a few small reddish spots on tail. Ventral surface very pale green, approaching white on disc and on throat; immaculate. All fins pale greenish; in one individual some indication of probable former occurrence of a few small reddish or reddish brown spots.

Brain

The dorsal aspect of the brain is more or less clearly traceable in all our specimens. It differs from that of Creocele cardinatis, described above, as follows: total width, relative to interorbital, noticeably greater, equal to at least fourfifths of interval between supraorbital ridges; whole brain set further forward, re1ative to orbit, anterior border of cerebral hemispheres being in advance of middle of orbit, and level of posterior orbital rim crossing optic lobe in anterior one-third of 1atter.

\section{Comparison of species measurements}

Comparisons have been made of the means in the above samples of the three Tasmanian species of the nine ratios reported in species diagnoses in the monograph by Briggs. The results are set out in the first nine lines of table 5 .

A further comparison, by pairs of species, involving the means of TLS lengths to certain important morphological landmarks along the general anteroposterior axis provides some additional useful criteria for the separation of the local clingfishes. The data are given in the last eight 1 ines of table 5 .

It will be noted that, in the great majority $(80 \%)$ of the entries in table 5 , probability either, on the one hand, lies well below the level of formal statistical significance $(P 0.05)$ or, on the other hand, reached $P 0.001$, or better. It would be of interest to ascertain whether this combination of virtual identity and marked disparity of mean TLs value for these dimensions characterizes only the present small group of species, or whether differences between species, where they occur, are generally trenchant. The lower measures of significance exhibited by length to front of disc as compared with length to back of disc are accounted for by greater variability of the latter dimension in all species, the relevant coefficients of variation being $8.2,3.2$ (Creocele cardinalis), 10.7, 3.2 (Cochleoceps spatula), 8.1, 2.3 (Aspasmogaster tasmaniensis).

In view of the taxonomic value of the three-term system, relative locations of hind end of disc, vent, anal origin, considerable importance is attached to the virtually constant mean permillage length to vent found in these species - with the middle value, that for Aspasmogaster tasmaniensis (66) taken as a norm, the greatest value 
Creocele carainalis (Ramsay, 1882, 10 specimens, Cochleoceps spatula (Günther, 1861), 7 specimens, and Aspasmogaster tasmaniensis (Günther, 1861), 3 specimens. Value of $t$, with probability levels of $0.05,0.01,0.001$ denoted by one, two, three asterisks, respectively, for difference of means, by pairs of species, first, of the ratios reported in species diagnoses by Briggs (1955) (first 9 lines), secondly, of lengths, as permillages of standard length to certain points along anteroposterior axis of fish (last 8 ines).

\author{
Ratio \\ or \\ Length (TLS) to specified point
}

Depth in standard length

Depth of caudal peduncle in its length

Length of head in standard length

Width of head in standard length

Snout in head

Eye in (bony) interorbital

Eye in head

Postdorsa1-caudal in dorsal base

Length of disc in standard length

End of head

Front of disc

Back of disc

Vent (middle)

Origin of dorsal

Origin of anal

End of dorsal

End of anal
C. cardinazis
c. spatuza
c. cardinalis
A. tasmaniensis
C.C. spatula
A. tasmaniensis

\begin{tabular}{|c|c|c|c|c|c|}
\hline$* * *$ & 5.046 & * & 2.602 & - & 1.668 \\
\hline$* * *$ & 5.960 & - & 0.062 & $\dot{*}$ & 3.283 \\
\hline$* * *$ & 21.632 & - & 0.627 & $* * *$ & 17.160 \\
\hline$* * *$ & 11.034 & $\star * *$ & 9.843 & - & 0.266 \\
\hline- & 0.024 & $* *$ & 3.754 & * & 2.411 \\
\hline$* * *$ & 6.765 & $* * *$ & 4.479 & - & 0.421 \\
\hline$* * *$ & 4.897 & $* * *$ & 11.822 & - & 0.605 \\
\hline$\star \star \star$ & 10.045 & $\star \star \star *$ & 7.797 & $\star \star \star$ & 22.391 \\
\hline$* * *$ & 10.159 & * & 2.907 & $* *$ & 4.031 \\
\hline$\star \star \star$ & 6.974 & - & 0.759 & $\star \star *$ & 5.474 \\
\hline ** & 3.754 & * & 2.741 & - & 0.220 \\
\hline$* * *$ & 6.791 & - & 0.677 & $* * *$ & 4.625 \\
\hline - & 1.475 & - & 0.755 & - & 0.934 \\
\hline$* * *$ & 8.527 & - & 0.713 & $\star * *$ & 6.371 \\
\hline - & 1.916 & $* * *$ & 4.945 & $* * *$ & 7.032 \\
\hline - & 2.043 & - & 1.865 & $\star \star$ & 4.702 \\
\hline - & 1.815 & - & 0.985 & * & 3.175 \\
\hline
\end{tabular}


(Cochteoceps spatuza) is in excess of it by on1y $1.2 \%$, the least (Creocele cardinatis) is in deficit of it by only $1.4 \%$. For length to end of disc the highest value (Creocele cardinalis) and the lowest (Cochleoceps spatula) are 1.5\% above, $9.6 \%$ below the middle value (Aspasmogaster tasmaniensis, 525). For length to anal origin the highest value (Cochteoceps spatuza) and the lowest (Aspasmoguster tasmaniensis) are $2.1 \%$ above and $7.8 \%$ below the middle value (Creocele cardinalis, 818 ).

The apparent pattern, noted above, of a combination, for difference of means of species by pairs, of high with low degree of significance, with no or few jnternediate values, is met with also in some variates other than 'length to' permillage measurements. Three examples may be cited. With species pairs in the sequence of table 5 , $t$ values for width of posterior element of disc are $10.481^{* * *}, 4.758^{* *}, 1.987$; for soft interorbital $11.797^{* *}, 3.343^{* *}, 2.050$; for width at back of eyes $6.621^{\star * *}$, $5.564^{* * *}, 0.328$.

In seeking to interpret any of the above results it is to be borne in mind that the data relate only to the present samples and that these are small. Further, the size of our specimens differs considerably both within and between species (standard length in Creocele cardinalis $25.0-50.3, \bar{x} 39.27 \pm 2.41$, Cochleoceps spatiza 15.5-19.5, $\vec{x}$ $17.26 \pm 0.54$, Aspasmogaster tasmoniensis $35.2-65.8, \bar{x} 56.63 \pm 7.73$ ), and we are at present without useful knowledge of possible relative growth in any of the regions involved. On the other hand, the high $t$ values for some measurements and some proportions clearly reflect gross morphometric differences and are of immediate taxonomic relevance.

\section{Fanily GOBI IDAE}

Only three gobies are credited to Tasmania in the Australian Check-list (McCulloch, 1929): (i) Nesogobius hinsbyi (McCulloch \& Ogilby, 1919) (ex Johnston MS), (ii) Gobius tasmanicus Whitley, 1929 (ex Johnston MS), (iii) Gobius tamarensis Johnston, 1883; all have Tasmania as type locality. The lists of Lord (1923, 1927) and of Lord \& Scott (1924) included also (iv) Gobius Zateralis Macleay, 1881 (Lord \& Scott suggesting $(i i z)$ is probably identical with $(i v))$ : (iv) is referred in the name-list of Whitley (1964) to Favonigobius Whitley, 1930.

In a survey of the Tasmanian gobiid fauna, as then known, made in this journal four decades ago (Scott 1935) accounts were given of (i) and (iii), the latter being figured (pl. IV, fig. 1) for the first time; it was considered likely (ii) was a synonym of $(i i i)$, and the possibility of ( $i v)$ appearing in the local list in error was explored. A new genus, Tasmonogobius, was instituted and a new species, T. Zordi, was described and illustrated (text figs 1,2, p1. IV, fig. 2).

Additions to our list since 1935 comprise (vi) Arenigobius bifrenatus (Kner, 1869), first Tasmanian records by Olsen (1954), in stomach contents of juvenile Caleorhinus australis (Macleay 1881), and by Whitley (1954), with further local records by olsen (1958), Scott (1963); (vii) Stigmatogobius poieizosoma (Kner, 1865), [ so listed by Koumans (1953); variously recorded by Australian authors, e.g., by McCulloch \& Ogilby (1919) and by McCulloch (1929) as Magizogobius gazwayi McCulloch $\varepsilon_{\text {f Wate, }} 1918$, by Scott (1962) as Ellogobius olomm (Sauvage, 1880), by Whitley (1964) as Lizagobizs lomm (Sauvage, 1880), by Scott et al. (1974) as Iizagobius ga7wayi (McCulloch : Waite, 1918) J, tirst Tasmanian record in Part XI, from The Arm, George Bay, east coast; (viii) Callogobius mucosus (Günther, 1871) [appears in McCulloch \& Ogilby as Calzobius hassettii Bleeker 1851, with C. hassettii var. mucosus Ginther as the form in southern Australia; Whitley's name-list recognizes both Bleeker's species and Gunther's; Scott and Scott et az. treat the South Australian records as C. mocosus], first Tasmanian record in Part XIII, as $C$. hasseltii, based on thrce examples from Greens Beach, north coast, where it has since been taken in abundance. 
Keys to species on our 1 ist at the time were given in the review in 1935 and in Part XI (1963) - from species ( $i),(i, i)$, ( $\left.i i_{i}\right)$, covered by the later key, (viii) is separable at sight by its possession of prominent raised lines of papillae on head and body.

The Tasmanian gobiid fauna is richer than the present census would indicate -- on several occasions unrecorded, and possibly undescribed, species have come under the writer's notice.

\section{Genus ARENIGOBIUS Whitley, 1930}

Arenigobius Whitley, 1939, Aust. 20ol., 6 (2), p.122. Orthotype, Gobius bifrenatus Kner.

\section{Arenigobius bifronatus (Kner, 1865)}

Gobius bifrenatus Kner, 1865, Reise Novara Zool. Fische, p.177, pl. 7, fig. 3. Type locality: Sydney, New South Wales.

[Gobius] bifrenatus McCulloch \& Ogilby, 1919, Rec. Aust. Mus., 12 (10), p.242. Arenigobius bifrenatus 01sen, 1954, Aust. J.mar. Freshw. Res., 5 (3), p.359. Id. Whitley, 1954, Proc. R. Zool. Soc. N.S.W. (1952-3), p.29. Id. Scott, 1953; Pap. Proc. R. Soc. Tasm., 97, p.24.

Status of genus

For remarks on the genus Arenigobius see below, under Arenigobius tamarensis.

Material

Three series were taken in the course of an ecological survey of the Tamar River, northern Tasmania, by the Queen Victoria Museum in March and April 1975. Sample (A) 70 specimens from one pool on a mud flat, Middle Arm, approximately $12 \mathrm{~km}$ from the river mouth, 5 March, Q.V.M. Reg. No. 1975/5/39: (B) 49 specimens from York Town Rivulet, discharging into the Tamar some $14 \mathrm{~km}$ from its mouth, 4 April, Q.V.M. Reg. No. 1975/5/54: (C) 106 specimens from Anderson's Creek, entering the Tamar about $13 \mathrm{~km}$ from its mouth, 23 April, Q.V.M. Reg. No. 1975/5/64.

A morphometric analysis of sample A, and some observations on the coloration of fresh examples are made below.

\section{Length distribution}

Inspection of the distribution of standard length of the 70 individuals of the total sample $(A)$ suggests the existence of two sub-populations, one $(\alpha)$ of 63 larger individuals, the other $(b)$ of 7 smaller individuals. That the two subsamples are genuinely distinct appears probable: they are separated by 8 empty 1-mm cel1s (only 3 empty cells at lower end of distribution of larger subsample); the upper extreme value of $(b)$ ies beyond $\bar{x} \pm 3 s$ for $(a)$; a test of the significance of the difference of the means yields $t=9.303 * * *$ (for $L t t=7.611^{* * *}$ ).

For $(A),(a),(b)$ the Ls ranges, mn, are $27.2-83.0,45.7-83.0,27.2-36.1$. Means are $58.7 \pm 1.40,61.6 \pm 1.02,32.5 \pm 0.959$; medians $59.4,59.9,33.3$; standard deviations $11.7 \pm 0.987,8.12 \pm 0.724,2.54 \pm 0.678$; coefficients of variation $19.9 \pm 1.7$, $13.2 \pm 1.2,7.8 \pm 2.1$. The distribution is tolerably symmetrical in $(a)$ and $(b)$, naturally less so in $(A)$; the number of entries within $\bar{x} \pm s$ being, respectively, 43, 4, 55 (cf., for $\bar{x} \pm \sigma$, with $N=\infty, 43,5,48$ ) : skewness, measured by $S k=3$ (meanmedian)/s, $+0.350,=0.980,-0.170$.

The Ls frequency distribution of the whole sample in 19 classes, 26.5-29.4..80.583.4 , with values for $(b)$ in parentheses, is $(1),(2),(3),(1), 0,0,1,1,8,8,10$, $10,6,7,4,2,4,1,1$. 
Arenigobius bifrenatus Kner, 1865. Specification of head, trunk, tail (to hypura1), caudal fin, as permillages of standard length, in a Tasmanian population $(A)$ of 70 individuals, $L s 27.2-83.0, \ddot{x} 58.7 \pm 1.40$, treated also as two subpopulations, (a) of 63 individuals, Ls 45.7-83.0, $\bar{x} 61.6 \pm 1.02,(b)$ of 7 individuals, Ls $27.2-36.1, \vec{x}$ $32.5 \pm 0.96$. In last 1ine, 'expected' $=$ frequency in normal distribution $(N=\infty)$.

\section{Statistic}

$N$

Range

$\bar{x}$

Md

Mo $; h=1(f)$

$s$

V

Sk

Within $\bar{x} \pm s$

('expected')
Head

(a)

Trunk

(a) (b)

70
$223-311$
$269.7 \pm 1.63$
267
$275(5)$
$13.64 \pm 1.15$
$5.1 \pm 0.4$
+0.625

$42(48)$

$$
63
$$

223-309

$267.1 \pm 1.23$

265

$275(5)$

$9.78 \pm 0.871$

$3.7 \pm 0.3$

$+0.646$

$36(43)$

Tai1 (to hypura1)

(A)

70

411-540

$477.4 \pm 3.10$

475

483(5)

$25.95 \pm 2.19$

$5.4 \pm 0.5$

$+0.279$

$52(48)$ (a)

63

411-533

$476.4 \pm 3.06$

475

$483(5)$

$24.30 \pm 2.16$

$5.1 \pm 0.5$

$+0.177$

$40(43)$

$40(4)$

(b)

243-311

$292.6 \pm 8.13$ 298

$21.51 \pm 5.75$

$7.4 \pm 2.0$

$-0.757$

$6(5)$
(A)

70

155-352

$252.7 \pm 3.61$

255.5

259 (4)

$30.20 \pm 2.55$

$11.9 \pm 1.2$

$-0.274$

$56(48)$

(b)

434-540

$486.4 \pm 14.10$

493

$34.41 \pm 9.74$

$34.41 \pm 9.74$
$7.5 \pm 2.0$

$-0.541$

$4(5)$

$232-590$

333.5

$70.75 \pm 18.91$

$20.4 \pm 5.7$

$+0.177$

$49(48)$
63

$174-352$

$256.3 \pm 3.52$

259

$259(4)$

$27.94 \pm 2.55$

$10.9 \pm 1.0$

$-0.297$

$48(43)$

Cauda1 fin

(a)

(b)

$346.0 \pm 26.43$

$285,302,339(2)$

241-590

$351.1 \pm 23.10$

338

285,339 (2)

$61.11 \pm 16.33$

$17.4 \pm 4.8$

$+0.219$

$42(43)$

$5(5)$
155-259

$221.1 \pm 11.76$ 210

$31.34 \pm 8.38$

$14.2 \pm z .9$

$+1.067$

5(5)
232-360

$300.6 \pm 13.55$

308

$35.94 \pm 9.58$

$11.9 \pm 3.2$

$-0.207$

('expected') 


\section{E.O.G. Scott}

growth cannot be determined from available data, though it may well do so: a general inspection of the two April series finds they show a marked tendency to fall into three size classes of Ls round about $25-35,50-60,70-75 \mathrm{~mm}$.

Comparison of $(A)$ with $(B)$ and $(C)$

In $(A)$, the sample examined above, the proportion of $f$ ish of 1 arge or moderate size is higher than in either $(B)$ or $(C)$, the precentages of specimens in the 50.5-53.4 class and higher classes of $L s 87,26,10$, respectively, the means $58.7,37.5,34.6$, the medians 59.4, 43.0, 31.5: the highest entry in $(A)$ extends 7,4 size-classes $(h=3 \mathrm{~mm})$ beyond the highest in $B, C$, respectively.

The Ls frequency distribution of the York Town Rivulet sample in 16 classes, $14.5-17.4 \ldots 59.5-62.4$, is $1,0,4,5,7,5,0,0,2,7,2,2,6,2,2,2$; that of the Anderson Creek sample in 18 classes, $17.5-20.4 \ldots 68.5-71.4$, is $2,6,11,18,21$, $13,5,4,4,8,3,4,2,2,0,2,0,1$. They show indications of being trimodal, with modes at 26.5-29.4 (7 entries), 41.5-44.4 (7), 50.5-54.4 (6) and at 29.5-32.4 (21), 44.5-47.4 (8), 50.5-53.4 (4). The 7 individua1s of subsample $(b)$ of $(A)$ with mean 32.5 might thus wel1 be coeval with individua1s in the $26.5-29.4$ and $29.5-32.41$ owest modal classes of $(B)$ and $(C)$.

The Ls specifications of $(B)$ are range $17.0-62.0, \bar{x} 37.5 \pm 2.15, s 14.8-1.53, V$ $39.5 \pm 4.7 S k-1.17$, entries within $\bar{x}-s 36$ (expected 32 ); of $C$ range $18.5-70.5, \bar{x}$ $34.6 \pm 1.02, s 10.5-0.722, V 30.4-2.3, S k+0.889$, entries with $\vec{x} \pm s 74$ (expected 73 ).

\section{Relative growth}

Lengths of head, trunk, tail (to hypural joint), caudal fin, as permillages of standard length, have been calculated for a11 specimens; the specifications of these dimensions in each of the three groups $(A),(a),(b)$ are exhibited in table

As inspection of the table shows, the mean TLS value for head in $(b)$ is greater than that in $(\alpha)$, i.e., relative length of head decreases with increasing size of fish: the difference between the means is highly significant, $t=5.477 * * *$. For the whole sample $(A)$ the correlation of TLs head with Ls is $r=-0.357(z=0.373), t=3.140^{\star \star *}$. In the case of the trunk the mean. Ths value of $(b)$ is less than that of $(a), i . e$., relative length of trunk increases as fish grows: for difference of means $t=3.069 * *$. The correlation for $(A)$ is $r=+0.218(z=0.222)$, $t$ not being formally significant (1.848) - it should be noted the range is very wide (155-352, the second of these values being outside $\bar{x} \pm 3 s$; the next extreme entries are 174, 322). With three body regions recognized, head, trunk, tail (to hypural) - caudal fin considered separately, below - any significant variation with growth in relative proportion among these appears to be confined to head and trunk, the relative decrease in length of the former being more or less completely balanced by the relative increase in the 1 ength of the latter; the tail, with its Ths versus ts $r=-0.0886(z=0.0888)$, $t=0.734$, representing a virtually constant fraction of the length.

As an appendage, the caudal fin calls for separate consideration. From the data of table 6 it will be seen its relative length in the subsample of larger individuals $(a)$ is about one-sixth as great again as in the subsample of smaller individuals $(b)$ : the difference of the means is significant at $t=2.115^{*}$; while the correlation of TLs length of fin and length of fish $(L S)$ in the whole sample $(A)$ is $r=+0.488$ $(z=0.533), t=4.609^{* * *}$. As figured - Kner's original illustration reproduced in Scott et al. (1974, p. 269) - this species has the caudal long and pointed, a feature regularly noted in local descriptions - e.g., Castelnau (1873, p.47) (as synonymic G. caudatus), Macleay (1881, p.597), McCulloch \& Ogilby (1919, p.242), Scott et al. In our sample the median backward extension of the fin (which may finally become filamentous) tends very generally to become more pronounced with age, a striking indication of this being the fact that a length of 400 or more Tls units is encountered in on 1 y 2 individuals in the lower half of the series (specimens in order of increasing Ls), but 
characterizes $12 \mathrm{fish}$ in the upper half. Since with ageing the relative size of caudal increases while that of head decreases, specification of one in terms of the other ( $c f$. Macleay) is without diagnostic value unless supplemented by information on overall size of fish. In passing from $(b)$ to $(a)$ here, mean length of head suffers a decrease of $8.7 \%$, while mean size of caudal shows an increase of $14.4 \%$; in other terms, at the smaller size the caudal is barely longer than ( 1.03 times) the head, while at the larger size it is decidedly longer (1.34 times) - much greater differences of course being encountered in individuals.

Life colours

A good account of the coloration of a fresh New South wales specimen $142 \mathrm{~mm}$ long has been given by McCulloch \& Ogilby $(1919,243)$. The species is an ornate one. Detailed notes, made within an hour of capture, on several of our examples, of which a summary is given below, reveal a number of interesting differences in these Tasmanian fish, and also specify some markings not mentioned by McCulloch and Ogilby.

General colour of trunk and tail olivaceous, darker above; ventral surface in advance of vent buff, iridescent in lateral strip, behind vent olivaceous barely lighter than flank. Short bars and/or blotches (6-10, modally 8) just above ventral profile deep grey-black. Between and across main bars numerous slender downwardly and slightly backwardly oblique red-brown bars or pencil-like strokes; one series of a dozen or more swinging down from angle of operculum and running along flank to end at hypural about three times as far from dorsal profile as from ventral; a second series of up to a score originating shortly above first, running back higher up on flank to end at hypural about three times as far from ventral profile as from dorsal (these markings not recorded by McCulloch \& Ogilby). Iridescent spots in two rows in front, becoming irregular in last one-third of length; each gross 'spot' being a group of two or three fairly closely approximated subcircular components; in one specimen spots pale green (darkening caudad), some behind these pale blue or blue-violet; in a second specimen some green, some blue (darker than in first specinen); in a third specimen violet.

General colour of head olivaceous. Three red-brown stripes running back from eye; one, widest, from about 7 o'clock (left side viewed), curving down on to pectoral base; one, from about 9 o'clock, sloping down on to flank, obscurely making contact there with line of lateral bars; one, from about 11 o'clock, swinging up on to dorsal surface, where right and left fellows approximate or coalesce, running back to origin of first dorsal; a short black stripe, from near $70^{\prime} \mathrm{clock}$, passing downwards and forwards towards lip. Lips dark olive; upper lip with dark superior border. Pupil black; iris mostly silvery white but with a large olive lunule covering upper onefourth.

Second dorsal fin with membrane yellow, brighter above well-defined red stripe across fin at about one-third of its height; rays in general more or less colourless, but with reddish or pinkish flush towards tip. First dorsal similar to second but with slightly stronger colour. Pectoral clear translucent yellow ochre, a trifle darker towards tip; region on base below end of red-brown stripe from eye wholly iridescent, its upper portion blue, lower whitish. Pelvic mainly greenish with some bluish iridescence; a wide median stripe of light yellowish olive; a prominent dark grey-black proconcave arc across whole of distal border; in some examples almost wholly dusky. Anal mernbrane in one specimen reddish brown basally, then becoming yellowish, finally darkening distally; in another specimen almost wholly yellowish grey, with brief distal darkening; rays of both reddish brown. Caudal rays hyaline, membrane dusky olive; a conspicuous clear yellow arc along most of upper border; crossed by six proconcave arcs; in one example arcs, in succession from base, pink-red, olive, pink-red darker than first, olive similar to second, approaching violet, violet, in another purple, olive, dark purple, olive, extremely dark purple, olive, dark purple. 
Arenigobius tomarenis (Johnston, 1883). Specification of standard length, mm, of a sample of 402 topotypical specimens; also specification of standard length, mm, and, as permillages of standard length (TLs), of head, trunk, tail (to hypural), caudal fin of a subsample of 100 individuals. In bottom line 'expected' $=$ frequency in normal distribution.

Statistic

$\begin{array}{lll} & \begin{array}{l}\text { Standard } \\ \text { length }\end{array} & \begin{array}{c}\text { Standard } \\ \text { length }\end{array} \\ N & 402 & 110 \\ \text { Range } & 15.0-57.0 & 18.2-57.20 \\ \bar{x} & 31.66 \pm 0.337 & 35.43 \pm 0.596 \\ \text { Md } & 31.7 & 36.15 \\ \text { Mo }: h=3 \mathrm{~mm}(f) & 31(75) & 36(31)\end{array}$

Mo: $h=10$ TLs units $(f)$

$S k$

Within $\bar{x} \pm s$

('expected')

\section{Absolute dimensions, mm}

Head

110

$225-398$

$297.7 \pm 2.68$

297

-

290 (19)

$6.70 \pm 0.238$

$21.3 \pm 0.8$

$-0.160$

$6.25 \pm 0.421$

$17.6 \pm 1.2$

$-0.348$

$307(274)$
$67(75)$
Relative dimensions, TLS

$\begin{array}{ll}\text { Trunk } & \text { Tail } \\ & \text { (to hypural) }\end{array}$

110

$138-286$

110

424-578

$213.6 \pm 2.96$

$491.14 \pm 4.00$

206.5

$-$

$220(16)$

485

$-$

480 (18)

$42.0 \pm 2.83$

$8.5 \pm 0.6$

$+0.455$

$83(75)$
$14.5 \pm 1.0$

$+0.667$

$72(75)$
Caudal fin

110

$248.7 \pm 3.90$

250

$250 \quad(24)$

$30.4 \pm 2.05$

$12.2 \pm 0.8$

$-0.131$

$77(75)$ 


\section{Arenigobius tomarensis (Johnston, 1883)}

Gobius tomarensis Johnston, 1883, Pap. Proc. R. Soc. Tasm. (1882), p.120. Type locality: Tamar river, Tasmania ('enters the fresh water of the Tamar'). Gobius tamarensis Whitley, 1929, Pap. Proc. R. Soc. Tasm. (1928), p.61 (Johnston MS) . Gobius tasmonicus Whitley, 1929, Pap. Proc. R. Soc. Tasm. (1928), p.62 (ex Johnston MS). Type locality: Tamar, Launceston ('brackish water').

Arenigobius tomarensis Scott, 1935, Pap. Proc. R. Soc. Tasm. (1934), P.50, p1. 4, fig. 1. Id. Whitley, 1964, Proc. Linn. Soc. N.S.W., 89 (1), p.55.

\section{History of species}

Johnston's original account of his Gobius tamarensis is a somewhat brief one, ending with the statement it 'approaches very close to Gobius Lateralis (Macleay)': in his redaction of Johnston's memoranda Whitley (1929a) stated that his notes are 'practica11y the same as the text of the published description,' except for the addition of some measurements (quoted) of an example of total length $211 / 16$ inches (68 mm). A full account of the species, based on five examples 67.5-84.5 in total length, and accompanied by a figure was given by the writer forty years ago (1935, p.50, p1. iv, fig.1), this treatment suggesting Gobius tasmanious Whitley, 1929 (based on Johnston MS) is synonymic, a view later accepted by whitley in his definitive Australian speciẹs name-list (1964).

The species appears, as Gobius tamarensis, in Johnston (1891), Lord (1923, 1927), Lord $\xi$ Scott (1924), [who list it separately, but observe it is 'probably identical with' Gobius Zateralis (Macleay, 1881); date rendered 1880] McCulloch \& Ogilby (1919), McCulloch (1929), and, as Arenigobius tomarensis, in whitley (1964) - none of the references does more than list it, and, as far as can be ascertained, no addition to our knowledge of it has followed the appearance of the 1935 description and figure. Some data based on recent extensive collecting are here offered, preceded by a brief consideration of its generic status.

\section{Generic status}

Pointing out that McCulloch \& Ogilby in their important review of our gobiid fauna realised a necessity for dividing cumbersome larger genera such as Gobius Linné, 1758 , but themselves took no such action, whitley (1930) expressed the view that future work on the group would be rendered easier by the provision of some new generic names for Australian species. Accordingly he listed seven such names, noting for each only its genotype, but stating that generic characters can be derived from McCulloch \& Ogilby's key. Arenigobius, with genotype Gobius bifrenatus Kner, 1865, was thus proposed; this genus coming later, in the name-1ist of 1964, to include also $A$. tamarensis (Johnston, 1883), A. frenatus (Günther, 1861), A. castelnaui (Macleay, 1881). (It may be noted, in passing, Scott et al. (1974) continued to refer Kner's species to Gobius.) .

A formal diagnosis of Arenigobius has thus not been published. As potentially characterized in the key by McCulloch \& Ogilby, it would include the following features (cited in order of their appearance there): soft dorsal and anal 'shorter', free from caudal; body scaly; chin and mandible without barbels; first dorsal with 6 spines; head with only microscopic papillae in rows; opercles naked or nearly naked, cheeks naked; exposed edge of shoulder girdle smooth; upper pectoral rays not free nor diffrom the others; tongue not deeply notched; head 'longer', without spines or large papillae; scales 'larger', 36 or less in a longitudinal row; nape and greater portion of neck naked; gill-openings not extending forward below, fifth ventral ray as long as the fourth; breast and pectoral base scaly; caudal pointed, body 'longer'.

The last feature but one calls for comment. While McCulloch \& Ogilby's key 
requires that both breast and pectoral base be scaly, their account of (Gobius) bifrenatus correctly reports thorax scaly, pectoral base naked, features found also in the present species [scales 'cease, on the dorsal surface, at about the level of the hinder edge of the pectoral base mesially, and a little in advance of the posterior border laterally, and, on the lower surface, at about the level of the origin of the ventrals; pectoral base naked' (Scott 1935, p.51)] Thus in respect of the condition of the pectoral base Johnston's species is in agreement with that found in the genotype of Arenigobius; though not, as predicated in Whitley's paper, in conformity with the specification of the key.

All other characters of the key as listed above are applicable to our fish, which is accordingly here referred to Arenigobius, with the specification of that genus providing for a naked pectoral base.

Material

Collections made by Mr R.H. Green, Queen Victoria Museum and other members of the Museum staff in the Tamar during the course of an ecological survey of some sections of the river in March and April 1975 included long series of gobies (chiefly the present species; 215 examples of Arenigobius bifrenatus, the subject of some observations above; 10 specimens of an apparently undescribed species), together with 11 other species of fish (see next section).

Material of the present species taken at West Arm, approximately $10 \mathrm{~km}$ from the mouth of the estuary, on 3 March 1975, sample $\left(B_{1}\right)$, and on 5 March 1975, samples $\left(A_{1}\right)$, $\left(B_{2}\right),\left(C_{1}\right),(D)$ (Q.V.M. Reg. No. 1975/5/35) comprises samples from different zones, as follows. Sample $(A)$ above tide level, 819 individua1s, Ls 21.5-67.5, Lt 25.8-83.0: in one jar (of two), with 374 specimens, only 2 exceed $59 \mathrm{~mm}$ in Ls. Sample $(B)$, comprising $B_{1}$ from a single shallow pool on a mudf1at ( 3 March), 402 (this samp1e is discussed below), $\left(B_{2}\right)$ on tidal mudflats (5 March), 1034, Ls 15.1-58.2, Lt 19.0-72.9. Sample $(C)$ below high tide, 233, Ls 8.3-54.0, Lt 10.9-65.1. Sample (D) main stream, 952 , Ls 17.5-59.5, Lt 23.0-74.3

Two further samples were secured at other points on the river: (E), York Town Rivulet, approximately $14 \mathrm{~km}$ from the sea, 16 Apri1 1975 (Q.V.M. Reg. No. 1975/5/52), 86, frequency distribution (6 classes, $20-25 \ldots 45-50) 12,19,22,29,3,1:(F)$, Andersons Creek, approximately $13 \mathrm{~km}$ from the sea, 23 Apri1 1975 (Q.V.M. Reg. No. $1975 / 5 / 63), 236$, frequency distribution (9 c1asses, 10-15..50-55), 1, 21, 73, 58, 54, $19,6,2,2$.

\section{Associated species}

Sample $(F)$ includes 10 specimens of an apparently undescribed goby (represented in the Museum's collections by two other examples from the Tamar river, one from a mud poo1 at West Arm, and one from Muddy Creek, some $42 \mathrm{~km}$ from river mouth). Fish other than Gobiidae taken during the survey comprise: Galaxias maculatus (Jenyns, 1862, Gataxias truttaceus (Cuvier, 1816), Ammotretis rostratus Güther, 1842 an apparently new species of Rhombosolea Gunther, 1862, Aldrichetta forsteri (Cuvier, 1836), Taeniomembras tomarensis (Johnston, 1883), Gymapistes mamoratus (Cuvier, 1829), some notes on this species appear below), Girelza tricuspidata (Quoy G Gaimard, 1824), (juv.), Arripis georgianus (Valenciennes, 1831) (juv.) Arripis trutta esper Whitley,1951 (juv.), Sphaeroides hamiltoni (Richardson.1843).

\section{Frequency distributions}

For sample $\left(B_{1}\right)$ the frequency distributions of the standard lengths, in mm, of the whole sample ( $402 \mathrm{fish}$ ) and of a subsample (110) selected for more detailed investigation below, and, as TLS, of the four regional lengths head, trunk, tail, caudal fin in the subsamp1e, as specified in table 7 , are as follows.

Standard length, 402 specimens, 15 classes, 14.5-17.4..56.5-59.4: 3, 10, 29, 44, 
$66,75,61,73,19,9,6,2,4,0,1 ; 110$ specimens, 14 classes, 17.5-18.4..56.5$57.4: 4,6,7,9,10,14,31,10,6,6,2,4,0,1$.

Head, 110, 18 classes, 225-234..395-404:3, 1, 5, 5, 10, 8, 18, 18, 14, 10,8,4, 5, $0,0,0,0,1$.

Trunk, 110, 16 classes, 135-144..285-294:2, 1, 3, 6, 11, 8, 12, 10, 16, 15, 7, 8, 6, $2,0,3$.

Tai 1, to hypural, 110, 17 classes, 415-424..575-584:1, 2, 4, 7, 12, 10, 18, 11, 10, $5,9,10,2,4,3,1,1$.

Caudal fin, 110,15 classes, $175-184 \ldots 315-324: 2,3,2,9,4,12,18,24,10,5,6$, $4,6,0,5$.

Though the Ls distribution of the whole sample shows no indication of bimodality, the coefficient of variation $(21.3 \pm 0.8)$ is somewhat unexpectedly high. The reason for this is unclear - it may perhaps be attributed to variation in size in the sexes: other possibilities that suggest themselves include, first, that of the period of growth involved being considerable, and/or general environmental conditions being markedly variable, secondly, that of an extended period of hatching (the Iatter situation would seem compatible with the fact that the number of individuals of length above the modal length is $15 \%$ greater than the number of individuals of length below it; however, mean and median are, to measured degree of precision, identical).

Relative growth

Correlation of standard length with the relative lengths (measured as permillages of standard length) of head, trunk, tail (to hypural), caudal fin in the subsample have been investigated with the following results.

Head. Relative length of head increases with increasing standard length of fish: $r=+0.312(z=0.322), t=4.266^{* * *}$.

Trunk. The investigated subsample presents no significant evidence of change during growth in relative length of trunk: $r= \pm 0.0471(z=0.0472), t=0.0490$.

Tail, measured to hypural joint. Tail without caudal fin shows a marked decrease in relative length with growth: $r=-0.442(z=0.475), t=5.091 * \star \star$.

Caudal fin. The fin itself also shows a negative correlation: $r=-0.288(z=0.297)$, $t=3.131^{\star \star}$.

The pattern of relative growth in the present species of the regions selected for examination is, somewhat surprisingly, markedly different from that found in the sample of Arenigobius bifrenatus considered above, the sequence of correlations for the four regions, proceeding caudad, being in the latter species negative, positive, (as measured by difference of means of subsamples), no significant correlation, positive, while in the present form the sequence is positive, no significant correlation, negative, negative. The positive correlation of the caudal fin in A. bifrenatus is clearly connected with the increased growth in that species of the median rays that leads to the development in older fish of the characteristic posterior attenuation of the fin, whereas the caudal in $A$. tomarensis is more or less broadly rounded, with no or little median extension. It would be of interest to determine whether or no a negative correlation is regularly found in species with the (among Australian forms more usual) rounded or rounded truncate fin.

Reference to tables 6 and 7 shows the combined length of head and trumk (and hence length of tail without caudal $\mathrm{fin}$ ) is significantly the same in the prosent two species. 


\section{Character of regional regressions}

Different correlations with standard length of the several body regions examined thus being established, the need that next arises is that of ascertaining whether the relationships are of the first or of a higher degree, and of determining their parameters. The measurements of 110 individuals arranged in ascending order of mag. nitude of standard length have been divided into five sets, and in each of these the standard length (mm) and the lengths (TLS) of head, trunk, tail to hypural, caudal fin have been summed. The plotting of these results shows the relationship is in each case clearly a linear one. The regression equations are set out below.

Head $(H)$ on standard length $(L): H=0.2716 L+27.09 ; t=15.805^{* * *}$. The summed values for the five series (predicted, in parentheses) are 136.6 (140.1), 219.8 (216.7), $244.9(241.9), 251.5(255.6), 303.7(306.4)$

Trunk (B; from body): $B=0.2005 L+167.28 ; t=7.337^{* *}: 110.1$ (99.3), 139.4 (155.9), $165.3(174.9), 190.9(184.6), 230.7(222.3)$.

Tail, to hypural $(T): T=0.3382 L+118.52 ; t=17.197^{\star * \star}: 266.5(259.3), 344.4$ $(354.7), 383.9(386.1), 400.4(403.1), 474.3(466.3)$.

Caudal fin $(F): F=0.1769 L+56.91 ; t=13.416 * * *: 132.6(130.5), 179.2(180.4)$, $201.6(196.2), 195.0(205.8), 243.9(238.8)$.

It is to be noted the magnitudes plotted are summed values for the set, not its arithmetic mean; to obtain equations for $\bar{H}, \bar{B}, \bar{T}, \bar{F}$ the independent term needs in each case to be divided by 22 , the coefficients of the variates (slopes) remaining unchanged: further, $t$ values are hence those resulting from the use as primary data of the five sums, with d.f. $=3$.

Remarks

The 1935 account of this species, based on two lighter coloured individuals, Lt 75, 67.5 (1atter figured) and three darker coloured, Lt 72.5, 77, 84.5, taken in the Tamar in March and April 1934, the first series from the Launceston wharf, the second from the upper reaches of the river near Tamar Island, about $45 \mathrm{~km}$ from the sea, provides a reasonably adequate description of it: examination of the present extensive additional material provides occasion for the subjoined remarks.

Johnston noted 4 branchiostegals in $A$. tamarensis and 5 in G. tasmaricus (the latter treated in the 1935 paper as a synonym of the former). The 1935 count of 5 for A. tamarensis holds good in the present material. However, one ray, the lowest, is much shorter than the rest and is set far apart from them, the distance between its base and base of ray nearest it being subequal to the interval within which the insertions of all the four other rays are comprised: this smallest, lowest ray could readily be overlooked.

Light coloured and dark coloured individuals - the extremes of the two types markedly different in general aspect - are found in various gradations in all samples examined, and in individuals of all sizes save the smallest. However, the basic clements of the colour pattern on the body - a midlateral row of dark spots, modally 7 , more or less equidistant, from behind pectoral to caudal base, and 4 dark areas at dorsal profile (1935, pl. 4, fig. 1) - are almost invariably conspicuous, or are at least adnumbrated. In the lighter examples (as in that figured) few or no other markings are present: in darker examples almost the whole of the lateral surface, from dorsal profile to within a short distance of ventral, may bear numerous small spots, splashes, or short bars of chromatophores, these areas of pigmentation being much smaller and decidedly less intense than those constituting the main elements of the pattern. On the head the basic markings are less constant than those on the body, the dark spot on the operculum and the less extensive spot on the preoperculum usually 
being present, but being variable in size and in depth of colour, and being sometimes absent, the preopercular spot the more frequently so. Both pectoral and ventral range from being virtually colourless through an intermediate stage in which each of the rays is defined by a single series of minute closely-set melanophores to, in a few individuals, an overall state of pronounced duskiness.

In Johnston's description the pectoral was noted as 'reaching to vertical from third ray of second dorsa1', while in the 1935 material it was not found to extend beyond the origin of the fin. In the present samples it modally falls at, or just short of, level of dorsal origin; however, in occasional examples it extends as far as below the second or third ray. The ventrals may just fail to reach, or may extend shortly beyond, the vent, the former condition appearing to be more common in smaller fish.

With a total length of $84.5 \mathrm{~mm}$, the largest of the five 1935 specimens would appear to be close to the maximum size of the species, the largest individual here examined having a total length of 83.0 , the next largest (2) 78.9 , and only half a dozen or so exceeding 70. Johnston reported 'two to two and three-fourths inches [51-70 mm] long", while his memoranda, redacted by Whitley (1929a, p.62), noted an example of total length $211 / 16$ inches $[68 \mathrm{~mm}]$. The smallest specimen in our material is 8.3 in standard, 10.9 in total, length.

\section{Fami ly SCORPAENIDAE}

Genus GYMNAPISTES Swainson, 1839

Gymnapistes Swainson, 1839, Nat. Hist. CZassif. Fish. Amphib. Rept., 2, pp.63, 180, 265. Logotype, Apistus marmoratus Cuvier.

\section{Gymapistes marmoratus (Cuvier, 1829)}

Apistus mamoratus Cuvier, 1829, Hist. Nat. Poiss., 4, p.416. Type locality: 'Timor' (Péron). [Check-list, 'probably = West Australia'].

Apistes marmoratus Gray, 1838, Anr. Maq. Nat. Hist. 1, p.111. Type locality: Van Dieman's Land (Gunn).

Remarks

Some observations on the more taxonomically important features and their variation, life colours, behaviour, based on two examples, Ls 105.5, 120, from George Bay, east coast, together with notes on the local history and the vernacular names of the species appeared in Part IX (1960). The present contribution provides some morphometric data on, and on account of the colour pattern in, a juvenile sample; together with data on relative regional growth derived from a comparison of this sample with an adult sample. Length measurements of the juveniles are found not to be in conformity with a published version of the growth curve of the species.

Material

$(A)$ Juveniles. A series of 36 specimens, Ls 16.6-25.1, Lt 22.0-33.5, taken during an ecological survey by the Queen Victoria Museum of part of the Tamar river, at West Arm, (approximately $10 \mathrm{~km}$ from the sea) on 5 March 1975 (Q.V.M. Reg. No. 1975/ $5 / 36)$.

(B) Adults. (a) Ls 114, It 140, Kelso, Tamar river, in tidal grass, 5 February, R.H. Green, Q.V.M. Reg. No. 1975/5/60; (b) Ls 115, Lt 143, same history; (c) Ls 119, Lt 147, Greens Beach, north coast, 5-7 November 1966, R.H. Green, Reg. No. 1972/5/466; (d) Ls 126, Lt 158, Swan River, east coast, 9 October 1971, A. Brooks, Reg. No. 1972/ 5/330; (e) Ls 130.5, Lt 165, 11 November, 1970, George Bay, east coast, W.J. Head, Reg. No. 1970/5/30; (f) Ls 132, Lt 158, Beauty Point, Tamar river, 22 July 1964 , P. Rowley, Reg. No. 1964/5/2; (g) Ls 138.5, tt 166.5, Swan Point, Tamar river, 16 March 
1967, Reg. No. 1967/5/10; (h) Ls 153, Lt 192.5, C1ifton Beach, southern Tasmania, 2 November 1964, M.Mooney, Reg. No. 1969/5/31.

\section{Length specifications}

Standard and tota1 lengths of each of the 8 adult individuals have been noted above: the range, mean, standard deviation of $L s$ being 114-153, 128.50 $\pm 4.34,12.28 \pm$ 3.07 ; of $L t 140-192.5,158.75 \pm 6.43 ; 18.18 \pm 4.54$. In the sample of 36 juveniles the standard length range is $16.6-25.1$, mean $20.74 \pm 0.372$, median 20.6 , standard deviation $2.23 \pm 0.263$, coefficient of variation $10.8 \pm 1.3$, frequency distribution ( 9 classes, $16.5-17.4 \ldots 24.5-25.4$ ) $3,2,6,6,5,3,7,3,1$, with 23 (cf., normal curve, 25) entries within $\bar{x} \pm s$. For total length the corresponding values are 22.0-33.5, $27.56 \pm 0.5 .10,27.4,3.06 \pm 0.361,11.1 \pm 1.3,(13$ classes, $21.5-22.4 \ldots 33.5-34.4) 3$, $1,1,5,3,5,3,4,3,6,1,0,1(25)$.

Head

With length of head expressed as permillage of standard length, the range, mean, standard deviation, coefficient of variation in the adult fish are $371-425,386.6 \pm$ $5.44,15.4 \pm 3.85,4.0 \pm 1.0$. For the juveniles the values are $382-475,420.6 \pm 3.46$, $20.8 \pm 2.45,4.9 \pm 0.6$.

It will be seen the mean relative length of head in the young fish considerably (by $8.8 \%$ ) exceeds that in the adult. A test of the significance of the difference of the means shows it to be highly significant $\left(t=4.255^{* * *}\right)$.

Preanal length

In the adult fish the TLe range, mean, standard deviation, coefficient of variation of the combined length of head and body (TLS) are 615-701,652.0 $\pm 9.94,28.1 \pm$ $7.03,4.3 \pm 1.1$ : in the juveniles $650-704,623 \pm 4.29,33.2 \pm 3.91,5.3 \pm 0.6$. For difference of means $t=2.121 *$.

Thus although in $j$ uveniles the mean relative 1 ength of head is greater than in adults, the juvenile length to vent is the lesser. By simple subtraction of the means, TLs length of trunk in adult is 265.9 , in juvenile 203.3, i.e., with growth, relative lengths of head and of tail (vent-hypural) decrease, while relative length of trunk increases.

Caudal fin

Statistics in sequence as before for relative length of caudal fin ( $L t-L s$ ) are, adults, $197-264,235.1 \pm 8.27,23.4 \pm 5.85,9.9 \pm 2.5$; juveniles, 264-450, 333.4 $\pm 6.97,41.9 \pm 4.93,12.6 \pm 1.5$.

The great excess of the mean relative length of the fin in the young fish (42\%; ranges barely overlapping) is clearly highly significant; $t=6.277^{* * *}$.

Depth

Statistics for greatest depth (TLs) are, adults, 314-409, 359.1 $\pm 11.3,32.2 \pm$ $8.05,9.0 \pm 2.3$; juveniles, $312-441,374.1 \pm 4.74,28.4 \pm 3.35,7.6 \pm 0.9$. The difference of the means is not statistically significant $(t=1.283)$.

Growth curve

A growth curve for Gymapistes marmoratus in Tasmania has been proposed by Grant (1972), total, not standard, length being considered throughout; all dimensions in $\mathrm{cm}$. Measurements were made of 103 males and 67 females, and, no great difference in size between the sexes being found (on the published data, a test of the difference of the means yields a non-significant $t$ value of 1.385), the data for the sexes were pooled for the purposes of computation (sexes plotted separately, however, in fig. 7; not in figs 5,6$)$, the range of the weighted means over the observed growth period being 8.0-17.7 (table 1). Age was determined by otolith examination, and was regarded as 
ranging in the material examined from 2 to 13 years.

The formulation employed was the growth equation of von Bertalanffy (1937, 1938) namely, $L_{t}=L_{\infty}\left[1-\exp \left\{-K\left(t-t_{0}\right)\right\}\right]$, in which $L t=$ length of fish at age $t$ years, $L^{t}=$ maximum length towards which fish is tending, $K=$ rate of change of length movement, $t_{0}=$ hypothetical time at which the fish would have been zero length had it always grown in accordance with the expression. Parameters were obtained as follows. The value of $L_{\infty}$ was arrived at by means of the Walford transformation of the growth curve (Walford 1946), and was found (fig. 5) to be 21.4. The parameters $K$ and $t_{0}$ were obtained by a plot (fig. 6) of $\log _{e}\left(\log L-\log L_{t}\right.$ ) against $t$ years (Ricker 1958), the slope of the regression being $-K=0.1168$ and $t_{0}$ coming out at -2.3 years. Substitution of these values in the von Bertalanffy equation gives the growth curve of Gymaspistes marmoratus as $L_{t}=21.4[1-\exp [-0.1168(t+2.3)\}]$. A comparison of calculated with observed lengths is presented in Grant's fig. 7, which shows the calculated curve based on data for sexes pooled, but plots also male and female values separately.

The earliest age for which measurements are available is 2 years: however, the fitted curve is extrapolated back to 0 years and beyond to $t_{0}$. The length at 0 years is shown in the graph as $5.0 \mathrm{~cm}$ (by calculation from the equation 5.04). It is of interest to note that in the Tamar River sample here reported upon total length $(2.20-3.35, \bar{x} 2.76 \mathrm{~cm})$ falls well below the predicted length at zero age, the largest, mean and smallest lengths being only $66 \%, 55 \%, 44 \%$ of that estimate, and 8 of 36 individuals failing to reach half the calculated size.

Thus, while providing a satisfactory fit for ages 4-13 years (less satisfactory for ages 2-4), the published curve is probably not applicable below age 2 , certainly not for age 0 . Some consideration is given below to two lines of inquiry.

In the first of these the weighted mean lengths have been plotted against their year classes 2-13: the length data have been calculated directly from table 2 (mean length shown in table 1 records means only to $0.1 \mathrm{~cm}$; if data in table 2 are correct, several numerical errors occur in table 1). It is found a clearer picture of the general nature of the size change with age is presented by this single graph than any readily to be gathered from inspection of the male and female graphs shown together in fig. 7 (along with calculated curve). As thus plotted, the curve for ages $4-13$ can be eye-fitted by a single sweep of (upwardly convex) curve. However, between year 2 and year 4 there appears to occur a recognizable point of inflexion, the overall sense of the graph obtained by joining 2 to 3 and 3 to 4 by 1 inear segments being upwardly concave, and no continuation to the left of the curve between ages 13 and 4 to pass, without marked change of gradient, through points for years 3 and 2 being feasible. The excesses of estimated over plotted magnitudes at the region of ovcrsweep of the curve are considerable, those at years $2,3,4$ being $5.4 \%, 2.6 \%, 4.1 \%$, respectively, compared with $0.1 \%-1.5 \%, \bar{x}=0.68 \%$ found among the remaining 9 year classes. This excess of calculated over measured values in the early years involves compensatory deficits in the later years; hence, instead of positive and negative deviations being distributed at random along the curve, the customary outcome of the intrinsic variability of samples (in the equation noted below, confined to the years $4-13$, the sequence of sign of the deviations is,,,,,,,,+-++-+--+$)$, there arises a systematic fitting bias, expressed as a raising of the graph above plotted points in early years with concomitant lowering of the graph below points in later years.

In a second line of approach a simple exponential relation of the form $L t=b t^{k}$, which, expressed as $\log L_{t}=k \log t+\log b$, yields a convenient linear graph, has been looked at. The plot is found to be separable at sight into two elements, a significantly linear segment covering ages 4-13, and a line of greater slope, joining the coordinates for years 2 and 3 - a qualitative discontinuity in the growth curve round about age 4, or earlier, is thus again encountered. A convenient indication of the 
magnitude of the change of direction is provided by a comparison of the slopes of the two segments, namely, 0.4505, 0.3599; that for the points 3 and 4 being 0.6607 , that for 2 and 4 (3 omitted) 0.5378. The equation for the $4-13$ years segment is $\log L_{t}=$ $0.3599 \log t+0.8512 ;$ (Student's) $t=52.927^{* *}$. Over the relevant age range this equation provides a somewhat better fit than the published equation, percentage deviations of predicted from observed lengths being $0.2-1.5, \bar{x}=0.7$, as against $0.1-4.1$, $\bar{x}=1.3$. As might be expected, neither the linear graph for years $4-13$ nor that for years $2-3$ yields on extrapolation a biologically valid magnitude for $L_{O}$, the values being $7.05,5.87 \mathrm{~cm}$.

In summary: total lengths $(2.20-3.35, \bar{x}=2.76 \mathrm{~cm})$ found in a sample of Gymapistes mamoratis from the Tamar River fall well below the calculated length at zero age, 5.04 $\mathrm{cm}$, in a published growth curve for the species (Grant, 1972); the published curve, while providing a satisfactory fit for age classes 4-13 (fit for years 2-4 1ess satisfactory), is not applicable to fish in the age range 0-2 years; in early years the curve needs to exhibit a steeper gradient, and it is possible the total curve may take a sigmoid form.

In a study of reproduction, growth and size allometry of Mugiz cephazus Linné, 1758 from North Queensland inshore waters (Grant and Spain 1975) that came to notice a few days after the above was written the authors, while calculating the von Bertalanffy equation for this species (comparative observed and calculated growth curves shown in fig. 10), express some reservations about the procedure, reporting 'The von Bertalanffy equation closely approximates observed growth in larger fish, but is a poor fit at the lower limits of growth.' (p. 196). Noting the life history includes lag phases in the larval stage and at puberty, the growth curve thus being sigmoid, they remark Modelling the growth of $M$. cephalus by use of a relatively simple growth function thus seems somewhat ambitious (von Bertalmanffy 1964). It may better be approached by attempting to model the several apparent growth phases independently'. The relevance of these extracts to the present discussion is apparent - they cannot, of course, be taken, however, as representing fully the authors' views, for which reference should be made to the paper cited.

Adult coloration

Concerning the coloration of adults Macleay (1881) wrote 'dirty yellowish, largely marbled with brown'; McCulloch (1915), who figured a Western Australian example $137 \mathrm{~mm}$ long, stated 'The markings ... differ very much in several specimens from various localities, both in form and intensity, though their disposition is much the same in all; in some the larger dark blotches are brown, and surrounded by more or less abundant mottlings, while in others they are deep black on a plain white background'; Waite (1906) remarked of Victorian specimens 'the markings appear to be very constant and remarkably well defined', and later (1923) gave as a short diagnosis 'greyish yellow marbled with brown'. These accounts all refer to preserved material: as reported in Part IX (1960) live fish from George Bay, east coast, exhibited a very wide range of colours and tints, including pale and medium grey, greenish grey, green, greenish gold, flesh, flesh tinted with gold, white, warm and reddish and golden brown, dusky, olivaceous, pink, pinkish fawn, pale orange, purple.

Juvenile colour pattern

All descriptions agree, and examination of specinens confirms, that the major markings in the adult are blotches (one or more of which may be quite large) and a number of rather widely variable mottlings. The sample of juvenile specimens here reported upon exhibits a noticeably different, decidedly bolder series of markings, the basic elements of which are so distinctive and so regularly developed as strongly to suggest it represents a characteristic juvenile colour pattern.

The most striking feature of this pattern is the presence on the side of at least two conspicuous dark brown or blackish bars; first bar, modally about an eye diameter 
in width, completely covering caudal peduncle and adjoining region forward beyond level of insertion of membrane of dorsal to, or almost to, membrane of anal; anterior border proconcave, usually deeply so; posterior border overall strongly proconvex, somewhat furcate, constituted mainly by two large lateral continuations back on to base of caudal, each more or less in the form of rather more than half a cone, extending outward right to edge of fin, its most caudad point just internad of external ray: second bar a little narrower than first, in advance of it by rather more than its median anteroposterior extension, running subvertically, continuous from profile to profile, its slightly proconvex borders generally parallel throughout most of their length, but usually showing some divergence at their upper end, below middle of base of soft dorsal, anterior border here frequently giving rise an often subtriangular forward spur, subequal in length to vertical height of whole bar. In some individuals a rather conspicuous dark marking runs down as a continuous bar from near middle of base of spinous dorsal almost to ventral profile; more commonly this marking is interrupted, being represented usually by two, occasionally by three, segments, modally about as wide as high. Of these three bars, none normally occurs in the adult, though remants of that at base of caudal may be traceable in an occasional individual. In most specimens a dark brown or black subrectangular or ovoid patch occupies most of area between upper border of operculum and fin base above it. Ventral surface whitish and/or (especially on chest) yellowish; marked, regularly in front and frequently behind, by scattered red-brown or dark brown chromatophores.

Dark brown markings on head tolerably extensive, less regularly patterned than those on body; comprising, when best developed, a conspicuous downwardly and backwardly oblique bar from orbit (regularly developed, but quite variable in both extent and intensity), its width subequal to diameter of pupil, variable patches behind eye, above eye, on dorsum of snout, on opercle. Ventral surface sprinkled, sparsely or abundant$1 y$, with deep brown or reddish brown chromatophores. Lips usually mottled.

Spinous dorsal with dark blotches, commonly black or approaching black, characteristically one covering first two-three spines, then suffering an interruption for one or two spines, or continuing unbroken to near sixth or seventh spine; usually a* small dark marking on last spine or two. Soft dorsal with a large dark area, modally occupying its middle one-third, or rather more. Anal dark brown or intensely black on anterior portion, continuous here with penultimate bar on flank; rest of fin either greyish or conspicuously white. Pectoral mostly black or blackish, lower one or two rays white; sometimes base of fin, or middle of its length, whitish. Ventral usually black proximally, white or whitish distally; occasionally white proximally, black distally. Caudal characteristically exhibiting four regions: basal one-eight the dark half cones continued from peduncle; thereafter to about middle of length silvery; posterior half dark brown or blackish nearly to tip, which is white or greyish.

\section{Family APLOACTINIDAE}

The above form of the family name is that adopted by Greenwood et al. in their provisional classification of living teleosts (1966) to include Aplodactylidae and, as a queried entry, Bathyaploactidae. The form Aploactidae was adopted in the general classifications of Jordan (1923) and Berg (1940); this is the version of the Checklist (McCulloch, 1929) and that adopted by most Australian writers, e.g., (Lucas 1890), Waite (1921), Whitley (1933), Scott (1942), (T.D.) Scott (1962), Munro (1957), Scott et al. (1974). Earlier these fish were usually grouped (Günther 1880, Macleay 1881) with the Scorpaenidae, with the scaleless members of which, sometimes given separate recognition as the Tetrarogidae, they agree in having the anterior dorsal spines constituting a more or less distinct, usually crestlike, section and in showing a reduction in the number of ventral fin rays; differing from them most noticeably in the presence of numerous velvety villi on the skin. Marshall (1964) treated the group as the Aploactinae, a subfamily of the Scorpaenidae. Whitley (1933, p.98) noted the Synancejidae are not distantly related. 
Only two members of the family appear in the Check-1ist, Aploactis milesii Richardson, 1850 (synonym, Aploactisoma schomburgki Castelnau) and Paraploactis trachyderma Bleeker, 1855 (synonym Ap Zoactis Zichen De Vis, 1884). Whit1ey's name-list (1964) added Adventor elongatus (Whitley, 1952), Bathyaploactis curtisensis Whitley 1933 (with two subspecies), and recognised a subspecies from New South wales and Victoria of Richardson's species, Aploactisoma milessi horrenda Whitley, 1933.

\section{Genus APLOACTTSOMA Caste1nau}

Aploactisoma Caste1nau, 1972, Proc. Zool. Acclim. Soc. Vict.1, p.244 et ibid., 1873, 2 p.63. Haplotype, Aploactisoma schomburgki ( = Aploactis milesii Richardson, 1850 ).

\section{Aploactisoma milesii (Richardson, 1850)}

Aploactis milesii Richardson 1850, Proc. Zool. Soc. London, p.60, Pisces, p1.1, figs 1-2. Type 1ocality: King George's Sound, Western Australia.

Aploactis schomburki Castelnau, 1872, Proc. Zool. Acclim, Soc. Vict., 1, p.244. Type locality: St. Vincent's Gulf, South Australia.

Aploactis schomburgkii Caste1nau, 1873, Proc. Zool. Acclim. Soc. Vict., 2,p.64.

Occurrence in Tasmania

Though Scott (1962), who followed Whitley in recognizing two subspecies, A. m. mizesii from Western Australia, South Australia and Tasmania, and $A$. m. horrenda from Victoria and New South Wales, said of the former that it is 'reasonably common' in South Australia, the species would appear not to be abundant in this state, not being included in any of the published local lists - Johnston $(1883,1891)$, Lord $(1923,1927)$, Lord \& Scott (1924) - or accredited to Tasmania in the Check-1ist (McCu1loch 1929). The first Tasmanian record appeared in Part $V$ of these observations (1942, p.52), based on a specimen, Ls 130, Lt 160 (Q.V.M. Reg. No. 1939, 147), taken at Low Head in 5 fathoms $(9 \mathrm{~m})$; a specimen, $L \mathcal{3} 74.8$, Lt 92.0, collected early in 1975 in Anderson's Bay, Bridport, by Mr Peter Last (Q.V.M. Reg. No. 1975/5/217) is the only other example to come under the writer's notice. Some observations on these two fish follow: data for the smaller specimen are given first throughout.

Fin counts

$$
\text { D. XIII, 15; XIV ,16, A.13; I,14 =15?. P.11; 11. V. I, 2; I,2. C.13,13. }
$$

\section{Proportions}

No set of proportional measurements for this species appears to be available: some dimensions, as permillages of $L s$, of our examples are noted. Total length 1230, 1236. Length to origin; termination (1ast spine) of first dorsal 79, 71; 627, 559 : of second dorsal 652, 591 (first ray); 976, 945 (1 ast ray) or 996, 969 (membrane) : of anal 623, 587; 909,945. Length to vent (middle) 556, 563. Length to pectoral origin 279,236 ; length of fin 328, 331; longest (4th, 4th) pectoral ray 311, 272 . Length to ventral 242, 232; length of fin 178, 153; length of longer (inner, inner) ray 151,137 .

Head 316, 283. Snout 80, 75. Eye 78, 67. Interorbita1 80, 92. Length of maxilla 112,118 , greatest width 40,43 , least distance from eye 66,57 . Depth at front of eyes 178,173 , back of eyes 201,200 , opercular border 281, 299, vent 269, 315, immediately behind vent 267,260 , anal termination 120, 142; greatest depth 287, 378; depth of caudal peduncle 107, 106.

Body form

In the terminology of Gregory (1928) the body form is mesosomatic, hypsisomatic, gasterion supapical, gasterion postapical; vertex anterior; gasterion anterior, 
gasterion median; mesonotic; mesogastric, bathygastric; leptopygidial; opisthion preuranic. It will be seen that, of the ejght variable factors, the first, second, fourth and sixth are represented by two specifications. In each case the first specification, that for the 1975 fish, may be regarded as being normal and definitive; the presence in the 1942 fish of ripe ovaries with numerous eggs produces a marked distention of the abdomen leading to what may be regarded as being an adventiously high value for the anterior ventral vertical and an adventiously posterior location of the gasterion.

General features

A very good and comprehensive description of his Aploactis mizesii (based on a dried specimen, its condition probably bringing into special prominence the remarkable modelling of the head) was given by Richardson (1850): Castelnau's much shorter account of his Aploactisoma schomburgki (1873; as A. schomburgkii) was concerned almost entirely with the shapes and dimensions of the fins; while his original notice of the species consists only of the dorsal fin formula and a sentence on coloration. Little is added in later treatments by McCulloch (1915) and Whitley (1933), the chief new contributions being the presentation by the former of some variants in dorsal and anal counts(together with the correction of Castelnau's erroneous statements that there are teeth on the palatines and 'two teeth rather larger than the others' at the front of a longitudinal ridge at the symphysis of the upper jaw), and the calling of attention by the latter author to differences in shape of villi, size, relative depth, features used to distinguish subspecies (see Discussion, below). Some comparative observations on our material follow.

In specimen (b) both the dorsal count, XIV, 16, and the anal count XV (I, 14), are higher than in Richardson's type, XIV, 14, and 12; than in Castelnau's two specimens, $X I I, 15$, and I,11; and than in any of the eight examples examined by McCulloch, with ranges 28-29 (XIII, XIV, 14-15) and 12-13 (I,11-12). Height 'nearly one-fourth of length of fish, caudal included' (Richardson), 'four times in the total length' (Castelnau), here $4.28,3.27$ in $L t$, or $3.48,2.71$ in $L s$, the markedly greater relative depth of the larger specimen being accounted for, as noted above, by distension of the abdomen by the presence of seasonally enlarged ovaries, depth jmmediately behind vent $(3.74,3.85$ in $L S)$ showing no significant difference. Head in total length: Richardson's data would give about four times; Castelnau, three and two-thirds; here 3.90, 4.44. Eye in head: Castelnau, five times; here 4.07, 4.23.

In Richardson's statement that the height of the tallest spine is but a little less than that of the head it would appear from his figure that maximum height of head is meant (height of fin subequal to height of body below it): in our specimens it is $1.00,0.79$ height of head below spine, but is $1.50,2.00$ times in greatest head depth. Castelnau noted the length of the iongest dorsal spine as equal to distance from tip of snout to middle of orbit; in both Tasmanian fish it somewhat exceeds distance from tip of snout to posterior border of orbit. Both Richardson and Castelnau specify the second spine as the longest, and this is the case in (b); however in (a) the first spine is slightly longer than the second, though the latter stands tallest, the extra length of the first being related to its more inferior insertion. The dorsal presents a dip in outline in Richardson's fish, in Castelnau's and in our (b), the fin in each case rising from first to second spine, then decreasing to fifth-sixth, fifth, eighth, respectively, thereafter increasing in length to last; the shortest being in our specimen 0.46 of the largest, 0.76 of the last. However, in the smaller individual the spines decrease in length from first to last, the latter being 0.29 of the former. For further consideration of dorsal spines, see Fin patterns below.

\section{Additional descriptive data}

Some features not, or inadequately, noticed in published accounts may be here considered. Maxillary extends to below $0.5,0.3$ eye (in illustration stops well short of eye). The lateral line runs backwards and somewhat downward from just behind opercular angle to midline of flank at level of vent, thereafter proceeding almost 
horizontally, to end at caudal base a trifle nearer to upper than to lower margin of peduncle. In (b), in wich it is more readily observable, it comprises 12 elements, the first eight of which take the form of a slender tapering process, thickly beset with minute copies of itself, most numerous proximally, sometimes completely absent distally, the whole structure surrounded at its base by a cluster of dermal processes, separate from, and noticably smaller than, those on the body nearby; between adjacent tentacles a narrow strip lacking the ordinary processes but sometimes bearing a short median strip of about half a dozen much smaller processes; largest tentacle subequal to eye, size decreasing caudad. The posterior 4 elements each consist of an anteroposteriorly set strip of small processes, much as if the free tentacle of the anterior part of the series had been depressed and become adnate: in the well developed example at base of caudal, about half an eye diameter in length, there are 16 processes, very closely set, arranged biserially.

The anterior nostril, just below level of eye, a little closer to orbit than to upper lip, presents a backwardly, and in (b) somewhat downwardly, directed membranous flap, subrectangular in (b) subtriangular in (a), upper border convex, lower sigmoid. The posterior nostril appears to be represented by a fleshy envelope, somewhat similar to the anterior nostril, lying in the front of a well developed adorbital depression flanking on either side the conspicuous medial depression on the forehead: neighbouring minute circular naris-like aperture in the summit of a low mammiliform eminence lying close against the transverse ridge of the prefrontal that constitutes the posterior wall of this lateral depression and that is confluent internally with the trenchant circumorbital ridge at $100^{\prime}$ clock (left side viewed), being probably a simple open cephalic pore, several of which occur (as noticed by Richardson) on the mandible. The characteristic subtriangular median frontal depression (in this genus base facing mouth; in Paraploactis and Adventor facing dorsal fin) is wholly filled in the larger specimen with a distended smooth whitish translucent bag: the presence of this structure may possibly be due to the fish having been subjected to some abrupt change in pressure, an inflated tyre of similar material surrounding each eye.

The anterior gill arch, which is more evenly bowed, less sharply divisible into upper and lower limbs than usual, bears in its lower half three mounded, minutely spinulose gill rakers, in general more or less contiguous, with the first (uppermost) showing most tendency towards being separate; there being also an indication of the continuation of the last as a long ridge; from one to three extremely small rectangular elevations, their height less than one-fifth that of the other elevations, occur separate from, and some distance above, the others, but still within the presumed extent of the lower limb. All teeth villiform, minute: in upper $j a w$ on either side in a boldly curved flat band, broadest anteriorly, decreasing evenly to a point posteriorly, the two bands imperfectly separated at the symphysis by a fleshy strip, part or all of which is mounded; no special enlarged teeth: in lower jaw two similar, but slightly narrower, bands, separated at the symphysis by a narrow groove, naked in the smaller specimen, occupied in the other example by a fleshy process running forward from a crescentic skin-fold that flanks the dentigerous region throughout its length: on vomer in a small lunule. A frenum on the palate contiguous anteriorly with the tooth-band, and nearly as wide as it, is delicately corrugated throughout, with the tip of each ridge produced posteriorly as a short pointed process, the free border of the membrane thus forming a finely denticulate arc. It is conceivable the points on this arc may have been interpreted as a series of palatine teeth.

The dermal papillae cover the greater part of head and body; largest on flanks, smallest on abdomen; absent from part of upper lip, supralabial sulcus, most of lower lip, parts of some cephalic depressions, central portion of anal area, much of branchiostegal membrane, most of lower border of preoperculum. On dorsal and anal they invest virtually whole fin, becoming progressively smaller distally, finally degenerating to minute knobs, which in $(a)$ are sparse on the membrane: in (b) they extend to the broad tips of the pectoral rays, while in $(a)$ they are absent from the tips, here 
more slender, more pointed and free for a greater distance, relatively and absolutely, from the membrane. By writers other than Richardson these structures are customarily referred to as villi, usually with the epithet velvety. Richardson, dealing with a dried specimen, speaks of them as 'straight acute spines, each enveloped in a skinny sheath'. When the fingertip is drawn along the body in our material, first in one then in the other direction, the resultant sensation with the large fish is in both cases velvety; with the smaller fish the caudad motion gives a tolerably smooth feel, the cephalad motion a distinctly prickly one. The spine, described by Richardson as straight, in our material somewhat recurved, is either partly bare or is invested in a quite thin membrane in the smaller fish, but is embedded in thick integunent in the larger. Papillae in different regions of the head range in form from stout pyriform to slender digitiform, varying in bulk by a factor of 10 or more. The crest of the dorsal in $(b)$ bears on each side a dozen specialized papillae of differing size, the largest several times the size of the smallest and five to six times as large as those of the tolerably uniform series of the flank; these are ramose, developing up to a dozen processes.

Some of the complex cephalic armature has been described by Richardson; one remarkable feature, the larger, more posterior of two ridges given off from the first suborbital merits more detailed attention. This ridge, arising from a mounded elevation just below $7 \mathrm{o}^{\prime} \mathrm{clock}$ on the orbit (left side viewed) preceeds downward and forward, increasing in height, for about two-thirds of an eye diameter, and then divaricates, the ridge thus formed, the general sense of which is horizontal, comprising a median upwardly convex arc, flanked on either side by a downwardly convex arc, the elevation as it proceeds becoming thickened and rounded, and being briefly continued in a re-entrant curve directed towards the primary ridge, the two free lateral tips thus assuming a somewhat knobbed appearance. The whole structure exhibits a considerable degree of mobility, the strongly scalloped terminal portion, the fore-and-aft extension of which is about twice the length of the median ridge, being readily raised above the general surface of the cheek, disclosing an area of smooth glistening white integument. This process would appear to be represented also in Paraploactis, which genus Bleeker (1865) stated 'Se distingue...par l'armature de son sousorbitair'anterieur mobile à la façon des Apistes'.

As noted above, the marked distention of the larger individual is due to the presence of ripe gonads. Each ovary is a large broadly fusiform body, approximately $24 \mathrm{~mm}$ long, 8 wide, $12 \mathrm{deep}$; its thin transparent external membrane tightly packed with pale orange ova, near1y all well developed, spherical, 0.7-1.0 $\mathrm{mm}$ in diameter; left ovary, viewed from below, with anterior one-third covered by larger lobe of liver, right covered only by tip of smaller lobe.

Our two specimens differ markedly in general appearance, largely as the result of, first, the variation in depth, already noted; secondly, the nature of the general integument, thick and rubber-like in appearance in $(b)$, more membranous in $(a)$; thirdly the coloration; fourthly, the length-pattern of the dorsal spines: the last two features receive consideration below.

Coloration

Specimen $(\alpha)$. Body chiefly almost uniform light tan, a little lighter on lower half of trunk, becoming still lighter ventrally, approaching whitish mesially for about two-thirds of a head length in advance of vent, which is white: flank with fewer than a score of dark markings, three or four of these, first above opercular angle, rest shortly behind this, largest, darkest, approaching black, the remainder scattered, less defined. Head largely concolorous with body, lighter on side in advance of eyes, on chin, and on much of branchiostegal membrane; two or three dark spots behind eye; a subrectangular area darker than rest of cheek just behind gape. Dorsal chief$1 y$ concolorous with body; membrane of part of fin above head and that between last three rays somewhat lighter, most so distally; some darker, reddish brown clouding 
involving part of upper half of fin from first to third spines; a dark, almost black spot covering distal one-third of membrane between twelfth and fourteenth rays; tips of spines and rays tending to be 1 ighter than remainder. Anal lighter than dorsal, somewhat yellowish fawn; conspicuous broad dark bar, shading internally to reddish, on distal one-fourth of rays 11-13 and their membrane, continued forward, decreasing in height, on tips of three preceding rays, and, 1 ess deep in colour, on tips of rays 14,15. Pectoral mostly concolorous with trunk, uppermost ray and several lower rays more or less distinctly banded with whitish and tan; extreme tips of rays whitish, translucent. Ventra1 rays concolorous with body nearby; caudal about concolorous with anal; darker brownish in outer two-fifths, still darker, approaching black, at upper and lower borders; a narrow lighter bar across middle half dozen rays at distal four-fifths of length of fin.

Specimen (b). Ground colour throughout medium grey, liberally sprinkled with midbrown markings in the form of some four score spots, most more or less rounded, and a few larger irregular patches, spots on head tending to be smaller; some areas of much lighter grey, including one, the most conspicuous, behind head by about postorbita1 head, four times as far from ventral as from dorsal profile, and a pair, somewhat smaller, about above termination of anal; a small conspicuous white spot immediately in advance of the lower of the two light grey markings, and, on right side only, a whitish spot in advance of upper. Elevated portion of spinous dorsal chiefly dark, almost black; free tips of spines grey sprinkled with white: membrane in rest of fin dark grey with diffuse peppering of pink and white, and, usually, one more or 1ess central pink splash between adjoining spines. Anterior two-thirds, or so, of soft dorsal whitish or pinkish, heavily punctulated with purplish; elevated posterior section similar in distal half to anterior, dark grey basally; a black patch near tips of longest two rays; tips of al1 rays briefly white. Anal warm dark brown; a sprinkling, particularly proximally, of very small touches of white provided by minute papillae; ends of rays light grey. Pectoral very dark brown, with several streaks, most marked on upper ray and lower three or four rays, and splashes of lighter, where a number of papillae, elsewhere more or less concolorous with membrane, are dead white, this white extending forward ventrally across base of $f$ in to opercular border; pointed free tips of rays variable, mostly banded with brown and grey, sometimes hyaline. Ventral rays obscurely banded brown and grey. Caudal chiefly greyish, in places with a suggestion of pinkish, heavily punctulated with reddish brown; three arcs of dark brown, the proximal involving only five or six inner rays, the next, well developed, near middle of length of fin, almost black on lowest ray; the distal marking 1 ess continuous, including a black spot near tips of two lower rays; a dark spot near end of three middle rays; several small spots and patches of white or whitish on outer one-sixth of fin; free tips of all rays hyaline or whitish.

\section{Fin patterns}

The lengths of the dorsal spines and rays, anal rays, pectoral rays, pelvic spine and rays, are all found to exhibit the relation $L=b N k$, or $L=b N(k)$, or a combination of these ( $N$ being serial number, in the set, of spine or ray, counting caudad, or, in pectoral, downward; $N^{1}$ counting cephalad, or, in pectora 1 , upward).

(a) Dorsal spines. The length-number relations are exceptional in being different in the two specimens (see Discussion, below); moreover each pattern is an unusual one.

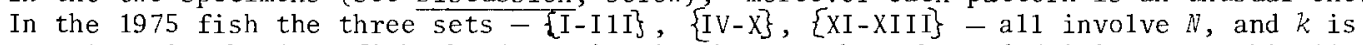
negative: in the $1942 \mathrm{fish}$ the 1st spine is shorter than the 2nd (giving a graphical1y trivial set of $\{I-I I\})$, while of the remaining sets - $\{I I-V\},\{V I-V I I I\},\{I X-X I V\}-t h e$ first two involve $N^{1}$, the third $N$, all values of $k$ being positive.

The equations, in logarithmic form, are, 1975, $\log 1=-0.1024 \log N+1.467$, $\log L=-0.2205 \log N+0.8701, \log L=-0.08838 \log N+0.6424 ; t 19.801^{*}, 15.247^{* * *}$, 8.201*: $1942, \log L=0.3888 \log N^{1}+0.0375, \log L=0.1365 \log N^{1}+0.9400, \log L=$ $0.1391 \log N+0.9530 ; \quad t 22.450^{* *}, 28.861^{\star *}, 40.565^{* * *}$. Predicted (measured) lengths, $1975,14.0(14.0,13.1(13.1) ; 12.6(12.5) ; 7.4(7.6,6.4(6.1)$ 
$5.8(5.9), 5.5(5.4), 5.2(5.2), 5.0(5.0), 4.8(4.9) ; 4.4(4.4), 4.1(4.1), 4.0$ (4.0): 1942, [lst spine 18.5]; $18.7(19.0), 16.7(16.5), 14.3(14.1), 10.9(11.0)$; $10.1(10.1), 9.6(9.6), 8.7(8.7) ; 9.0(9.0), 9.9(9.8), 10.4(10.5), 10.9(10.9)$, 11.2 (11.2), 11.5 (11.5) - the lengths of the spines thus decreasing from 1 st to 13 th in the 1975 specimen, whereas in the 1942 specimen they increase from 1 st to 2 nd, decrease to 8 th, increase to 14 th.

(b) Dorsal rays. The basic pattern is a common one, a long anterior section of rays of increasing length, graphable against $N$, followed by a shorter section of decreasing length, graphable against $N^{1}$. However, two points call for notice: in the 1942 specimen a slight notch occurs at the 11 th ray, which thus 1 ies outside the two main sets $\{1-10\},\{12-16\}$; in the 1975 specimen, of the two sets $\{1-10\},\{11-15\}$ the former, while yielding a linear graph (slope 0.2002 , intercept 0.7664) with a high degree of significance $\left(t=14.433^{* * *}\right)$, with predicted lengths differing from measured lengths by only 1.1-4.1, mean 2.0 percent, can be more precisely specified by being treated as two sections, $\{1-4\},\{5-10\}$. Values of $k$ for the 1942 fish are 0.1673 , 0.5324 , of $\log b 1.07462,0.9909 ; \quad t 99.177^{* * *}, 6.343^{* *}$; predicted (measured) 1 engths of rays $1-10,12-16,11.9(12.0), 13.3(13.0), 14.2(14.5), 15.0(15.0), 15.5(15.4)$, $16.0(16.1), 16.4(16.5), 16.8(16.8), 17.2(17.1), 17.5(17.5) ; 18.8(19.2), 16.7$ $(16.6), 14.3,(14.5), 11.5(11.2), 8.0,(7.9)$. Parameters for sets $\{1-4\},\{5-10\}$, $\{1.15\}$ of the 1975 fish are $0.1606,0.09886,0.3820$ and $0.7771,0.8942,0.7779 ; t$ $6.311^{*}, 19.303^{* * *}, 24.118^{* * *}$; predicted (measured) lengths $6.0(5.9), 6.7(6.9)$, $7.1(7.1), 7.5(7.4) ; 7.8(7.9), 8.5(8.3), 8.7(8.7), 9.0(9.0), 9.2(9.2), 9.4(9.4)$, $11.1(10.9), 10.2(10.2), 9.1(9.2), 7.8(8.0), 6.0(5.9)$.

(c) Anal rays. These have been examined only in the more readily measurahle individual. The simple pattern has three components, $\{1-8\}$, length increasing, $N ;\{9-12\}$, length increasing, $N ;\{13-15\}$, length decreasing, $N 1$. Slopes of the graphs are $0.4392,0.06131,0.5370$; intercepts $0.6912,1.1317,0.8568 ; t=33.932^{* * *}, 7.816^{*}$, 103.013***; predicted (measured) lengths $4.9(4.9), 6.6(6.6), 7.9(8.1), 9.0(8.9)$, $10.0(10.0), 10.8(11.0) 11.5(11.5), 12.2(12.1) .13 .5(13.6), 14.1(14.0), 14.5$ $(14.5), 14.7(14.8), 13.0(13.0), 10.4(10.4), 7.2(7.2)$.

(d) Pectoral rays. The two specimens have the same pectoral pattern, a usual one, with one ascending set on $N$ (1st ray uppermost), and more than one set (here two sets) descending on $N^{1}$; the sets being $\{1-4\},\{5-7\},\{8-11\}$.

Values (left fin measured) of $k, 1942,0.4256,0.1092,0.4419 ; 1975,0.4773,0.1456$ $0.7915:$ of $\log b, 1942,1.2823,1.4694,1.1066 ; 1975 ; 1.0814,1.2767,0.7653 ;$ t, $1942,24.707^{* *}, 8.813,36.339^{* * *} ; 1975,51.979^{* * *}, 118.536 * *, 35.117^{* * *}$. Values of $\widetilde{L}(L), 1942,19.2(19.0), 25.7(26.0), 30.6(31.0), 34.6(34.0), 33.2(33.1), 31.8$ $(32.0), 29.5(29.4) ; 23.6(23.4), 20.8(21.1), 17.4(17.2), 12.8(12.8) ; 1975,12.1$ $(12.0), 16.8(16.9), 20.3(20.4), 23.3(23.1) ; 22.2(22.3), 20.2(21.0), 18.9(19.0)$; $17.5(17.6), 13.9(14.0), 10.1(9.8), 5.8(5.9)$

(e) Ventral spine and rays. The lengths of the spine (covered with integument, close$1 y$ bound throughout its length to the adjacent ray; readily distinguishable in the larger individual, traceable with difficulty in the smaller), the ray flanked by spine and ray (adherent to the ray for some four fifths of its length) and the inner ray exhibit a progressive increase of the exponential character encountered in other fins or sections of fins. Since the inner or immediately postaxial ray (that furthest from spine) is by convention (Part XIX, 1974a, p.294) treated as the first element of the fin, the relation between length and serial number assumes the form $L=b N 1(k)$. For the 1942 specimen the equation, in logarithmic form is, log $l=0.3545 \log N 1+$ 1.0728 , for the smaller example $\log L=0.2710 \mathrm{log} \| 1+0.9250$; $t$ being $21.347^{\star}, 31.490^{\star \star}$. Predicted (measured) lengths (spine first) are, 1942, 17.5 (17.4), 15.1 (15.2), 11.8 $(11.8) ; 1975,8.4(8.4), 10.2(10.2), 11.3(11.3)$. 
Discussion

The lastest available account of the species - that of Scott et al. (1974, p.184, fig. on p.184 after Richardson)-recognized two subspecies of $A$. milesii, the typical subspecies, A. m. milesii (Macleay, 1881), occurring in Western Australia, South Austra1ia, Tasmania, and A.m. horrenda Whitley, 1935, found in New South Wales and Victoria.

The comparison below is based on the following sources: in respect of $A$. m. horren$d a$ on Whitley's diagnosis of his subspecies and his figure (1933, pl.13, fig.3) of a New South Wales example (with, in parentheses, some contrasting specifications, from the same paper, of the typical subspecies); in respect of $A$. m. milesii Richardson's original description of Aploactis milesit and his figure of the type - reproduced in various sectional Australian catalogues, e.g., those of Waite (1923), McCulloch (1922), Scott (1962), Scott et al. (1974) - Castelnau's 1873 account (as Aploactisoma schomburgki $i$ ) of the very briefly described A. schomburgki Castelnau, 1872, from St Vincent's Gulf, South Australia, Scott et al. (1974, p.184, and figure after Richardson), and our two Tasmanian fish. For each of the four diagnostic features ascribed to it, $A . m$. horrenda is specified first in the notes below.

'Body deeper': from figure maximum depth about 4 , depth at vent about $4 \frac{1}{3}$, in $L t$. In $A . m$. milesii 'the height of the body nearly one-fourth of the total length, caudal included' (Richardson), and from his figure maximum depth about $43 / 4$, depth at vent about 6 , in $L t$; 'height contained four times in the total length' (Castelnau); our specimens, corresponding measurements, (a) 4.3, 4.6, (b) 3.9 (gravid), 4.8.

'Villi blunt' (contrast 'fine-pointed'). Our specimens, (a) slender, length modally 5-7 times basal diameter, slightly tapered, with fine point, $(b)$ (in the original account of $(b)(S \operatorname{sct} t, 1942)$ the villi were assessed, in the absence of comparative material, as 'fine'; they are, indeed, pointed, but compared with those of the 1975 example they are seen to be gross).

'Size larger, up to nearly 7 inches', about $180 \mathrm{~mm}$ (contrast 'to five inches', about $130 \mathrm{~mm}$ ). Size of type of A. milesii not specified; 'two specimens, the longest of which measures five inches, but $\mathrm{Mr}$ Waterhouse tells me he has one almost twice that size' (Castelnau); 'length to $23 \mathrm{~cm}$ ' (Scott et al.); our specimens, (a) 75, (b) $130 \mathrm{~mm}$.

'Colour more uniform and dark brownish' (contrast 'the prevailing tone of spirit specimens brown, with indistinct darker spots and marblings of purple and whitish, with anterior dorsal fin dusky'). In the type of A. milesii 'The only vestiges of colour remaining in the dried specimen are brown and purple bands and blotches on the dorsal, caudal and pectoral, with one or two rows of white spots on the two latter fins'; 'the colour is of a dark brown marbled with black; there is a spot of that colour at the posterior angle of the second dorsal, and the caudal and anal are bordered with the same' (Castelnau); 'Colour brown, with darker spots, the tips of the papillae reddish or orange' (Scott et al.); colours of our specimens, described above, differ considerably - judged by the criterion 'colour more uniform' $(b)$ would appear to qualify as A. $m$. horrenda, but judged by its lighter coloration as A. m. milesii, while the more variegated appearance of $(a)$ would identify it as $A . m$. milesii but its quite dark brown perhaps as $A, m$. horrenda.

There is a very marked difference in the general visual character of the integument in our two fish, that of $(b)$ being seemingly much thicker and appearing to be of a somewhat rubber-like consistency, that of $(\alpha)$ being apparently thinner and more of a membranous nature: while it is evidently not possible satisfactorily to determine the tactile properties of an integument of figured specimens, inspection of the illustrations of Richardson and Whitley leaves an impression that the former is more compatible with $(b)$, the latter more compatible with $(a)$.

While a definitive judgement must wait on an examination of a good range of comparative material, it would nevertheless appear from the foregoing analysis of available 
data that the existence of distinct geographical forms of the species is much to be doubted.

\section{REFERENCES}

Allport, M., 1876: Tasmanian record of Lepidopus caudatus. Proc. R. Soc. Tasm. $(1875), 75$.

Australian Encyclopaedia, no date: Article Macquarie Is Zand, 5, 453.

Barrett, C., 1933: SUN NATURE BOOK, 4, WATER LIFE, Melbourne.

Berg, L.S., 1940: The classification of fishes both recent and fossil. Trav. Inst. Acad. Sci. U.R.S.S., 5 (2), 86-117, figs 1-190 (in Russian) [n.s.]. Fdition in Russian and English, Ann Arbor, Mich., U.S.A., 1947 (J.W. Edwards).

Bertalanffy, L. von, 1937: Quantitative laws in metabolism and growth. Q. Rev. Biol., 32 217-31 [n.s.].

, 1938: A quantitative theory of organic growth. Hum. Biol., 10, 1964: Basic concepts in quantitative biology of metabolism.

Hetgol. Wiss. Meeresunters, 9, 5-37 [n.s.]

Bigelow, H.B. and Schroeder, W.C., 1948: Fishes of the Western North Atlantic, part 1, cyclostomes and sharks. Mem. Sears Found. mar. res., 1.

Bleeker, P., 1865: Notice sur 1e genre Paraploactis et description de son espèce type. Neder2. Tijdschr. Dierk., 2, 168-170.

Boulenger, G.A., 1910: Fishes (systematic account of Teleostei). In : Cambridge nat. hist., 7, 421-760, figs 240-440. McMi1lan \& Co., London.

Briggs, J.C., 1955: A monograph of the clingfishes (order Xenopterygii). Stanf. Ichth. BuzZ. 6, 1-224, figs 1-114, maps 1-15.

, 1962: Xenopterygii : Weber, M. \& De Beaufort, L.F., THE FISHES OF THE INDO-PACIFIC ARCHIPELAGO. Leiden e.g. E.J. Bril1.

Castelnau, F.L., 1872: Contribution to the ichthyology of Australia. No. 2 - Note on some South Australian fishes. Proc. zool. acclim. Soc. Vict., 1: 243-248.

, 1873: Contribution to the ichthyology of Australia. No. $4-$ Fishes

of South Austra1ia. Proc. 2002. acclim. Soc. Vict., 2, 59-82.

Cuvier, G., 1828: In : G. Cuvier \& A. Valenciennes, HISTOIRE NATURELLE DES POISSONS, 2. Paris.

Fowler, H.W., 1908: A collection of fishes from Victoria, Australia. Proc. Acad. nat. Sci., Phizad. (1907), 59 (30), 419-444, 10 figs.

Garrick, J.A.F., 1960: Studies on New Zealand Elasmobranchii. Part 12. The species of Squalus from New Zealand and Australia: and a general account and key to the New Zealand Squaloidea. Trans. R. Soc. N.Z, 88, 519-558, figs 1-6. 
Garrick, J.A.F. and Schultz, L.P., 1963: A guide to the kinds of potentially dangerous sharks, 1-60, figs 1-33. In: (iilbert, P.W. (ed.), SHARKS AND SURVIVAL Heath ६ Co., Boxton.

Grant, C.J. 1972: The biology of the soldier fish, Cymapistes marmoratus (Pisces: Scorpaenidae). Aust. J. mar. Freshw. Res.,23, 151-163, figs 1-9.

and Spain, A.V., 1975: Reproduction, growth and size allometry of Mugiz cephalus Linnaeus (Pisces: Mugilidae) from North Queensland in land waters. Aust. J. Zool., 23, 181-201.

Greenwood, P.J., Rosen, D.E., Weitzman, S.H. and Myers, G.S., 1966: Phyletic studies of teleostean fishes, with a provisional classification of living forms. Buzz. U.S. Mus. nat. Hist., 131 (4), 330-456, text figs 1-9, p1s. 21, charts 1-32.

Gregory, W.K., 1928: Studies in the body-forms of fishes. Zoologica, 8 (6), 325-431, figs $227-445$.

Günther, A. 1859: CATAIOGUE OF THE FISHES IN THE COLLECTION OF THE BRITISH MUSEUM, 1. British Museum, London.

, 1860: CATAlogue OF THE ACANTHOPTERygian Fishes in THE COLLECTION OF THE BRITISH MUSEUM, 2 . British Museum, London.

, 1861: CATAlogue OF THE ACANTHOPterygian FisheS IN THE COLleCtion OF THE BRITISH MUSEUM, 3 . British Museum, London.

, 1870: CATAlogue OF THE ACANTHOPTERygian Fishes in THE COLleCtion OF THE BRITISH MUSEUM, 8 . British Museum, London.

, 1881: AN INTRODUCTION TO THE STUDY OF FISHES. A. \& C. Black, Edinburgh.

Heath, E. and Moreland, J.M., 1973: MARINE FISHES OF NEW ZEALAND; first published 1967. H. \& A. Reid, Wellington.

Hutton, D.W. and Hector, J. 1872. Catalogue of the fishes of New Zealand. Colonial Mus. \& Geol. Sumey Publ., 18.

Huxley, J.H., 1871: ANATOMY OF VERTEBRATEd ANIMALS. J. G. A. Churchil1, London.

Johnston, R.M., 1883: General and critical observations on the fishes of Tasmania with a classified catalogue of al1. known species. Pap. Proc. F. Soc. Tasm. (1882), $54-144$.

, 1891: Further observations on the fishes and fishing industries of Tasmania, together with a revised list of indigenous species. Pap. Proc. $R$. Soc. Tasm. (1890), 22-46.

Jordan, D.S., 1923: A classification of fishes including families and genera as far as known. Stanf. pubz., univ. ser., biol. sci., 3 (2), 1-x+77-243.

Klunzinger, C.B., 1872: Zur Fischefauna von Sud-Australien. Arch. Naturg., $\underline{38}$ (1), $17-47$.

1879: Die v. Muller'sche Sammlung australischer Fishe in Stuttgart. Sitaungsh. $k$. Akad. Wiss Wien, 80, 325-40, pls 1-9. 
Koumans, F.P., 1953: Gobioidea in: THE FISHES OF THE INDO-AUSTRALIAN ARCHIPELAGO, M. Weber \& L.F. De Beaufort, 10. E.J. Bril1, Leiden.

Lord, C.E., 1924: A 1ist of the fishes of Tasmania. Pap. Proc. R. Soc. Tasm. (1922), $60-73$.

, 1927: A 1ist of the fishes of Tasmania. J. pon-Pac. res. Inst., 2 (4),

Lord, C.E. and Scott, H.H., 1924: A SYNOPSIS OF THE VERTEBRATE ANIMALS OF TASMANIA. oldham, Beddome \& Meredith, Hobart.

Lucas, A.H.S., 1890: A systematic census of indigenous fish, hitherto recorded from Victorian waters. Proc. R. Soc. Vict. (n.s.), 2, 15-47.

M 'Coy, F., 1885: PRODROMUS OF THE ZOOLOGY OF VICTORIA, 9, 1-45,, pls 101-110, Government Printer, Melbourne.

McCulloch, A.R., 1909: Studies in Australian fishes, No. 2. Rec. Aust. Mus., 7 (4), 315-321, pls 90-91, text fig. 18 .

1915: Notes on and descriptions of Australian fishes. Proc. Linn. Soc. N.S.W. 40 (2), 259-277, pls 35-37.

, 1921: Check-list of the fishes and fish-1ike animals of New South

Wales, Part 2. Aust. Zool., 2 (2), 14-58, p1s 4-24.

1922: Check-1ist of the fishes and fish-1ike animals of New South Wales, Part 3. Aust. Zool., 2 (3), 86-130, p1s 25-43.

1929: A check-1ist of the fishes recorded from Australia. Aust. Mus. Mem., 5 (1-4) (part 4, Index, 1930), i-x+1-534.

McCulloch, A.R. and Ogilby, J.D., 1919: Some Australian fishes of the family Gobiidae. Rec. Aust. Mus., 12 (10), 193-291, pls 31-37, text figs 4-5.

Macleay, W., 1881: Descriptive catalogue of the fishes of Australia. Parts 1, 2 . Proc. Linn. Soc. N.S.W., 5 (3), 302-444, and $\underline{5}$ (4), 510-629, p1s 13-14.

1882: Descriptive catalogue of the fishes of Australia. Parts 3,4.

Proc. Linn Soc. N.S.W., 6 (1), 1-138, p1s 1-2; and 6 (4), 202-387.

- 1884: Supplement to the descriptive catalogue of the fishes of Australia. Proc. Linn. Soc. N.S.W., 9 (1), 2-64.

Munro, I.S.R., 1956: Handbook of Australian fishes, 1, 2, 3, 1-16. Fisher. news 2. (now Aust. Fisher. $), 15(7,8,9)$.

1957: Handbook of Australian fishes, 10, 41-44. Fisher. news2. (now Aust. Fisher.), 16 (4).

, 1958. Handbook of Australian fishes, 29, 117-120. Fisher. newst. (now Aust. Fisher.), 17 (11).

, 1961. Handbook of Australian fishes, 40, 161-164. Fisher. newsz. (now Aust. Fisher.) 20, (8). 
Munro, I.S.R., 1967: THE FISHES OF NEW GUINEA. Port Moresby, New Guinea, Department of Agriculture, Stock and Fisheries.

Neave, S.A., 1940: NOMENCLATOR ZOOLOGICUS. A LIST OF THE NAMES OF GENERA AND SUBGENERA IN ZOOLOGY FROM THE TENTH EDITION OF LINNAEUS 1758 TO THE END OF 1935. Zoological Society, London.

Ogilby, J.D., 1885: Description of a new Diplocrepis from Port Jackson. Proc. Linn. Soc. N.S.W., 10 (2), 270-272.

01sen, A.M., 1954: The biology, migration, and growth rate of the school shark, Galeorhinus australis (Macleay) (Carcharhinidae), in south-eastern Australian waters. Aust. J. mar. Freshw. Res., 5 (3), 353-410, figs 1-15.

, 1958: New fish records and notes on some uncommon Tasmanian species. Pap. Proc. R. Soe. Tasm., 92: 155-159.

Parin, N.V. and Becker, V.E., 1972: Materials on taxonomy and distribution of some trichiuroid fishes (Pisces, Trichiuroidae: Scombrolobracidae, Gemplylidae, Trichiuridae). Trudy Inst. Okean., 93, 110-124 [in Russian : n.s.].

Penrith, M.J., 1972: Earliest description and name for the whale shark. Copeia, 2,362.

Phillipps, W.J., 1932: Notes on new fishes from New Zealand. N.Z. J. Sci. Techn., 13 (4), 226-234, figs 1-5.

Quoy, J.R.C. and Gaimard, P., 1824: VOYAGE AUTOUR DU MONDE SUR LES CORVETTES DE S.M. L'URANIE ET LA PHYSICIENNE, SOUS LE COMMANDEMENT DE M. FREYCINET. POISSONS. Paris .

Ramsay, E.P., 1882: On a new species of Gobiesox from Tasmania Proc. Linn. Soc. N.S.W., $7(2), 148$.

Ricker, W.E., 1958: Growth in length and in weight. In: Handbook of computations for biological statistics of fish populations, ch.9, 185-205. Fish. Res. Board Can. Buzz., 119 [n.s.].

Richardson, J., 1850: Notices of Austra1ian fish. Proc. zool. Soe. Lond., 18, 58-77, p1s 1-3.

Schu1tz, L.P., 1953: Family Echelidae in: Schultz et al.,Fishes of the Marsha11 and Marianas Is 1ands. U.S. nat. Mus. BulZ., 202 (1), 60-83.

Scott, E.0.G., 1935: Notes on the gobies recorded from Tasmania, with description of a new genus. Pap. Proc. R. Soc. Tasm. (1934), 63-75, p1. 6.

, 1942-1975. Observations on some Tasmanian fishes. Parts I-XXI: in this journal (except Part XVI, 1969, Aust. Zool., 15 (2), 160-177, fj.gs 1-2). Contributions here cited: 1936, Part III, 113-129, figs 1, 2. 1942, V, 45-54, p1. 7. 1953, VI (numbered V in error), 141-166, figs 1-4. 1957, VIII, $145-156$. 1960, IX, 87-102, fig. 1. 1961, X, 49-65, figs 1-3. 1963, XI, 1-29, figs 1-8. 1965, XIII, 53-65, fig. 1. 1974 a XIX, 247-292, fig. 1. 1974 b, XX, 171-191, figs 1-4. 1975, XXI, 127-173, figs 1,2.

Scott, T.D., 1954: Four new fishes from South Austra1ia. Rec. S. Aust. Mus., 11 (2), 105-112, p1. 22, text figs 1-3. 
Scott, T.D., 1962: THE MARINE AND FRESH WATER FISHES OF SOUTH AUSTRALIA. Government Printer, Ade1aide.

, Glover, C.J.M. and Southcott, R.V., 1974: THE MARINE AND FRESHWATER FISHES OF SOUTH AUSTRALIA. Government Printer, Adelaide.

Stead, D.G., 1963. RAYS AND SHARKS OF AUSTRALIAN SEAS. Angus \& Robertson, Sydney.

Tucker, D.W., 1956: Studies on the trichuiroid fishes - 3, a preliminary revision of the family Trichiuridae. Bull. Brit. Mus. Nat. Hist. zool., 4 (3), 73-110.[n.s.]

Waite, E.R., 1904: Additions to the fish fauna of Lord Howe Island, No. 4. Rec. Aust. Mus., 5 (3), 135-186, p1s 17-24, text fig. 32 .

, 1906: Descriptions of and notes on some Australian and Tasmanian fishes. Rec. Aust. Mus., 6 (3), 194-210, p1s. 24-26.

, 1907: The generic name Crepidogaster. Rec. Aust. Mus., 6 (4), 315 .

, 1916: Fishes of the Australasian Antarctic Expedition, Science Reports, series C. Austr. Antaret. Exped., (C) $\underline{3}$ (1), Eish, 5-82, pls 1-5, text figs $1-16$.

1921: Illustrated catalogue of the fishes of South Australia. Rec. S. Aust. Mus., 2 (1), 11-208, pl.1, 293 text figs.

, 1923: THE FISHES OF SOUTH AUSTRALIA. Government Printer, Adelaide.

Walford, L.A., 1946: A new graphic method of describing the growth of animals. Biol. Bulz., 90, 141-7 [n.s.].

Whitley, G.P., 1927: Studies in ichthyology. No. 1 Rec. Aust. Mus., 15 (5), $289-304$. pls 24-25, text fig. 1 .

1929 a: R.M. Johnston's memoranda relating to the fishes of Tasmania. Pap. Proc. R. Soc. Tasm. (1928), 44-68, p1s 2-4.

$1929 \mathrm{~b}$ : Additions to the check-list of the fishes of New South Wales No. 2 Aust. Zool., 5 (4), 353-357.

, 1930: Additions to the check-1ist of the fishes of New South Wales. No. 3. Aust. Zooz., 6 (2), 117-123, pl. 14 .

, 1931: New names for Australian fishes. Aust. Zooz., 6 (4), 310-334, pls $25-27$, text fig. 1 .

, 1933: Studies in ichthyology. No.7. Rec. Aust. Mus., 19 (1), 60-112, p1s 11-15, figs 1-4.

, 1934: Notes on some Australian sharks. Mem. QZd Mus., 10 (4), 180-200, p1s 27-29, text figs $1-4$.

1935: Fishes of the Sydney district. Aust. Mus. Mag., $\underline{5}$ (4), 291-304, $1 \mathrm{pl}, 13$ text figs. 


\section{E.O.G. Scott}

Whitley, G.P., 1939: Taxonomic notes on sharks and rays. Aust. Zool. 9 (3), 227-262, p1s 20-22, text figs 1-18.

, 1940: THE FISHES OF AUSTRALIA. Part. 1 THE SHARKS, RAYS, DEVIL-FISH, AND OTHER PRIMITIVE FISHES OF AUSTRALIA AND NEW ZEALAND. Royal Zoological Society of New South Wales, Sydney.

, 1943: Ichthyological notes and illustrations (Part 2). Aust. Zool., 10 (2), 167-187, text figs 1-10.

, 1948: A 1ist of the fishes of Western Australia. W. Aust. Fisher. Dept Buiz., 2, 1-35, map.

, 1950: C1ingfishes. Aust. Mus. Mag., 10 (4), 124-128, 4 text figs.

, 1951: Studies in ichthyology. No. 15. Rec. Aust. Mus., 22 (4), $389-408$, text figs $1-14$.

, 1954: New locality records for some Australian fishes. Proc. R. zool. SOC. N.S.W. $(1952 / 3), 22-30$, figs $1-5$.

$110-119,30$.

, 1955: Side1ights on New Zealand ichthyology. Aust. Zoor., 12 (2),

, 1962: THE MARINE FISHES OF AUSTRALTA, vo1. 1. Jacaranda Press,

Brisbane.

1964: Name-list of the fishes recorded from Australia. Presidential

address, appendix B. Proc. Linn. Soc. N.S.W., 89 (1), 32-60 (list).

, 1967: Sharks of the Australasian region. Aust. Zool., 14 (2),

173-187, p1. 4, text figs 1-2.

1968: A check-1ist of the fishes recorded from the New Zealand region. Aust. Zoo I., 15 (1), 1-102, figs 1-2.

\section{NOTE ADDED IN PRESS}

Reference is made on pages 157,162 and 163 to specimens of Alabes parvulus McCulloch, 1929 from Greens Beach, northern Tasmania, as constituting the first record of the species from this state. On 27 th September, 1976, while the present paper was in the press, a copy was received of an important paper which reports $A$. parvulus from Coles Bay, east coast, Tasmania. A new species, $A$. hoesei (differing in having two postocular sensory canal pores instead of one) is described from the same locality, al so from S.A. and N.S.W. The reference is:

Springer, V.G. and Fraser, T.H., 1976: Synonomy of the fish families Cheilobranchidae ( $=$ A1 abetidae) and Gobiesocidae, with descriptions of two new species of Alabes. Smithsonian Contribs to Zoology, 234 . 
